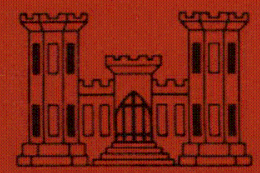

CONTRACT REPORT S-76-2

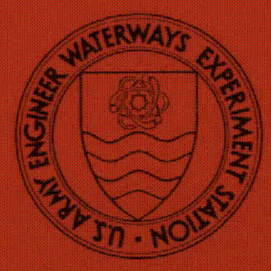

\title{
FINITE ELEMENT ANALYSES OF STRESSES AND MOVEMENTS IN BIRCH DAM
}

by

Antonio Soriano, J. M. Duncan, Kai Wong, Jean-Michel Simon

College of Engineering, Office of Research Services

University of California, Berkeley, California 94720

April 1976

Final Report

Approved For Public Release; Distribution Unlimited

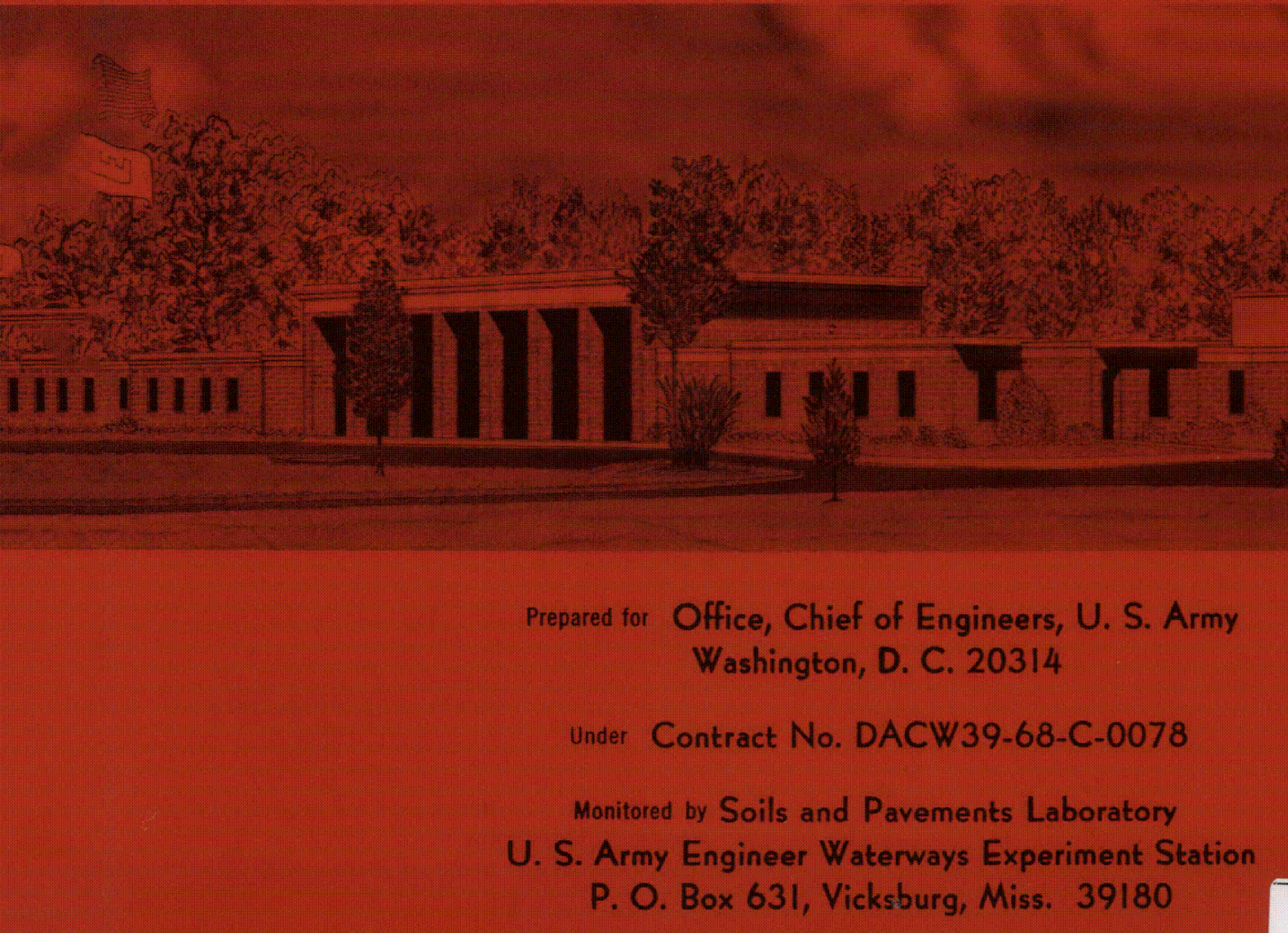

P. O. Box 631, Vicksburg, Miss. 39180 
Destroy this report when no longer needed. Do not return it to the originator. 
Unclassified

SECURITY CLASSIFICATION OF THIS PAGE (Whon Date Entored)

\begin{tabular}{|c|c|}
\hline REPORT DOCUMENTATION PAGE & $\begin{array}{l}\text { READ INSTRUCTIONS } \\
\text { BEFORE COMPLETING FORM }\end{array}$ \\
\hline \begin{tabular}{l|l|} 
1. REPORT NUMBER & 2. GOVT ACCESSION NO. \\
Contract Report S-76-2 &
\end{tabular} & 3. RECIPIENT'S CATALOG NUMEER \\
\hline \multirow[t]{2}{*}{$\begin{array}{l}\text { TITLE (and Subeit10) } \\
\text { FINITE ELEMENT ANALYSES OF STRESSES AND MOVEMENTS } \\
\text { IN BIRCH DAM }\end{array}$} & $\begin{array}{l}\text { 5. TYPE OF REPORT \& PERIOD COVERED } \\
\text { Final Report }\end{array}$ \\
\hline & 6. PERFORMING ORG. REPORT NUMBER \\
\hline $\begin{array}{l}\text { 7uTHoR(a) } \\
\text { Antonio Soriano Jean-Michel Simon } \\
\text { J. M. Duncan } \\
\text { Kai Wong }\end{array}$ & $\begin{array}{l}\text { 8. CONTRACT OR GRANT NUMBER(a) } \\
\text { DACW 39-68-C-0078 }\end{array}$ \\
\hline $\begin{array}{l}\text { 9. PERFORMING ORGANIZATION NAME AND ADORESS } \\
\text { College of Engineering, Office of Research } \\
\text { Services, University of Caiifornia, } \\
\text { Berkeley, California } 94720\end{array}$ & $\begin{array}{l}\text { 10. PROGRAM ELEMENT PROJECT, TASK } \\
\text { AREA Q WORK UNIT NUMBERS }\end{array}$ \\
\hline \multirow{2}{*}{$\begin{array}{l}\text { 11. CONTROLLING OFfICE NAME AND ADDRESS } \\
\text { Office, Chief of Engineers, U. S. Army } \\
\text { Washington, D. C. } 20314\end{array}$} & $\begin{array}{l}\text { 12. REPORT DATE } \\
\text { April } 1976\end{array}$ \\
\hline & $\begin{array}{l}\text { 13. NUMBER OF PAGES } \\
94\end{array}$ \\
\hline \multirow{2}{*}{$\begin{array}{l}\text { 14. MONITORING AGENCY NAME A ADDRESS(If difforent from Controllind Ollfce) } \\
\text { Soils and Pavements Laboratory } \\
\text { U. S. Army Engineer Waterways Experiment Station } \\
\text { P. O. Box } 631 \text {, Vicksburg, Miss. } 39180\end{array}$} & $\begin{array}{l}\text { 15. SECURITY CLASS. (ol thle roport) } \\
\text { Unclassified }\end{array}$ \\
\hline & $\begin{array}{l}\text { 15. DECLASSIFICATION/DOWNGRADING } \\
\text { SCHEOULE }\end{array}$ \\
\hline \multicolumn{2}{|l|}{$\begin{array}{l}\text { 16. OISTRIBUTION STATEMENT (of thio Roport) } \\
\text { Approved for public release; distribution unlimited. }\end{array}$} \\
\hline \multicolumn{2}{|l|}{ 17. DISTRIBUTION STATEMENT (of the ebatract entered in Block 20, it different from Report) } \\
\hline \multicolumn{2}{|l|}{ 18. SUPPLEMENTAAY NOTES } \\
\hline \\
\hline 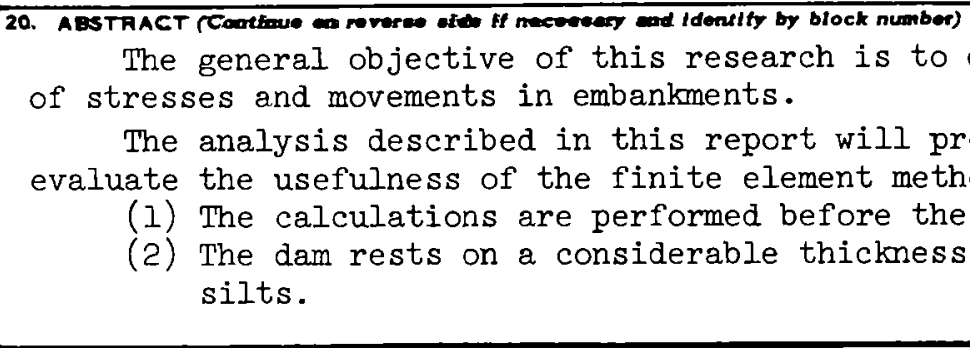 & $\begin{array}{l}\text { develop methods for analysis } \\
\text { covide an opportunity to } \\
\text { hod for conditions where: } \\
\text { dam is built. } \\
\text { of compressible clays and } \\
\text { (Continued) }\end{array}$ \\
\hline
\end{tabular}


Unclassified

ECURITY CLASSIFICATION OF THIS PAGE( Then Date Entered)

20. ABSTRACT (Continued).

(3) There is a considerable time delay in the movements due to consolidatron of the foundation.

(4) Because of the low strengths of the clays in the foundation of the dam, it will be necessary to build the dam in two stages, allowing time for consolidation of the foundation before the second stage is built.

Settlements, horizontal movements, and the pore pressures will be measured in the foundation and the embankment of Birch Dam during construction and after. When these measurements are available, an additional study will be conducted to compare the measurements with the predictions contained in this report. This follow-up study will provide a basis for evaluating the accuracy of the presently available finite element analysis procedures for a difficult set of conditions.

Unclassified

SECURITY CLASSIFICATION OF THIS PAGE(Whon Date Entered) 


\section{FOREWORD}

The work described in this report was performed under Contract No. DACW39-68-C-0078, "Behavior of Zoned Embankments and Embankments on Soft Foundations," between the U. S. Army Engineer Waterways Experiment Station and the University of California. This is the sixth report on investigations performed under this contract. The first report, "Finite Element Analyses of Stresses and Movements in Embankments During Construction," by F. H. Kulhawy, J. M. Duncan, and H. Bolton Seed, was published in November, 1969. The second report, "Three-Dimensional Finite Element Analyses of Dams," by Guy Lefebvre and J. M. Duncan, was published in May, 1971. The third report, "Effect of Reservoir Filling on Stresses and Movements in Earth and Rockfill Dams," by E. S. Nobari and J. M. Duncan, was published in January, 1972. The fourth report, "Hydraulic Fracturing in Zoned Earth and Rockfill Dams," by E. S. Nobari, K. L. Lee and J. M. Duncan, was published in January, 1973. The fifth report, "Finite Element Analyses of Transverse Cracking in Low-Embankment Dams," by Guy Lefebvre and J. M. Duncan, was published in October, 1974. The research was sponsored by The office, Chief of Engineers, under the Civil Works Program CWIS No. 31169.

The general objective of this research, which was begun in June, 1968, is to develop methods for analysis of stresses and movements in embankments. Work on this project is conducted under the supervision of J. M. Duncan and H. Bolton Seed, Professors of Civil Engineering. The project is administered by the office of Research Services of the College of Engineering. The phase of the investigation described in this report was conducted, and the report was prepared by Antonio Soriano, J. M. Duncan, Kai Wong, and J-M. Simon.

The contract was monitored by Mr. C. L. McAnear, Chief, Soil Mechanics Division, under the general supervision of Mr. J. P. Sale, Chief, Soils and Pavements Laboratory. Contracting officer was BG E. D. Peixotto, CE, Director of the U. S. Army Engineer Waterways Experiment Station. 



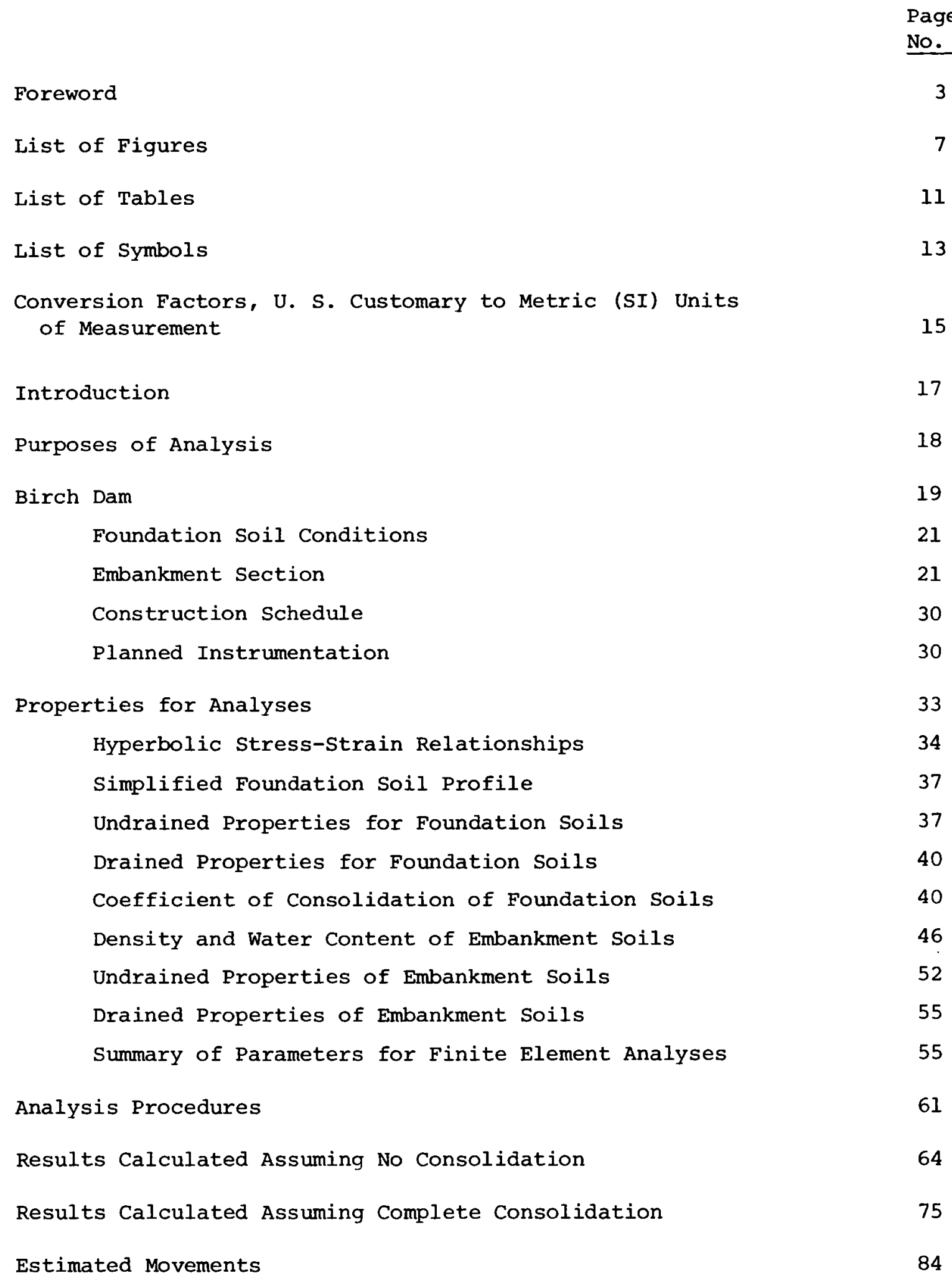




\section{LIST OF FIGURES}

Fig.

No.

Title

Page

1

Site Plan of Birch Lake Dam

No.

$2 \quad$ Plan View and Longitudinal Cross-section of Dam

Soil Profiles at Longitudinal Sections (M) and (

4 Soil Profile at Longitudinal section $L$, and Variations of Water Content and Liquid Limit with Depth 24

Transverse Cross-section (x) at Station $20+00$

Statistical Distribution of Atterberg Limits

$7 \quad$ Statistical Distribution of 8 of Fines and Liquid

Limit on Fill Materials from Borrow Area $A$

Statistical Distribution of 8 of Fines and Liquid Limit on Fill Materials from Borrow Area $B$

10 Stress-Strain Curves for Triaxial Tests on Soil at Two Values of Confining Pressure

11 Variation of Undrained Strength $\left(s_{u}\right)$, Dry Density $\left(\gamma_{d}\right)$, Modulus Number $(K)$ and Modulus Exponent $(n)$ with Depth in the Foundation

12 Drained Strength of Foundation Soils from Direct Shear Tests

e-Log $p$ Curves of Foundation Soils from Consolidation Tests

15 Incremental Coefficient of Lateral Earth Pressure (After Clough and Duncan)

16 Typical Consolidation Time Curves of Foundation Soil (CL)

17 Variation of Test Values on Field Compacted Samples with Respect to the Desired Limits on Perry Dam, Zone A Shell Materials 
Fig.

No.

18 Variation of Test Values on Field Compacted Samples with Respect to the Desired Limits on Perry Dam,

Zone A Shell Materials

19 Variation of Test Values on Field Compacted Samples with Respect to the Desired Limits on Perry Dam, Impervious Zone

20 Variation of Test Values on Field Compacted Samples with Respect to the Desired Limits on Littleville Dam for the Impervious Fill and the Random Fill

21 Compaction Curve and Properties of the Sandy silt Sample as Shell Material

Compaction Curve and Properties of the Clay Sample as Core Material

Drained Direct Shear Tests on Compacted Sandy Silt

Drained Direct Shear Tests on Compacted Clay

Finite Element Mesh for Birch Dam, Upstream Portion 
Fig.

No.

39

40 Strength Mobilized for CD Stage 2

$41 \quad$ Critical Circle for CD Stage 2

42 Displacements for $\mathrm{CD}$ Stages 1 and 2

43 Horizontal Displacements Due to Reservoir Filling

$44 \quad$ Estimated Displacements

45 Estimated Displacements after Reservoir Filling

46 Estimated Movements of the Slope Indicators

47 Estimated Movements of the Surface Monuments

Al

A2

A3
Variations of $\alpha_{j k}$ with Time Factor $T_{j}$

Variations of $\beta_{k}$ with Time Factor $T$

Comparison of UU, $\mathrm{CD}$ and Estimated Vertical Displacements Along a Typical Vertical Line $A-A$
Page

No.

79

80

81

82

83

85

86

87

88

95

98

100 



\section{LIST OF TABLES}

Table

No.

1 Descriptions, Index Properties, Densities and Water Contents of Foundation

2 Index Properties and Compaction Characteristics of Fill Materials

3 Summary of the Hyperbolic Parameters

4 Undrained Stress-Strain and Strength Parameters for Foundation Soils

5 Drained Stress-Strain and Strength Parameters for Foundation Soils

6 Hyperbolic Parameters used for Undrained Analyses of Birch Dam

7 Hyperbolic Parameters used for Drained Analyses of Birch Dam

Estimated Excess Pore Pressures at Sta. $20+00$
31

Page

No. 



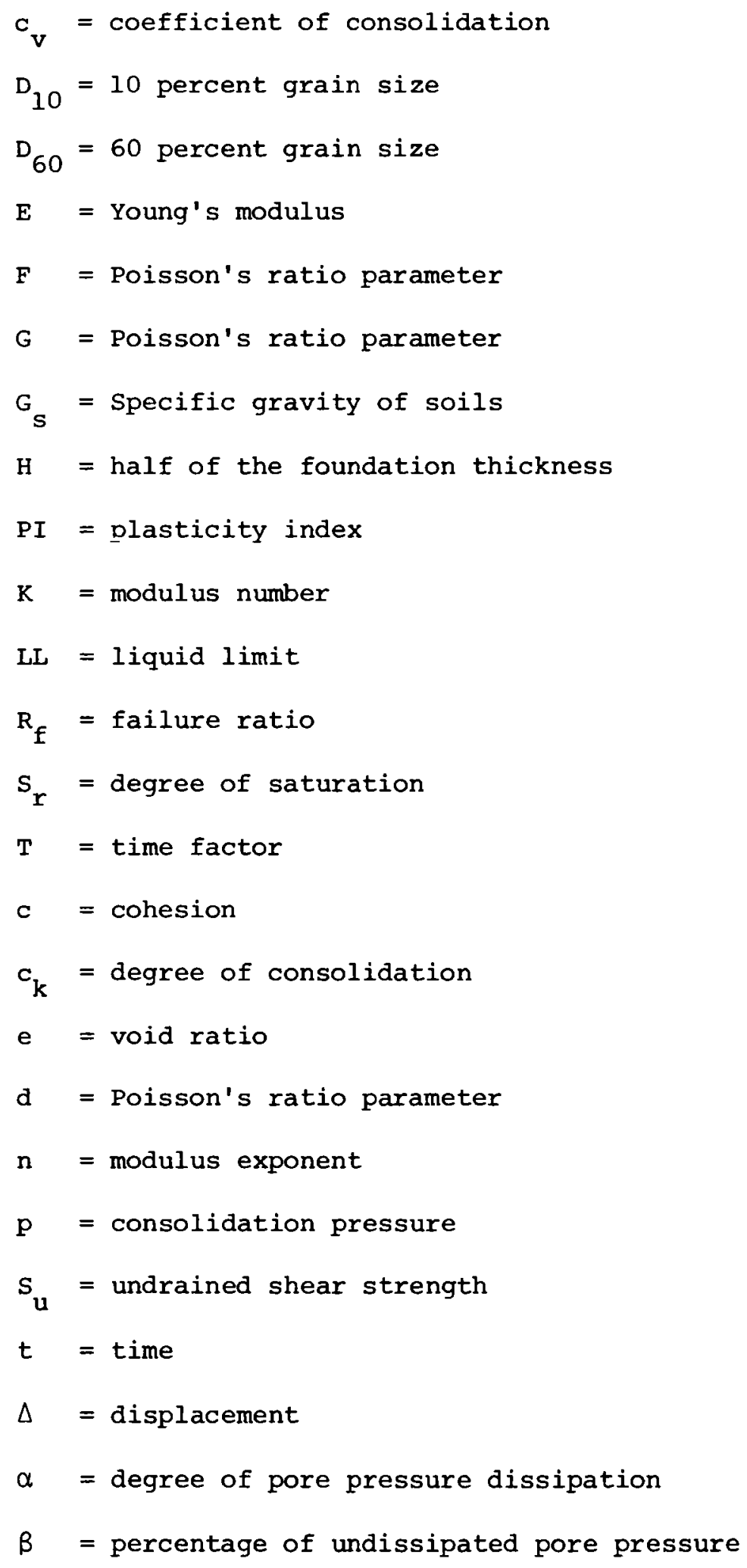


$\delta \quad=$ incremental displacement

$\sigma=$ normal stress

$\tau=$ shear stress 
CONVERSION FACTORS, U. S. CUSTOMARY TO METRIC (SI)

UNITS OF MEASUREMENT

U. S. customary units of measurement used in this report can be converted to metric (SI) units as follows:

Multiply

\section{feet}

pounds (force)

pounds (mass) per cubic foot

atmospheres

tons (force) per square foot

$\begin{array}{cl}\text { By } & \\ 0.3048 & \text { metres } \\ 4.448222 & \text { newtons } \\ 16.01846 & \text { kilograms per cubic metre } \\ 101.325 & \text { kilopascals } \\ 95.76052 & \text { kilopascals }\end{array}$





\section{INTRODUCTION}

Since 1967, when Clough and Woodward first demonstrated its potential usefulness for such analyses, the finite element method has been used to calculate stresses and movements in a number of earth and rockfill dams. In his state-of-the-art report at the Brazilian Conference on finite element analyses in 1974, Eisenstein reported that he could find 16 instances of such analyses, among published case histories and his own experience.

Several of the cases described in the literature include comparisons which show good agreement between measured and calculated movements in dams. Based on these cases it appears that quite reasonable values of movements and stresses may be calculated using stress-strain and strength parameters determined from laboratory tests. While these comparisons have shown clearly that such analyses have considerable potential for predicting stresses and movements in embankment dams, there are four aspects in which this case study differs from many previously published cases:

(1) In most of the cases in which the results of measurements and calculations have been compared, the analyses have been made "after-the-fact", and were not true predictions. Such afterthe-fact analyses are likely to be more accurate because more accurate information is available concerning construction sequence, zoning in the embankment, and field gradations and densities.

(2) Most of the cases in which the measured and calculated results compare most favorably concern dams on hard rock foundations. It is much more difficult to evaluate the properties of a natural soil deposit than it is to evaluate the properties of an embankment which has been built under careful control to assure its conformance to prescribed standards. Both the geometric distribution of the materials in the embankment and their properties are known with greater precision than could be established for a natural soil deposit. Because of the greater difficulty in defining the geometric distribution and properties of natural soils, the stresses and movements 
calculated for dams on compressible foundations will inevitably be less accurate than for dams on hard rock. The possible magnitude of the inaccuracies in the calculations will be greatest when the foundation is very compressible, and when the geologic conditions are complex and difficult to evaluate.

(3) Most of the cases where calculated and measured movements have been compared did not involve large time-dependent movement. Presently available analysis procedures apply best to completely undrained or completely drained conditions. Conditions of partial drainage are more difficult to analyze, and involve additional sources of uncertainty.

(4) Most of the cases where calculated and measured movements have been compared have been concerned with conditions where the factor of safety against slope or foundation failure was quite high. The accuracy of currently used stress-strain relationships decreases as the condition of instability approaches, and predicted movements at conditions close to failure are thus inevitably less accurate than for conditions far from failure.

PURPOSES OF ANALYSIS

The analysis of Birch Dam which is described in this report will provide an opportunity to evaluate the usefulness of the finite element method for conditions where:

(1) The calculations are performed before the dam is built. Construction of Birch Dam began in the Spring of 1974, and the dam will be completed in the summer of 1976 .

(2) The dam rests on a considerable thickness of compressible clays and silts. The highest portion of the dam will rest on about $37 \mathrm{ft}$ of alluvial sediments.

(3) There is a considerable time delay in the movements due to consolidation of the foundation. The rate of consolidation 
of the foundation clay is expected to be such that the excess pore pressures due to construction of the dam will dissipate only partially during construction, and consolidation settlements will continue for a considerable time after the construction of the dam is complete.

(4) Because of the low strengths of the clays in the foundation of the dam, it will be necessary to build the dam in two stages, allowing time for consolidation of the foundation before the second stage is built. At the end of the first stage of construction the fraction of strength mobilized in the foundation will be quite high.

Settlements, horizontal movements, and the pore pressures will be measured in the foundation and the embankment of Birch Dam during construction and after. When these measurements are available, an additional study will be conducted to compare the measurements with the predictions contained in this report. This follow-up study will provide a basis for evaluating the accuracy of the presently available finite element analysis procedures for a difficult set of conditions.

It should be emphasized that the most important part of a finite element analysis of embankment deformations is determining the stressstrain and strength properties of the foundation and the embankment materials. These properties were determined using the data in the Design Memoranda for Birch Dam, supplemented in some cases by additional data for similar soils from the writers' files, other 'Corps of Engineers publications, and the writers' collective engineering judgment. The exercise of judgment for interpretation and supplementation of available data is an essential part of all finite element analyses of stresses and movements in earth masses, and plays an important part in the final results.

\section{BIRCH DAM}

Birch Dam will be built across Birch Creek, in Osage County, Oklahoma, at the location shown in Fig. 1. The maximum height of the dam will be about $70 \mathrm{ft}$, and the length along the crest will be about $3200 \mathrm{ft}$. 


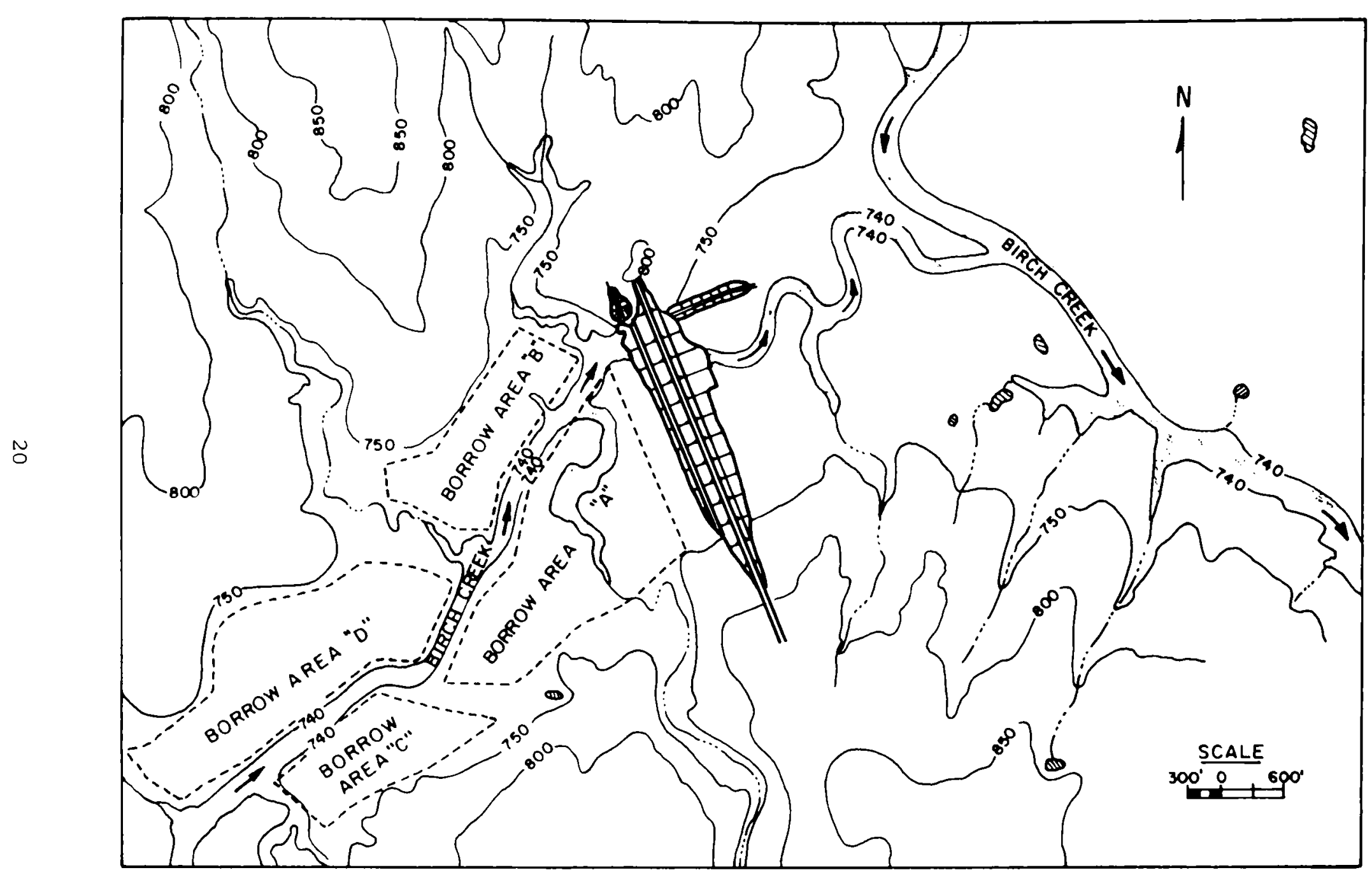

FIG. I SITE PLAN OF BIRCH LAKE DAM. 
Foundation Soil Conditions. The dam will be built on alluvial soil deposits which vary in thickness from less than $10 \mathrm{ft}$ on the abutments to a maximum of about $37 \mathrm{ft}$ in the center of the valley, as may be seen in Fig. 2. The predominant type of soil in the central portion of the valley is a clay of low to moderate plasticity. As may be seen in the crosssections shown in Figs. 3 and 4 , there are numerous lenses of silty and clayey sand within the clay, and in many locations there is a layer of silty sand beneath the clay. The water content and liquid limit profiles shown in the lower part of Fig. 4 indicate rather wide variations in soil type and index properties from one location to another. The depth to the water table varies from $10 \mathrm{ft}$ to $20 \mathrm{ft}$, and the upper layers of clay have been overconsolidated by desiccation. A number of samples were selected for detailed testing by the personnel of the Tulsa District of the U. $S$. Army Corps of Engineers, who designed the dam. The locations and classification characteristics of these samples are summarized in Table 1.

Embankment Section. A cross-section through the highest part of the embankment is shown in Fig. 5. The embankment will be about $70 \mathrm{ft}$ high in the center of the valley, with about 3.4 on 1 average slopes upstream and 2.8 on 1 average slopes downstream. The embankment will be zoned in two parts, as shown in Fig. 5.

The soil within the core zone and the cutoff trench will contain only materials which have liquid limits greater than 30 and more than 50\% passing the number 200 sieve. Coarser and less plastic materials may be used within the outer shell zones.

The distinctness of the zoning in the embankment will depend to some extent on the characteristics of the borrow materials. Should all or nearly all of the borrow materials be found to have liquid limits greater than 30 and more than $50 \%$ fines, the embankment would be essentially homogeneous. On the other hand, if a large portion of the materials is less plastic and coarser, the embankment would be zoned quite distinctly. The statistical distributions of borrow pit materials shown in Figs. 6, 7 and 8 indicate that not all of the materials will satisfy the core zone criteria, and it thus seems likely that there will be an 

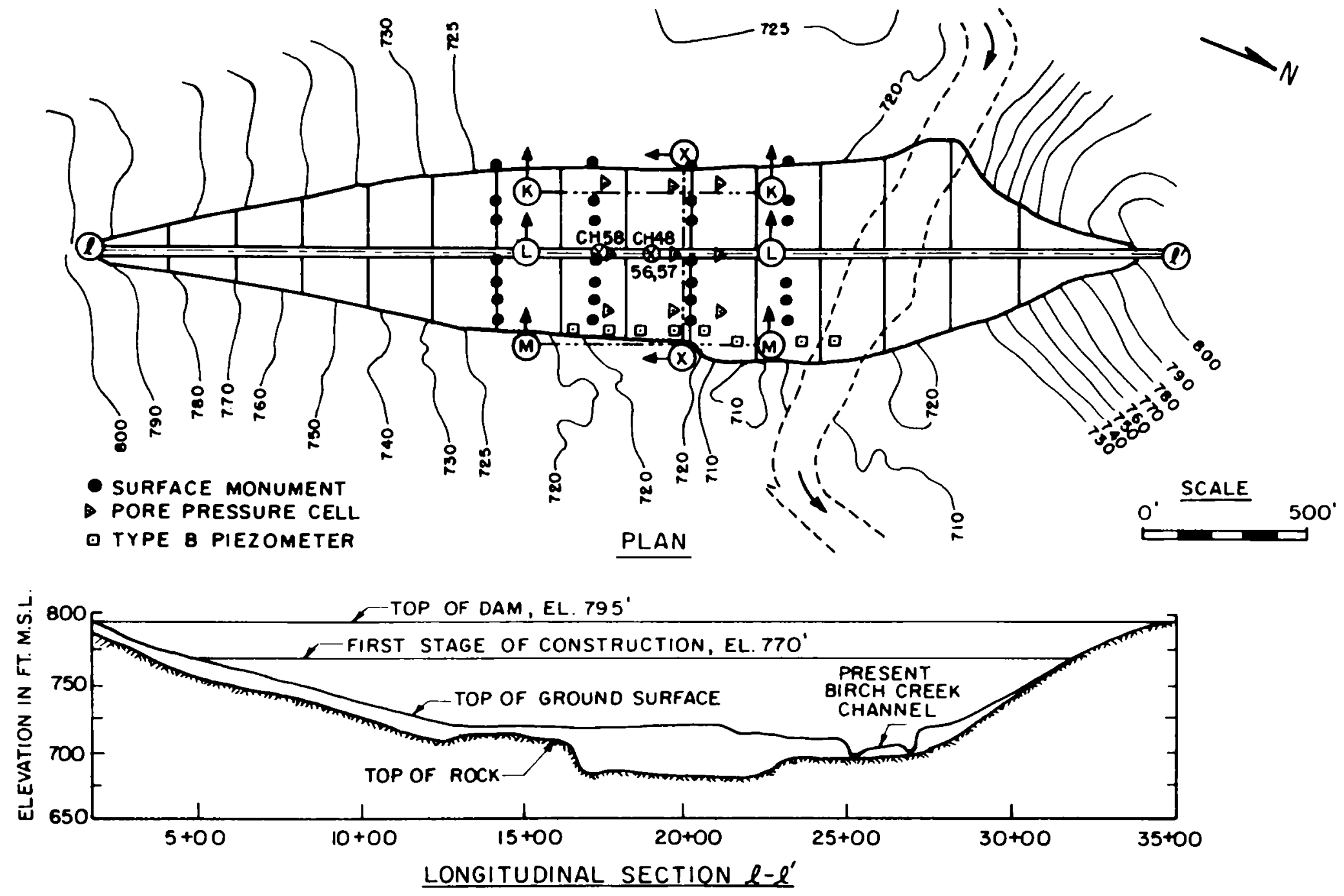

FIG. 2 PLAN VIEW AND LONGITUDINAL CROSS-SECTION OF DAM. 

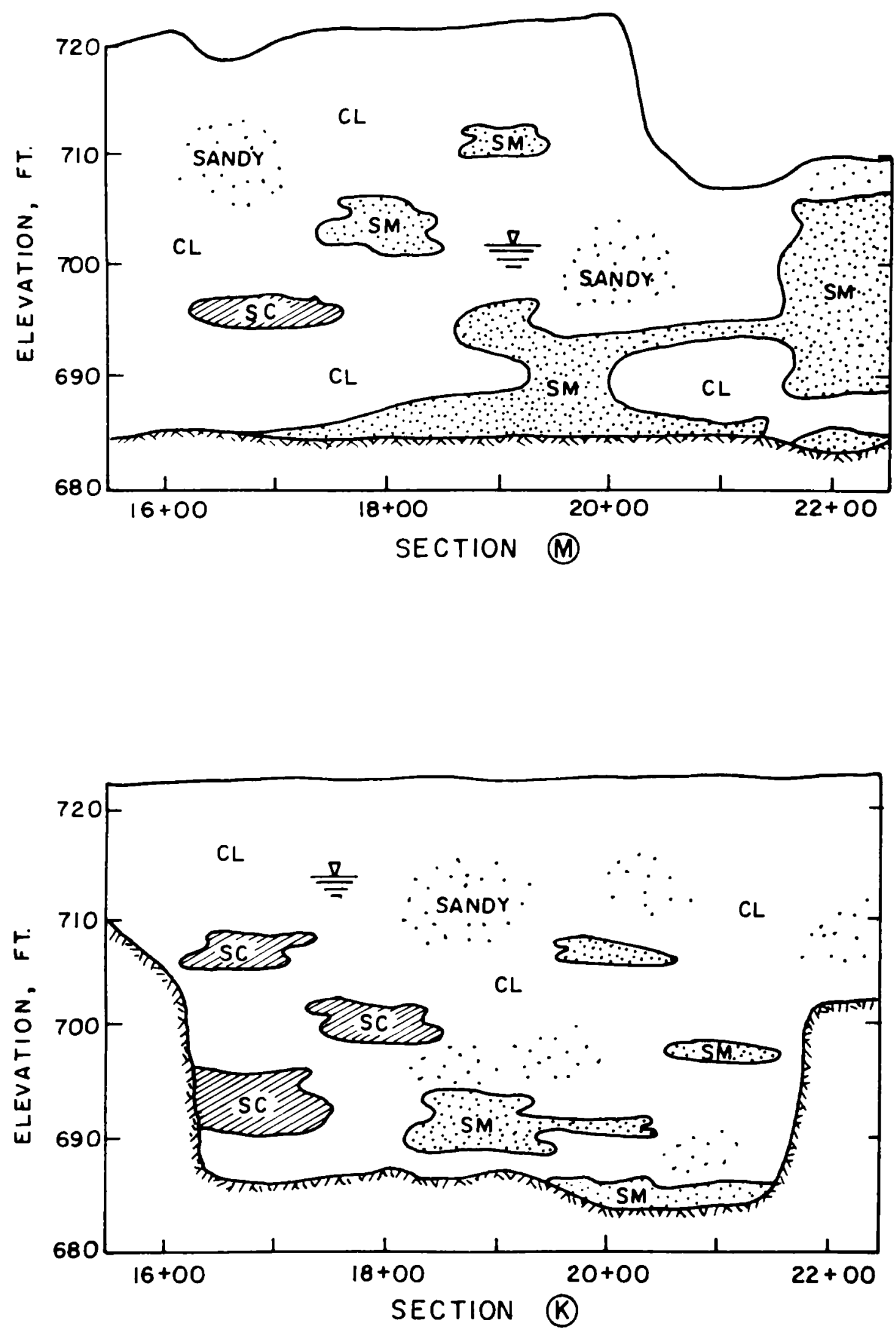

FIG. 3 SOIL PROFILES AT LONGITUDINAL SECTIONS (M) AND $(\mathbb{B}$. 

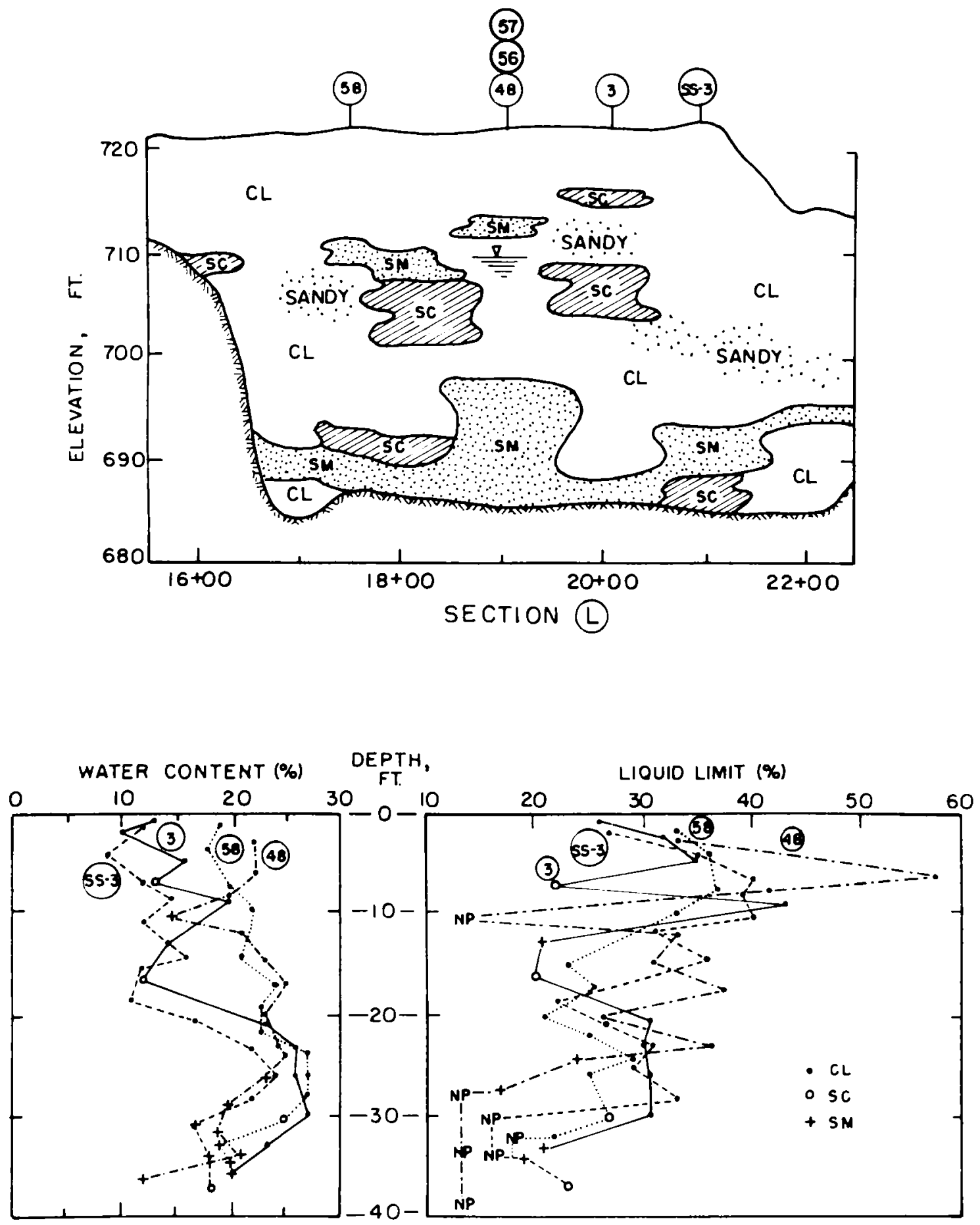

FIG. 4 SOIL PROFILE AT LONGITUDINAL SECTION (L), AND VARIATIONS OF WATER CONTENT AND LIQUID LIMIT WITH DEPTH 


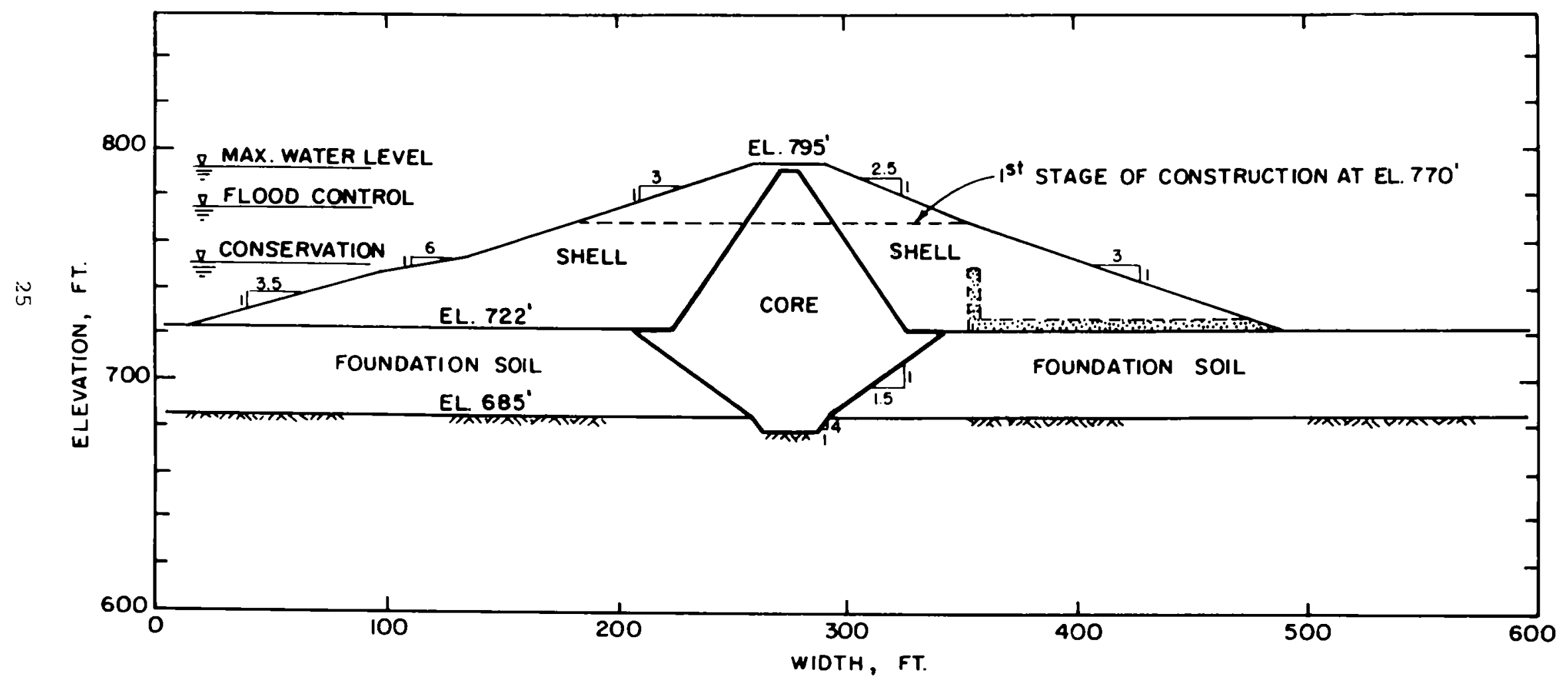

FIG. 5 TRANSVERSE CROSS-SECTION $\otimes$ AT STATION $20+00$. 


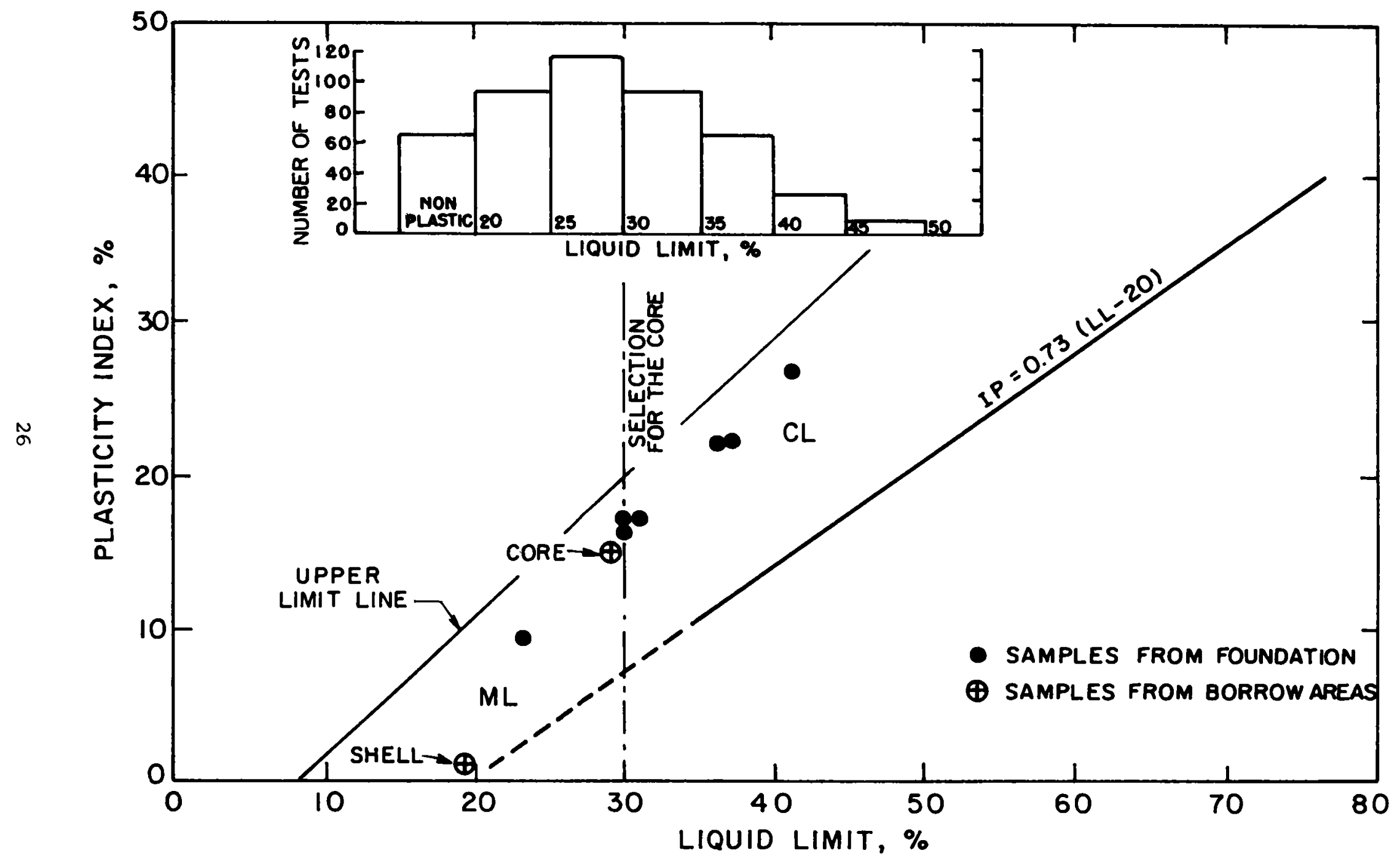

FIG. 6 STATISTICAL DISTRIBUTION OF ATTERBERG LIMITS. 


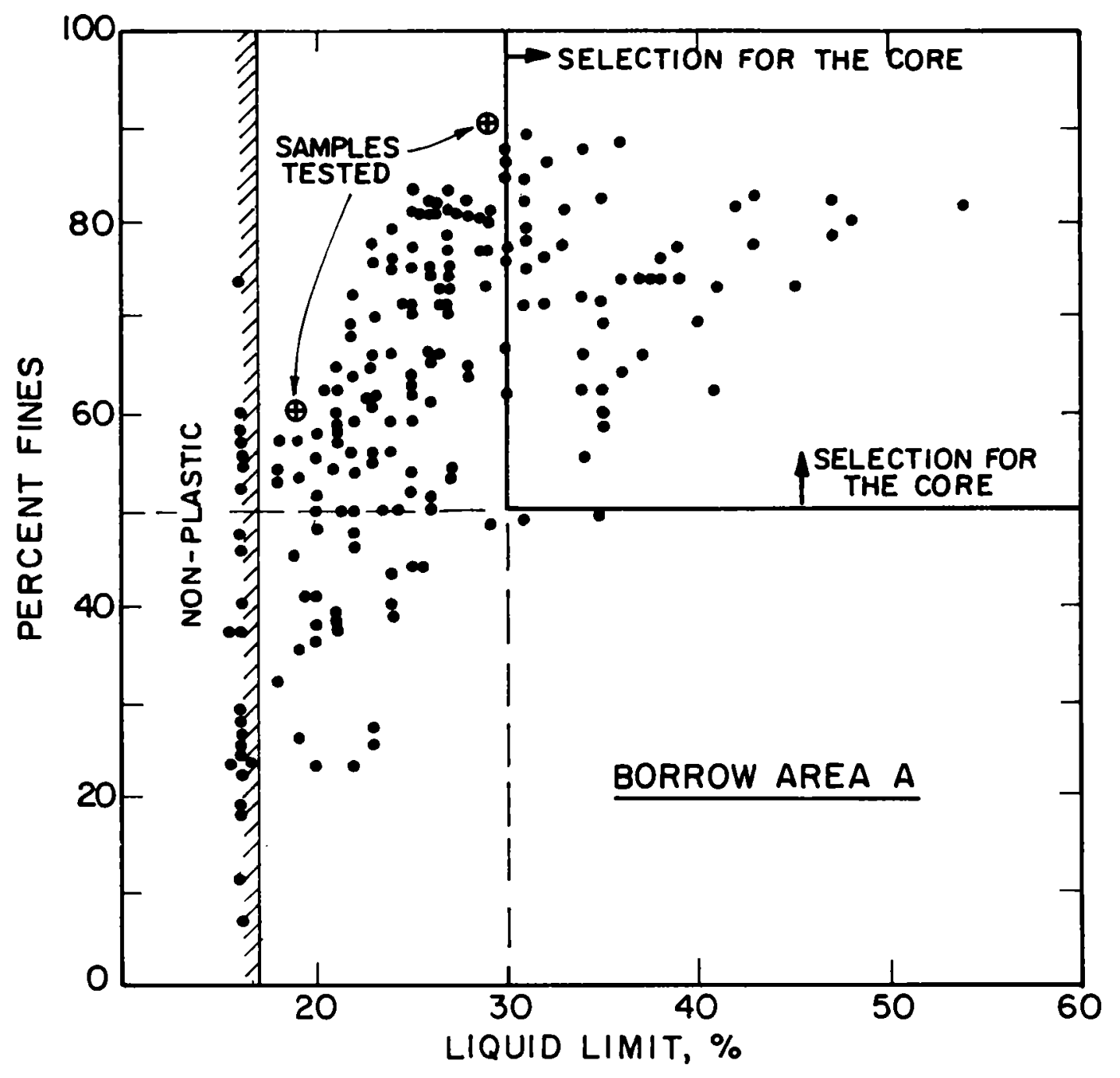

FIG. 7 STATISTICAL DISTRIBUTION OF \% OF FINES AND LIQUID LIMIT ON FILL MATERIAL FROM BORROW AREA $A$. 


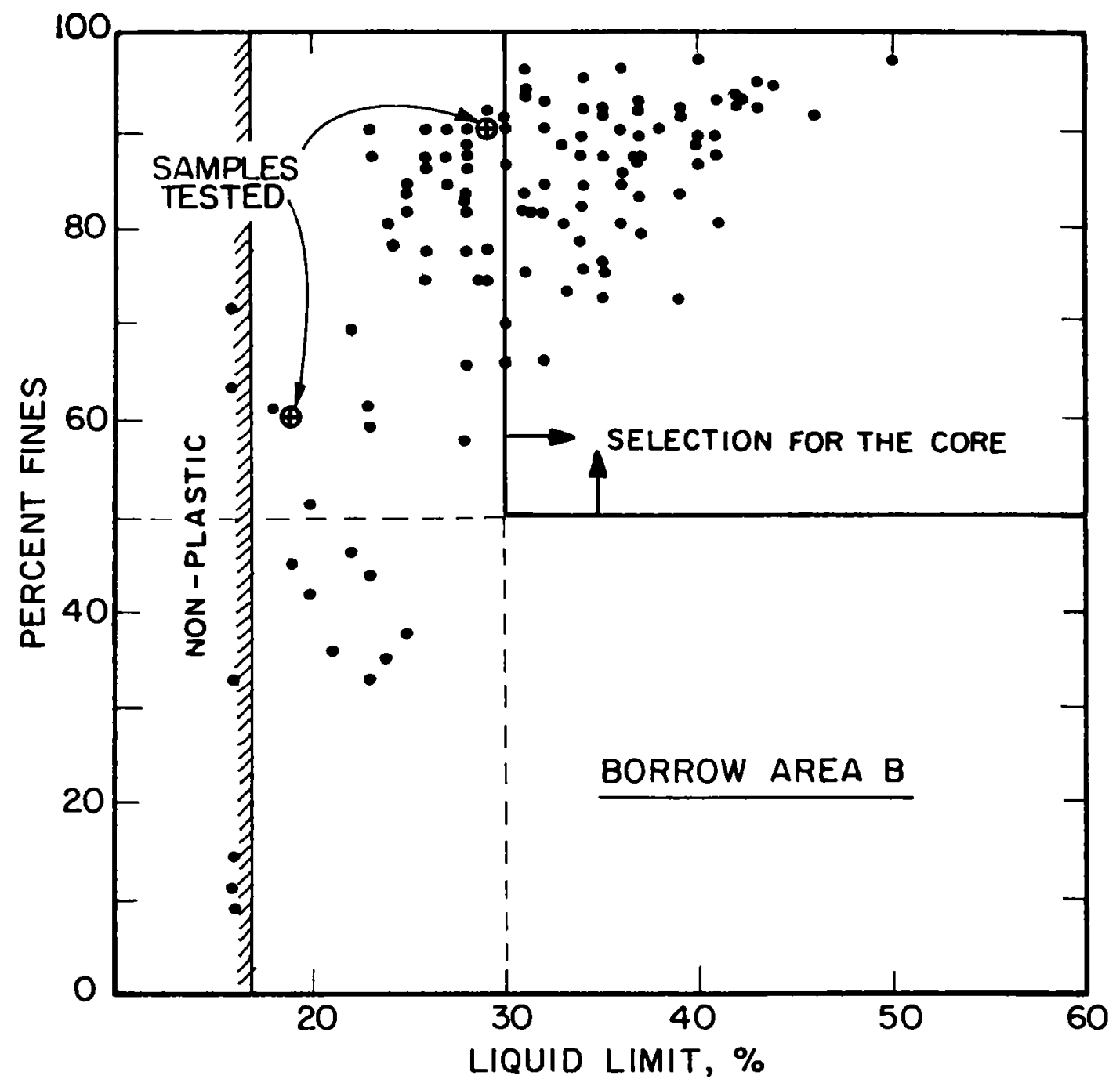

FIG. 8 STATISTICAL DISTRIBUTION OF \% OF FINES AND LIQUID LIMIT ON FILL MATERIAL FROM BORROW AREA B. 
Table 1. Descriptions, Index Properties, Densities and Water Contents of Foundation Solls

\begin{tabular}{|c|c|c|c|c|c|c|c|c|c|c|c|c|c|c|}
\hline \multirow{2}{*}{$\begin{array}{l}\text { Borling } \\
\text { No. }\end{array}$} & \multirow{2}{*}{$\begin{array}{l}\text { Depth } \\
\text { (ft) }\end{array}$} & \multirow{2}{*}{$\begin{array}{l}\text { So11 } \\
\text { Type }\end{array}$} & \multirow{2}{*}{ Soll Description } & \multicolumn{4}{|c|}{ Gra1n S1ze (m) } & \multicolumn{2}{|c|}{$\begin{array}{c}\text { Atterberg } \\
\text { LImits }\end{array}$} & \multirow{2}{*}{$w / c$} & \multirow{2}{*}{$\begin{array}{c}\gamma_{d} \\
(p c f)\end{array}$} & \multirow{2}{*}{$\begin{array}{l}S \\
(\%)\end{array}$} & \multirow{2}{*}{ e } & \multirow{2}{*}{$\mathrm{G}_{\mathrm{s}}$} \\
\hline & & & & $D_{60}$ & $\mathrm{D}_{30}$ & $\mathrm{D}_{10}$ & \% Fine & LL & PI & & & & & \\
\hline \multirow{3}{*}{$\begin{array}{l}\mathrm{CH} \\
48\end{array}$} & $7.8-8.8$ & $\mathrm{CL}$ & Dark brown clay, atiff & & & & 87 & 41 & 27 & $\begin{array}{l}18.0 \\
19.9 \\
19.0\end{array}$ & $\begin{array}{l}109 \\
106 \\
104\end{array}$ & $\begin{array}{l}91 \\
92 \\
86\end{array}$ & $\begin{array}{l}0.53 \\
0.575 \\
0.596\end{array}$ & 2.66 \\
\hline & $12.8-14.6$ & CL & Red-brn. sandy clay, soft & & & & 79 & 30 & 17 & $\begin{array}{l}25.5 \\
21.8 \\
29.6\end{array}$ & $\begin{array}{r}99 \\
105 \\
98\end{array}$ & $\begin{array}{l}99 \\
98 \\
93\end{array}$ & $\begin{array}{l}0.685 \\
0.59 \\
0.7\end{array}$ & 2.66 \\
\hline & $16.7-18.4$ & CL & Red-brn. clay, medium cons. & & & & 84 & 37 & 22 & $\begin{array}{l}22.2 \\
22.2\end{array}$ & $\begin{array}{l}100 \\
102\end{array}$ & $\begin{array}{l}89 \\
94\end{array}$ & $\begin{array}{l}0.666 \\
0.63\end{array}$ & 2.66 \\
\hline \multirow{2}{*}{$\begin{array}{l}\mathrm{CH} \\
56\end{array}$} & $11-13$ & CL & & & & & & 33 & 19 & 21.3 & 102 & 89 & 0.636 & 2.67 \\
\hline & $12-15.6$ & $\mathrm{CL}$ & & & & & & 33 & 19 & 24.0 & 100 & 97 & 0.66 & 2.67 \\
\hline \multirow{3}{*}{$\begin{array}{l}\text { CH } \\
57\end{array}$} & $8-9.7$ & SM & Red-brn. s1lty sand & 0.2 & 0.05 & 0.001 & 39 & $\mathbf{N P}$ & $\mathbf{N P}$ & 15.4 & 113 & 86 & 0.477 & \\
\hline & $12-13.7$ & CL & Red-brn. clay, medium cons. & 0.027 & 0.0015 & - & 84 & 31 & 17 & $\begin{array}{l}21.2 \\
21.6\end{array}$ & $\begin{array}{l}105 \\
105\end{array}$ & $\begin{array}{l}96 \\
96\end{array}$ & $\begin{array}{l}0.591 \\
0.606\end{array}$ & 2.69 \\
\hline & $14-16$ & CL & Red-brn. clay, medium cons. & 0.016 & 0.0012 & - & 89 & 36 & 22 & $\begin{array}{l}23.7 \\
22.5\end{array}$ & $\begin{array}{l}102 \\
103\end{array}$ & $\begin{array}{r}100 \\
98\end{array}$ & $\begin{array}{l}0.624 \\
0.609\end{array}$ & 2.66 \\
\hline \multirow{2}{*}{$\begin{array}{l}\text { CH } \\
58\end{array}$} & $8.5-10.6$ & $\mathrm{CL}$ & Red-brn. clay, stiff & 0.037 & 0.009 & - & 83 & 30 & 17 & $\begin{array}{l}19.4 \\
20.2\end{array}$ & $\begin{array}{l}107 \\
105\end{array}$ & $\begin{array}{l}93 \\
92\end{array}$ & $\begin{array}{l}0.553 \\
0.59\end{array}$ & 2.68 \\
\hline & $13.4-16.1$ & CL & Red-brn. clay, soft & 0.052 & 0.017 & 0.001 & 68 & 24 & 9 & $\begin{array}{l}20.8 \\
19.8\end{array}$ & $\begin{array}{l}104 \\
106\end{array}$ & $\begin{array}{l}95 \\
92\end{array}$ & $\begin{array}{l}0.595 \\
1.577\end{array}$ & 2.68 \\
\hline
\end{tabular}


appreciable difference between the properties of the core and shell zones. Assuming that the statistical distributions in Figs. 6, 7, and 8 are representative of the borrow materials, it appears that the core zone material will probably have average characteristics representative of a CL material, while the shell zone will likely have average characteristics representative of a ML material. Samples of the borrow materials considered representative of the core and shell zones were selected for testing at various compaction water contents and densities. The characteristics of these samples are summarized in Table 2.

Construction Schedule. From Sta. $16+00$ to Sta. $22+00$ the embankment will rest on about $37 \mathrm{ft}$ of clay. Because the undrained shear strength of the clay beneath this section of the embankment is rather low, it will be necessary to build this portion of the embankment in two stages, allowing time for consolidation of the foundation clay under the weight of the first stage before the second stage is built. The embankment cross-sections at the end of the first stage and at the end of construction are shown in Fig. 5.

It is planned to complete construction of the first stage within about 4 months, as shown in Fig. 9. Then, during a period of about 10 months, work will proceed on other sections of the embankment while time is allowed for consolidation of the clays beneath the embankment from Sta. $16+00$ to Sta. $22+00$. Pore pressure measurements and field vane shear tests will be used to monitor the pore pressure dissipation and strength increase. If the rate of consolidation is slower than estimated, either the waiting period will be extended or berms will be added to make it possible to construct the embankment up to its full height.

planned Instrumentation. It is planned to install a number of instruments in Birch Dam during construction to observe movements and pore pressures through the construction period and after. These include:

(1) Thirty-five surface reference monuments which will be installed on the upstream and downstream slopes to measure horizontal and vertical movements on the surface of the embankment. 
Table 2. Index Properties and Compaction Characteristics of F1ll Materials

\begin{tabular}{|c|c|c|c|c|c|c|c|c|c|c|c|c|c|c|c|}
\hline \multirow{2}{*}{$\begin{array}{c}\text { Fill } \\
\text { Material }\end{array}$} & \multirow{2}{*}{$\begin{array}{l}\text { Sotl } \\
\text { Type }\end{array}$} & \multirow{2}{*}{ Soll Description } & \multicolumn{4}{|c|}{ Grain Size (m) } & \multicolumn{2}{|c|}{$\begin{array}{l}\text { Atterberg } \\
\text { L1mits }\end{array}$} & \multicolumn{2}{|c|}{$\begin{array}{l}\text { Std. AASHO } \\
\text { Compact Ion }\end{array}$} & \multirow{2}{*}{$w / c$} & \multirow{2}{*}{$\begin{array}{c}Y_{d} \\
\text { (pcf) }\end{array}$} & \multirow{2}{*}{$\begin{array}{l}S \\
(z)\end{array}$} & \multirow{2}{*}{$e_{0}$} & \multirow{2}{*}{$G_{s}$} \\
\hline & & & $D_{60}$ & $\mathrm{D}_{30}$ & $\mathrm{D}_{10}$ & * Fine & LL & PI & $w / c$ & $\begin{array}{c}Y_{d} \\
(p c f)\end{array}$ & & & & & \\
\hline Core & CL & $\begin{array}{l}95 \% \gamma_{d_{\max }},-2 z d r y \\
95 \% \gamma_{d_{\max }}, \text { opt 1mum } \\
95 \% \gamma_{d_{\max }}+4 Z \text { wet }\end{array}$ & 0.045 & 0.01 & - & 89 & 29 & 15 & 14.5 & 110.3 & $\begin{array}{l}12.5 \\
14.5 \\
18.5\end{array}$ & $\begin{array}{l}105 \\
104 \\
105\end{array}$ & $\begin{array}{l}57 \\
66 \\
86\end{array}$ & $\begin{array}{l}0.580 \\
0.585 \\
0.575\end{array}$ & 2.65 \\
\hline Shell & ML & $\begin{array}{l}95 \% \gamma_{d_{\max }},-2 \% \text { dry } \\
95 \% \gamma_{d_{\max }} \text { opt 1mum } \\
95 \% \gamma_{d_{\max }}+3 \% \text { wet }\end{array}$ & 0.07 & 0.045 & 0.013 & 60 & 19 & 1 & 13.6 & 108.8 & $\begin{array}{l}11.8 \\
13.5 \\
16.3\end{array}$ & $\begin{array}{l}104 \\
104 \\
104\end{array}$ & $\begin{array}{l}53 \\
62 \\
74\end{array}$ & $\begin{array}{l}0.583 \\
0.578 \\
0.583\end{array}$ & 2.63 \\
\hline
\end{tabular}




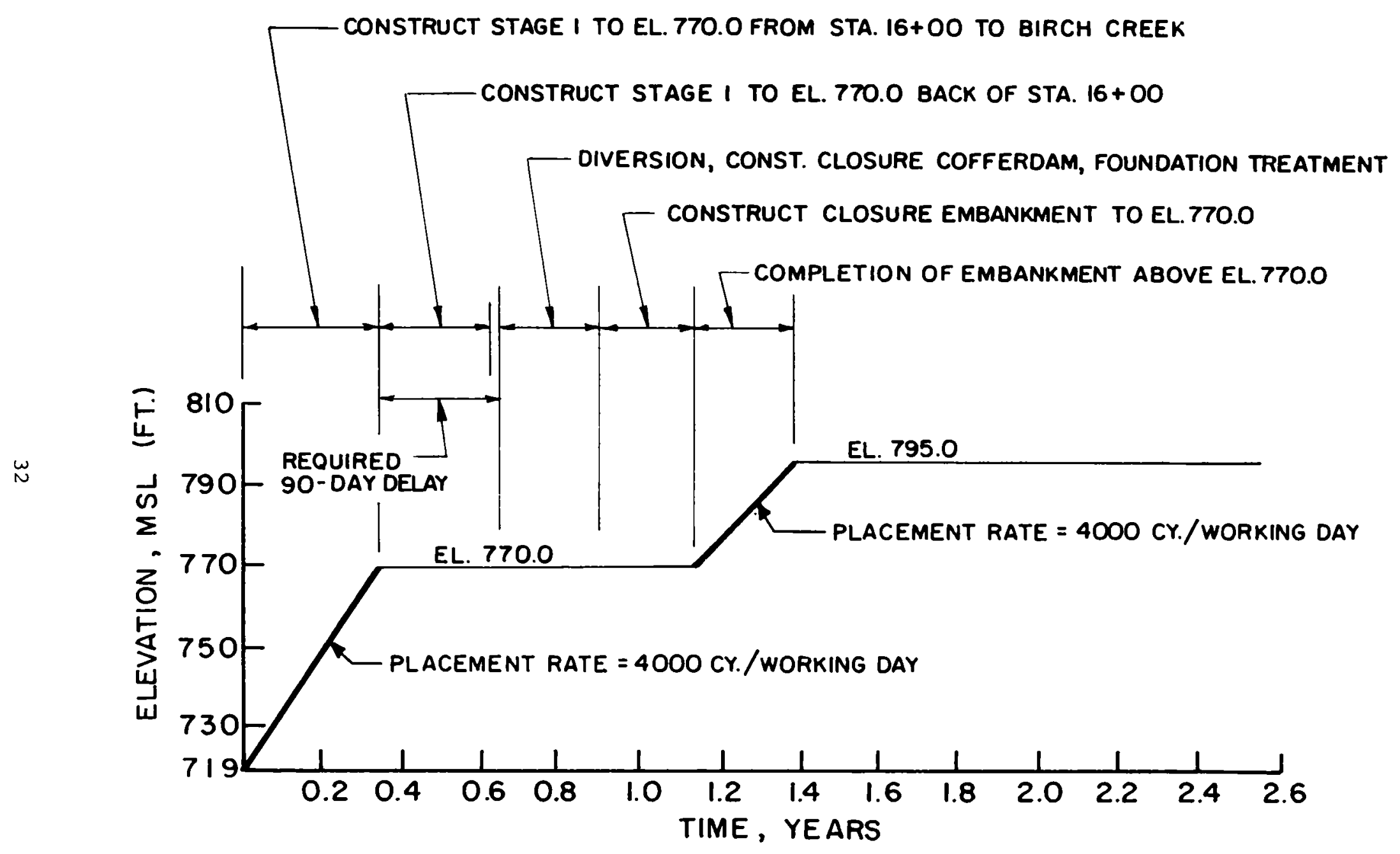

FIG. 9 ESTIMATED RATE OF FILL PLACEMENT. 
(2) Thirty pore pressure piezometers which will be installed to monitor foundation pore pressures during construction for the purpose of ensuring that the required degree of dissipation is achieved before construction of stage 2 begins. Eleven of these piezometers will be located in the foundation at Sta. $19+50$, very close to the section considered in the finite element analysis (Sta. $20+00$ ).

(3) Two slope indicators which will be installed in the dam to monitor later movements during and following construction. They will be located $100 \mathrm{ft}$ upstream and $100 \mathrm{ft}$ downstream from the centerline of the dam, at Sta. $20+00$.

The locations of the instruments are described in detail in Design Memorandum No. 17, Birch Lake Dam, Tulsa District.

Finite element analyses can be useful in planning instrument locations by pinpointing locations of probable large movements, or movements of a particularly critical nature. In this case the instrument locations were decided before the finite element analyses had been performed. Judging by the results of the finite element analyses described in later sections of this report, the instruments appear to be located so that they will provide a good picture of the performance of the dam, and useful information for judging the results of the finite element analyses.

\section{PROPERTIES FOR ANALYSES}

Undoubtedly the most important aspect of a finite element analysis of stresses and movements in an embankment dam is the determination of properties to represent the behavior of the embankment and foundation soils. In this study of the probable movements and stresses in Birch Dam, the greatest portion of the effort in the analysis was devoted to determination of properties for use in the analysis. The hyperbolic relationships which were used to characterize the stress-strain behavior of the soils, and the interpretations of the laboratory tests to determine the values of the required parameters are described in subsequent sections.

Hyperbolic Stress-Strain Relationships. If two identical soil specimens are subjected to triaxial tests at two different confining 
pressures, the resulting stress-strain curves will be as shown in Fig. 10. These stress-strain curves exhibit three important characteristics which nearly all soils have in common. These are:

(1) Nonlinearity. The stress-strain curves are nonlinear, and can not be accurately represented as straight lines over any appreciable portion of their lengths.

(2) Stress-Dependency. For any but saturated soils tested under undrained conditions, both the stiffness and the strength of the soil will vary with the magnitude of the confining pressure $\left(\sigma_{3}\right)$.

(3) Inelasticity. The stress-strain curves for unloading and reloading are different from that for primary loading, i.e. there are irrecoverable, or inelastic strains.

The hyperbolic relationships developed by Duncan and Chang (1970) and Kulhawy, et al. (1969), account for these characteristics by means of simple empirical relationships:

Nonlinearity is taken into account by approximating the shape of the stress-strain curves by a hyperbola.

Stress-dependency is taken into account by relating the values of the coefficients which govern the shapes of hyperbolas to the confining pressure. mirical equations are used for these relationships, as indicated in Table 3.

Inelasticity is taken into account by using the unloading-reloading modulus value for elements which are found to be undergoing unloading or reloading rather than primary loading.

Similar relationships are used to account for variations of Poisson's ratio with the magnitudes of the stresses, as indicated in Table 3 .

The hyperbolic stress-strain relationships can be applied to analyses of either drained or undrained deformation. For drained conditions in the field, consolidated-drained triaxial test data are used to determine values of the required parameters' and for undrained field 


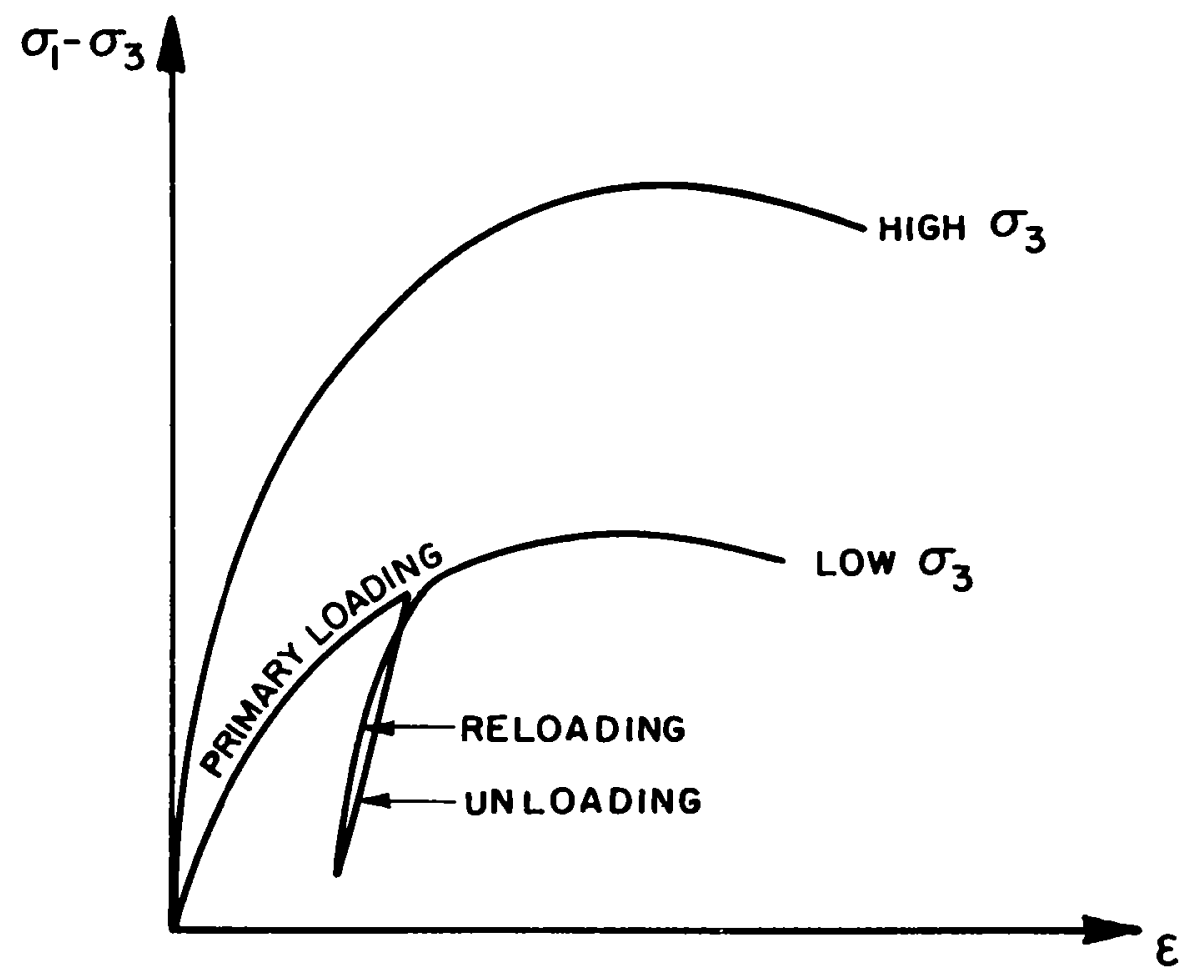

FIG. 10 STRESS -STRAIN CURVES FOR TRIAXIAL TESTS ON SOIL AT TWO VALUES OF CONFINING PRESSURE. 
Table 3. Summary of the Hyperbolic Parameters

\begin{tabular}{|c|c|c|}
\hline Parameter & Name & Function \\
\hline $\mathrm{K}, \mathrm{K}_{\mathrm{ur}}$ & Modulus number & \multirow{2}{*}{ Relate $E_{i}$ and $E_{u r}$ to $\sigma_{3}$} \\
\hline $\mathrm{n}$ & Modulus exponent & \\
\hline c & Cohesion intercept & \multirow{2}{*}{ Relate $\left(\sigma_{1}-\sigma_{3}\right)$ to $\sigma_{3}$} \\
\hline$\phi$ & Friction angle & \\
\hline$R_{f}$ & Failure ratio & Relates $\left(\sigma_{1}-\sigma_{3}\right)_{\text {ult }}$ to $\left(\sigma_{1}-\sigma_{3}\right)_{f}$ \\
\hline G & Poisson's ratio parameter & Value of $\nu_{i}$ at $\sigma_{3}=p_{a}$ \\
\hline $\mathbf{F}$ & Poisson's ratio parameter & $\begin{array}{l}\text { Decrease in } v_{i} \text { for ten-fold } \\
\text { increase in } \sigma_{3}\end{array}$ \\
\hline $\mathrm{d}$ & Poisson's ratio parameter & $\begin{array}{l}\text { Rate of increase of } v_{t} \text { with } \\
\text { strain }\end{array}$ \\
\hline
\end{tabular}


conditions, unconsolidated-undrained triaxial test data are used. Additional details concerning the hyperbolic formulations and the procedures used in determining the parameter values from laboratory test data are contained in the report by Wong and Duncan (1974).

Simplified Foundation Soil Profile. For purposes of the finite element analyses, a simplified representation of the soil conditions was developed based on the cross-sections shown in Figs. 3 and 4 . In this simplified representation, shown in Fig. 11 the soil properties were taken as uniform in the horizontal direction, and four layers were used to represent variations in soil type and stress-strain properties with depth. The layers represented in the analyses were:

(1) At the base of the soil profile, immediately overlying bedrock, is a $7 \mathrm{ft}$ thick layer of silty sand.

(2) On top of the silty sand is a $10 \mathrm{ft}$ thick layer of normally consolidated, saturated clay.

(3) Overlying the normally consolidated clay is a $10 \mathrm{ft}$ thick layer of lightly overconsolidated, saturated clay. The top of this layer is at the elevation of the ground water table.

(4) Above the groundwater table, extending up to the ground surface, is a $10 \mathrm{ft}$ thick layer of partly saturated clay which has been fairly heavily overconsolidated by desiccation.

Undrained Properties for Foundation Soils. A number of undisturbed samples of the foundation soils, from various locations and depths, were tested in unconsolidated-undrained test conditions by the Tulsa District of the U. S. Army Corps of Engineers, and the data from these tests are contained in Design Memorandum No. 6, Birch Lake (Tulsa District, Corps of Engineers, 1972). These data were used to determine values of the stress-strain and strength parameters which are summarized in Table 4. Variations of the soil properties with depth are shown in Fig. 11, together with the variations of these properties which were used in the finite element analyses.

The strengths used in the finite element analyses are higher than would normally be used in stability analyses, as can be seen in Fig. 11 . 

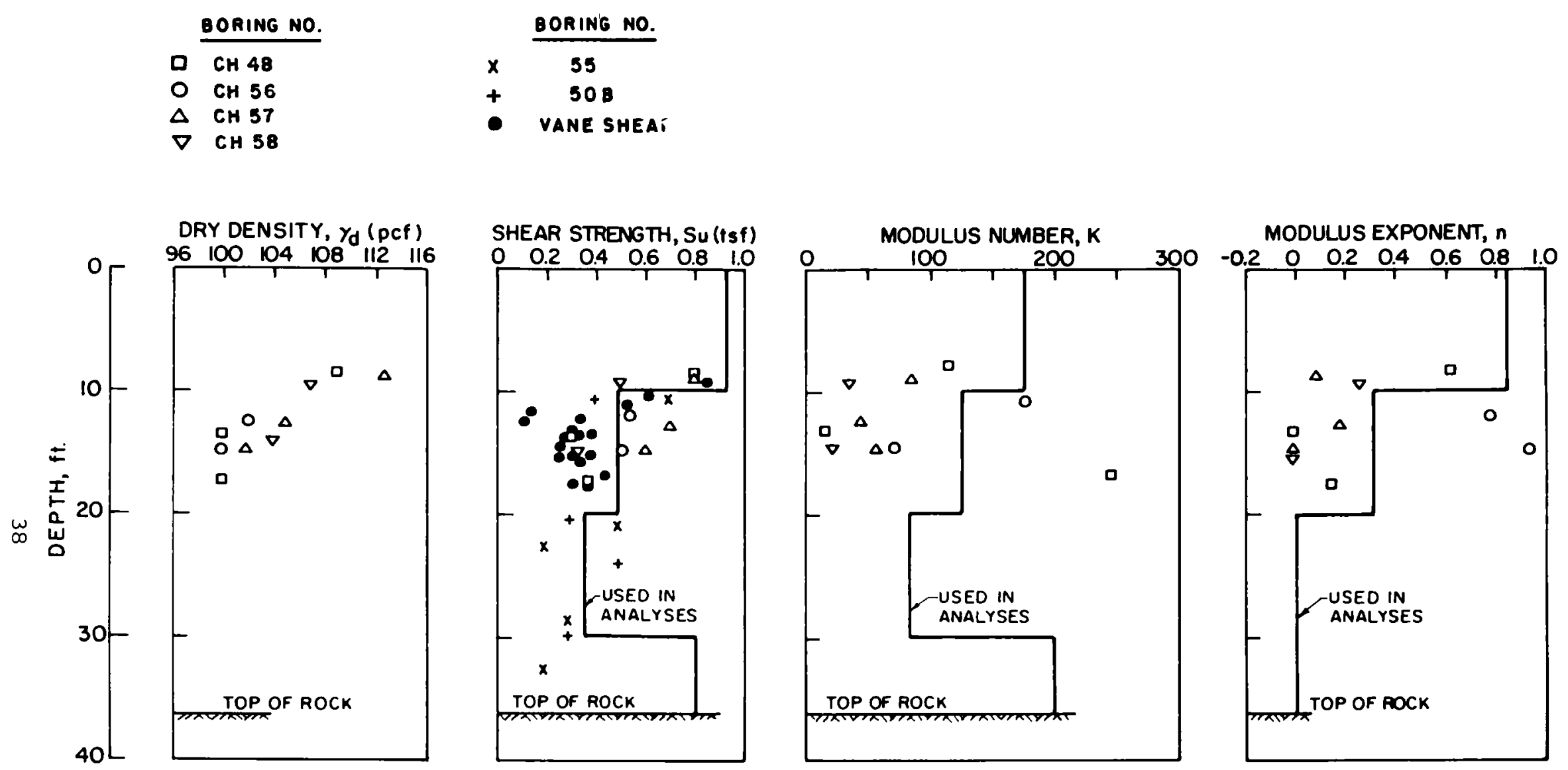

FIG. II VARIATION OF UNDRAINED STRENGTH (SU), DRY DENSITY $\left(\gamma_{d}\right)$, MODULUS NUMBER (K) AND MODULUS EXPONENT ( $n$ ) WITH DEPTH IN THE FOUNDATION. 
Table 4. Undrained Stress-Strain and Strength Parameters for Foundation Soils

\begin{tabular}{|c|c|c|c|c|c|c|c|}
\hline \multirow{2}{*}{$\begin{array}{l}\text { Boring } \\
\text { No. }\end{array}$} & \multirow{2}{*}{$\begin{array}{l}\text { Depth } \\
\text { (ft) }\end{array}$} & \multirow{2}{*}{$\begin{array}{l}\text { Soil } \\
\text { Type }\end{array}$} & \multicolumn{5}{|c|}{ UU - Triaxial Test Results } \\
\hline & & & $\begin{array}{c}c \\
(t s f)\end{array}$ & $\phi$ & $\mathrm{K}$ & $\mathbf{n}$ & $\mathrm{R}_{\mathbf{f}}$ \\
\hline \multirow{3}{*}{$\begin{array}{l}\mathrm{CH} \\
48\end{array}$} & $7.8-8.8$ & CL & $\begin{array}{c}0.8 \\
(1.5)\end{array}$ & $\begin{array}{c}6.0 \\
(0.0)\end{array}$ & 115 & 0.62 & 0.96 \\
\hline & $12.8-14.6$ & CL & 0.3 & 0.0 & 13 & 0 & 0.87 \\
\hline & $16.7-18.4$ & CL & 0.38 & 3.0 & 240 & 0.17 & 1.0 \\
\hline \multirow{2}{*}{$\begin{array}{l}\mathrm{CH} \\
56\end{array}$} & $11-13$ & CL & 0.55 & 5.0 & 174 & 0.78 & 0.98 \\
\hline & $14-15.6$ & CL & 0.50 & 2.0 & 70 & 0.95 & 0.93 \\
\hline \multirow{3}{*}{$\begin{array}{l}\mathrm{CH} \\
57\end{array}$} & $8-9.7$ & SM & 0.8 & 0.0 & 84 & 0.08 & 0.89 \\
\hline & $12-13.7$ & CL & 0.7 & 0.0 & 45 & 0.18 & 0.82 \\
\hline & $14-16$ & CL & 0.6 & 0.0 & 59 & 0 & 0.87 \\
\hline \multirow{2}{*}{$\begin{array}{l}\mathrm{CH} \\
58\end{array}$} & $8.5-10.6$ & CL & $\begin{array}{c}0.5 \\
(1.6)\end{array}$ & $\begin{array}{c}2.0 \\
(0.0)\end{array}$ & 34 & 0.24 & 0.82 \\
\hline & $13.4-16.1$ & $\mathrm{CL}$ & 0.38 & 0.0 & 21 & 0 & 0.84 \\
\hline
\end{tabular}


This is so because the strength values selected for the finite element analyses were intended to be best estimates of the strengths in the field, rather than conservative, reliable estimates of shear strength normally used in stability analyses.

In selecting the values of modulus number $K$ in Fig. 11 , the highest measured values were given more weight, because it is known that even a minor amount of disturbance can have the effect of causing considerable reduction in soil modulus. The values of $\mathrm{K}$ used in the analyses correspond to values of $E_{i}$ equal to 250 times the undrained strength $\left(E_{i}=250 S_{u}\right)$, based on the writers' experience with undrained stress-strain behavior of clay.

Drained Properties for Foundation Soils. The hyperbolic parameters for drained conditions in the foundation soils were determined from the results of drained direct shear tests and consolidation tests on undisturbed samples. The results of the drained direct shear tests on undisturbed clay specimens are shown in Fig. 12, together with the envelope used to characterize the drained strength, corresponding to $c^{\prime}=0.3 \mathrm{t} / \mathrm{ft}^{2}, \phi^{\prime}=28^{\circ}$. The e- $\log \mathrm{p}$ curves for consolidation tests on undisturbed clay specimens are shown in Fig. 13. Of these curves, the one labelled 5 appeared to be the least affected by disturbance, and therefore the most representative of the compressibility of the clay. The values of primary loading modulus number $k$, modulus exponent $k_{u r}$, and modulus exponent $\mathrm{n}$ which were used in the analyses were determined using this e- $\log p$ curve, the values of $c^{\prime}$ and $\phi^{\prime}$ shown in Fig. 12, and the value of the parameter $R_{f}$ equal to 0.8 was estimated from data for similar soils which has been compiled by wong and Duncan (1974). The values of the earth pressure coefficients $k_{0}$ and $k_{0}^{\Delta}$, which are required for these evaluations, were estimated using the correlations shown in Figs. 14 and 15. The values of the stress-strain and strength parameters determined from drained tests on foundation soils are summarized in Table 5.

No test data were available for the bottom foundation layer, which is silty sand. The parameters of this layer were estimated on the basis of data for similar soils contained in the report by Wong and Duncan (1974). 


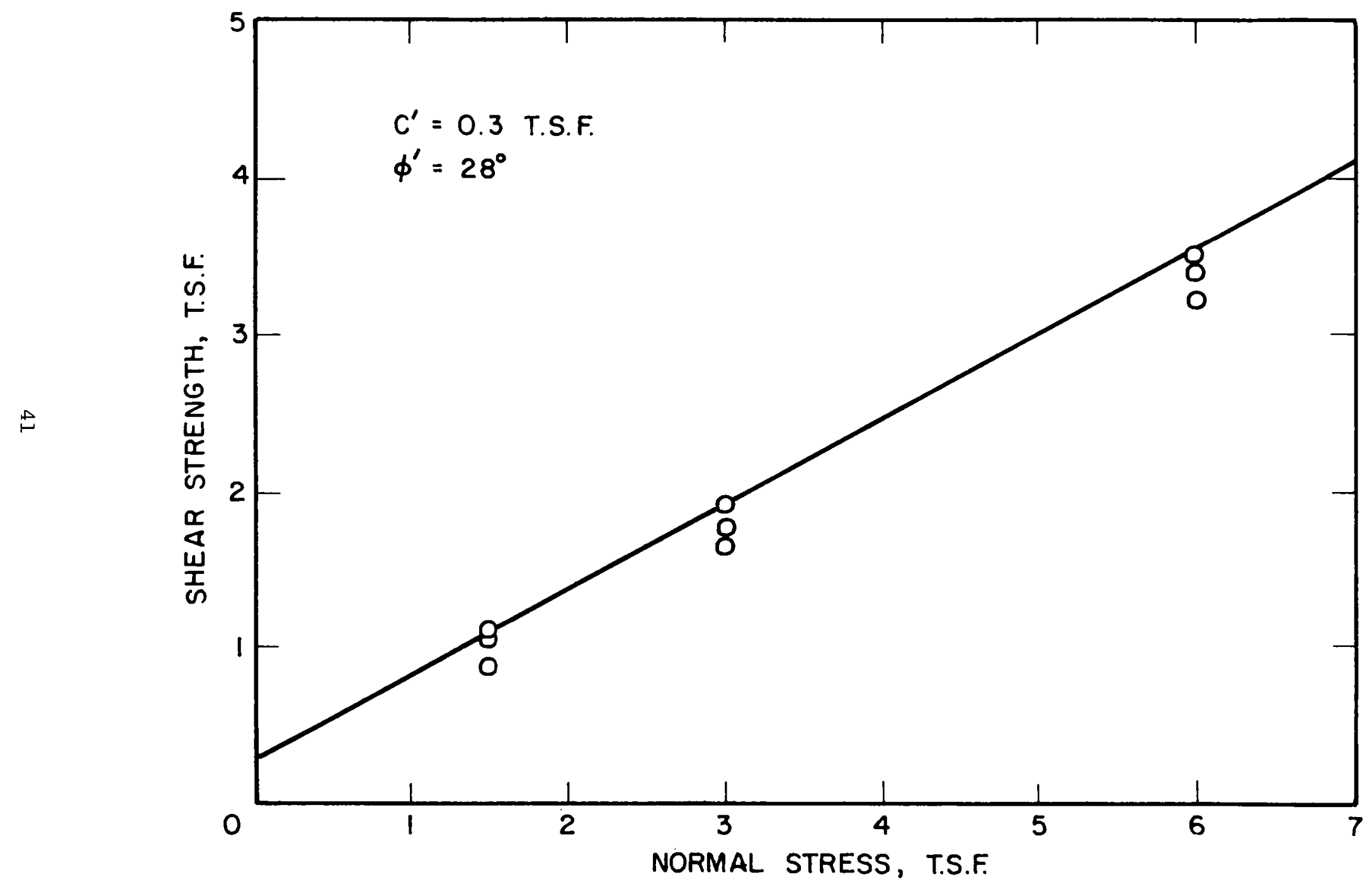

FIG. 12 DRAINED STRENGTH OF FOUNDATION SOILS FROM DIRECT SHEAR TESTS. 


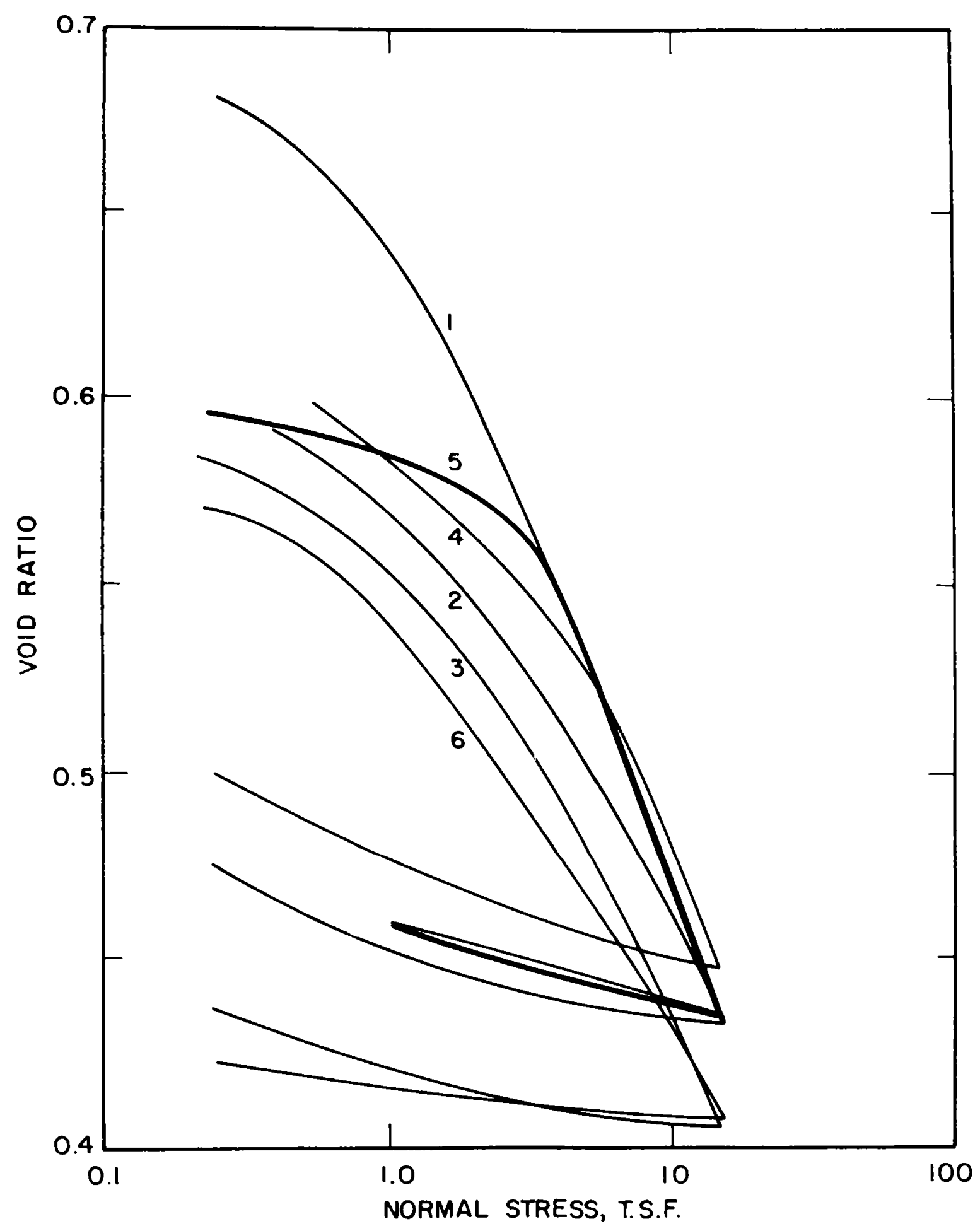

FIG. 13 e-LOG $p$ CURVES OF FOUNDATION SOILS FROM CONSOLIDATION TESTS. 


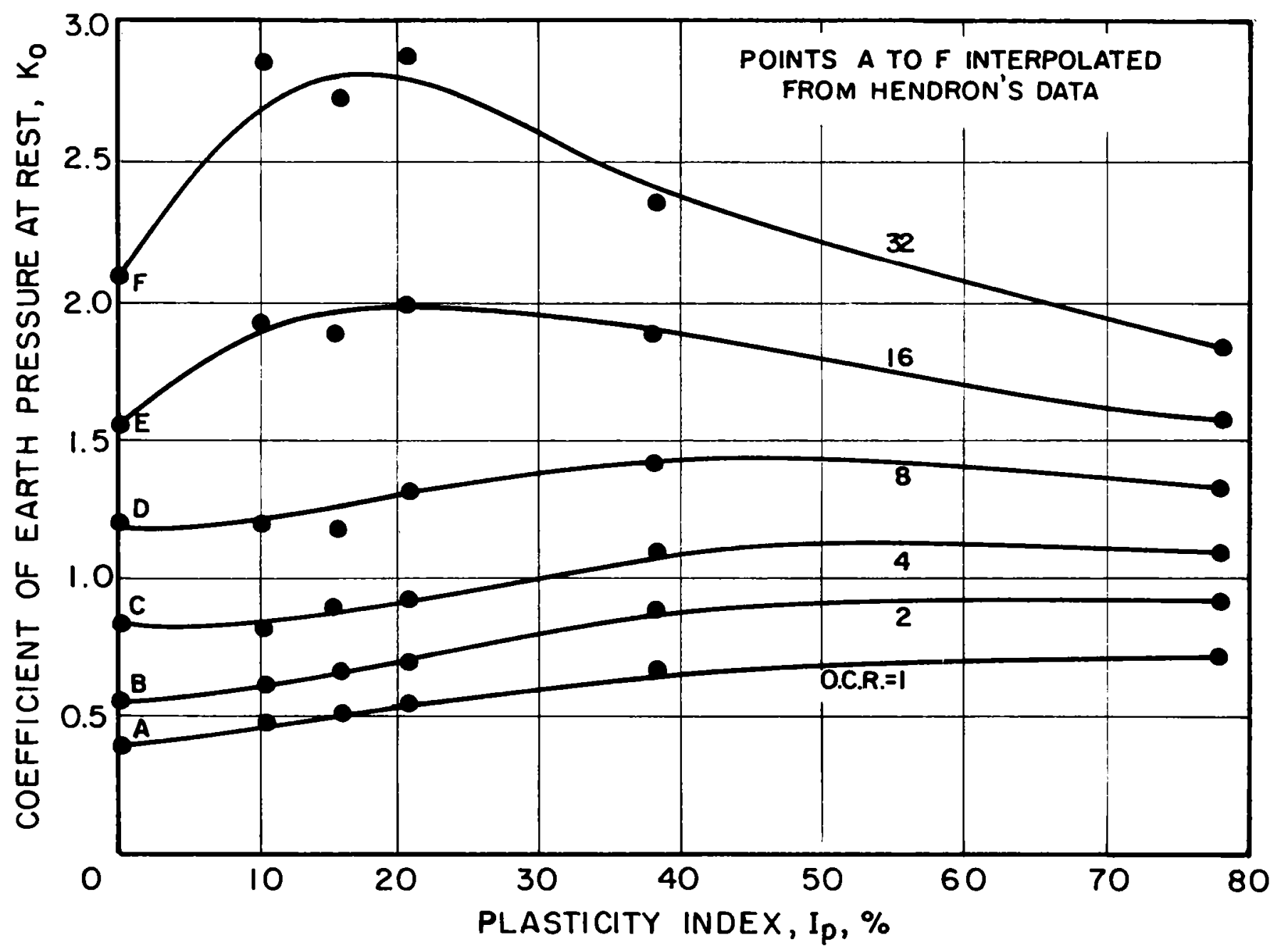

FG. 14 VARIATION OF $K_{0}$ VALUES WITH PLASTICITY INDEX FOR SEVERAL VALUES OF OVERCONSOLIDATION RATIO.

(AFTER BROOKER AND IRELAND) 


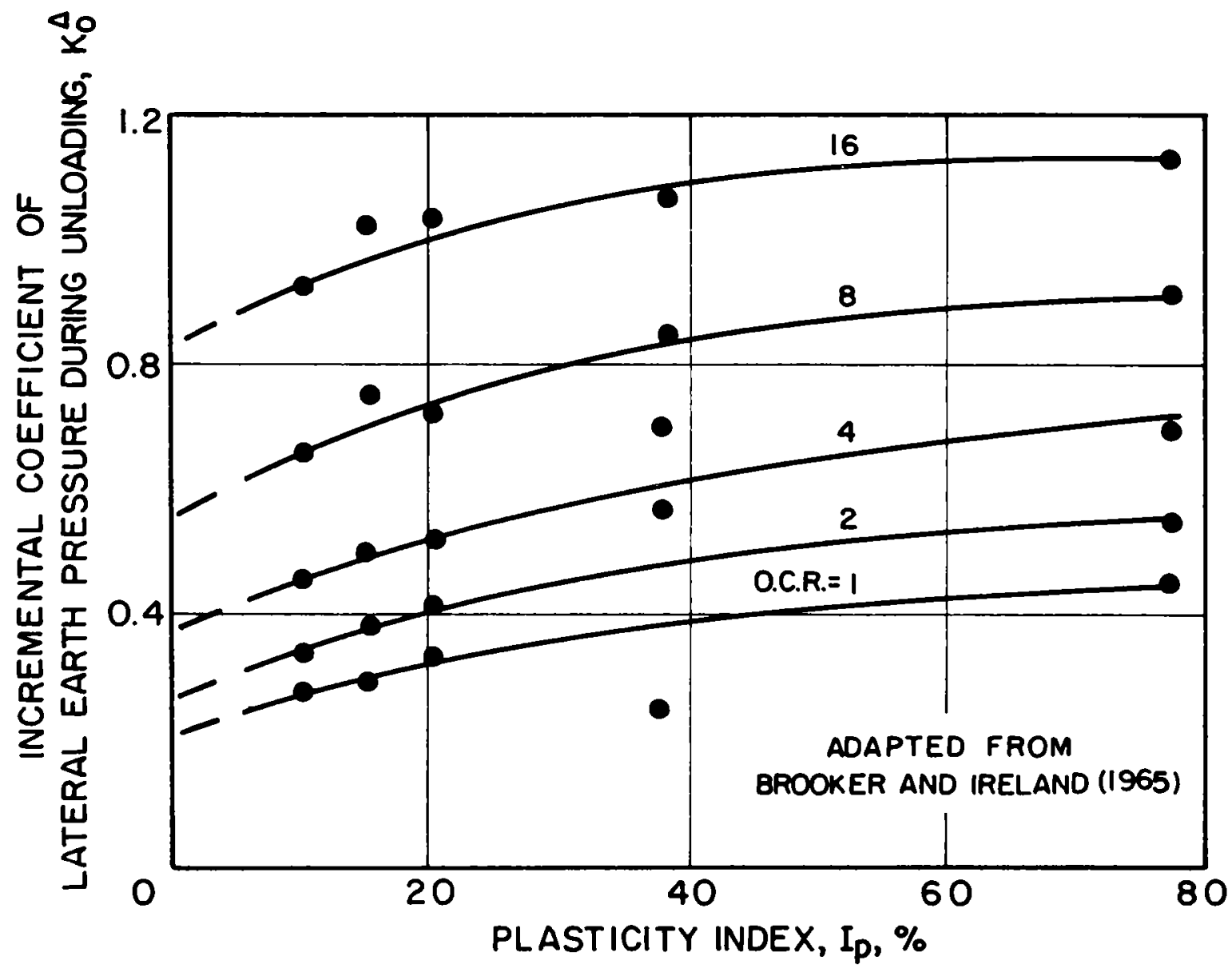

FIG. I5 INCREMENTAL COEFFICIENT OF LATERAL EARTH PRESSURE. (AFTER CLOUGH AND DUNCAN) 
Table 5. Drained Stress-Strain and Strength

Parameters for Foundation Soils

\begin{tabular}{|c|c|c|c|c|c|c|c|c|}
\hline \multirow{2}{*}{$\begin{array}{l}\text { Boring } \\
\text { No. }\end{array}$} & \multirow[b]{2}{*}{$\begin{array}{l}\text { Depth } \\
\text { (ft) }\end{array}$} & \multirow[b]{2}{*}{$\begin{array}{l}\text { Soil } \\
\text { Type }\end{array}$} & \multicolumn{2}{|c|}{ Direct Shear } & \multicolumn{4}{|c|}{ Consolidation Tests } \\
\hline & & & $\begin{array}{l}C^{\prime} \\
(t s f)\end{array}$ & $\phi^{\prime}$ & $\mathrm{K}_{\text {ur }}{ }^{\prime}$ & $K^{\prime}$ & $n^{\prime}$ & $\mathrm{R}_{\mathrm{f}}$ \\
\hline \multirow{3}{*}{$\begin{array}{l}\mathrm{CH} \\
48\end{array}$} & $7.8-8.8$ & $\mathrm{CL}$ & 0.3 & $27.4^{\circ}$ & 160 & 40 & 1.0 & $(0.8)$ \\
\hline & $12.8-14.5$ & CL & 0.3 & $28.2^{\circ}$ & 218 & 60 & 0.95 & $(0.8)$ \\
\hline & $16.7-18.4$ & CL & 0.1 & $28.0^{\circ}$ & & & & \\
\hline \multirow{2}{*}{$\begin{array}{l}\mathrm{CH} \\
56\end{array}$} & $11-13$ & CL & & & & & & \\
\hline & $14-15.6$ & CL & & & & & & \\
\hline \multirow{3}{*}{$\begin{array}{l}\mathrm{CH} \\
57\end{array}$} & $8-9.7$ & SM & & & & & & \\
\hline & $12-13.7$ & CL & $(0.3)^{\star}$ & (28) & 639 & 91 & 0.92 & $(0.8)$ \\
\hline & $14-16$ & CL & $(0.3)$ & (28) & 460 & 92 & 0.68 & $(0.8)$ \\
\hline \multirow{2}{*}{$\begin{array}{l}\mathrm{CH} \\
58\end{array}$} & $8.5-10.6$ & CL & $(0.3)$ & (28) & 600 & 76 & 0.99 & $(0.8)$ \\
\hline & $13.4-16.1$ & CL & $(0.3)$ & (28) & 884 & 140 & 1.16 & $(0.8)$ \\
\hline
\end{tabular}

*Values in parentheses are assumed values 
Coefficient of Consolidation of Foundation Soils. For purposes of estimating the movements due to consolidation of the foundation and the rate of dissipation of pore pressures during and following the construction period, the value of the coefficient of consolidation of the foundation soils was required. Time curves for one of the consolidation tests on the foundation soils are shown in Fig. 16. These data, and the data from other tests as well, showed that for the load increment from $2 \mathrm{t} / \mathrm{ft}^{2}$ to $4 \mathrm{t} / \mathrm{ft}^{2}$, the value of $\mathrm{C}_{\mathrm{v}}$ varied from $25 \mathrm{ft}^{2} / \mathrm{yr}$ to $95 \mathrm{ft}^{2} / \mathrm{yr}$, with an average value of $60 \mathrm{ft}^{2} / \mathrm{yr}$.

It was considered that this average value from laboratory tests is probably lower than the effective average value for the field: The foundation of Birch Dam contains sand lenses which comprise about $30 \%$ of its thickness. Even though it seems unlikely that these sand lenses are continuous, they will nevertheless have the effect of reducing the length of the vertical drainage path, thus increasing the effective average value of $\mathrm{C}_{\mathrm{v}}$ for the foundation clay. The foundation clay was considered to be a homogeneous layer $30 \mathrm{ft}$ thick and the value of $\mathrm{C}_{\mathrm{v}}$ was increased to account for the expected effects of the sand lenses in accelerating the rate of consolidation. Accordingly, a value of $C_{v}=180 \mathrm{ft}^{2} / \mathrm{yr}$ was used in the analyses. This choice was made largely on the basis of the writers' judgment and experience with estimating field settlement rates.

Density and water Content of Embankment Soils. The specifications for the shell zone and the core zone of Birch Dam are: For the shell, the minimum permissible dry density is 958 of the Standard AASHO maximum dry density, with a compaction water content in the range from 28 dry of optimum to $3 \%$ wet of optimum. For the core, the minimum permissible dry density is also $95 \%$ of the standard AASHO maximum dry density, with a compaction water content from $1 \%$ dry of optimum to $3 \%$ wet of optimum.

Because $95 \%$ is a minimum degree of compaction for the core and shell, the average density in both of these zones would be expected to be somewhat higher. To estimate how much higher than the minimum the average dry density would be, the record density tests for Perry Dam and Littleville Dam were examined, as shown in Figs. 17 through 20. These data were taken from reports No. 1 and No. 2, Analysis of Field Compaction 


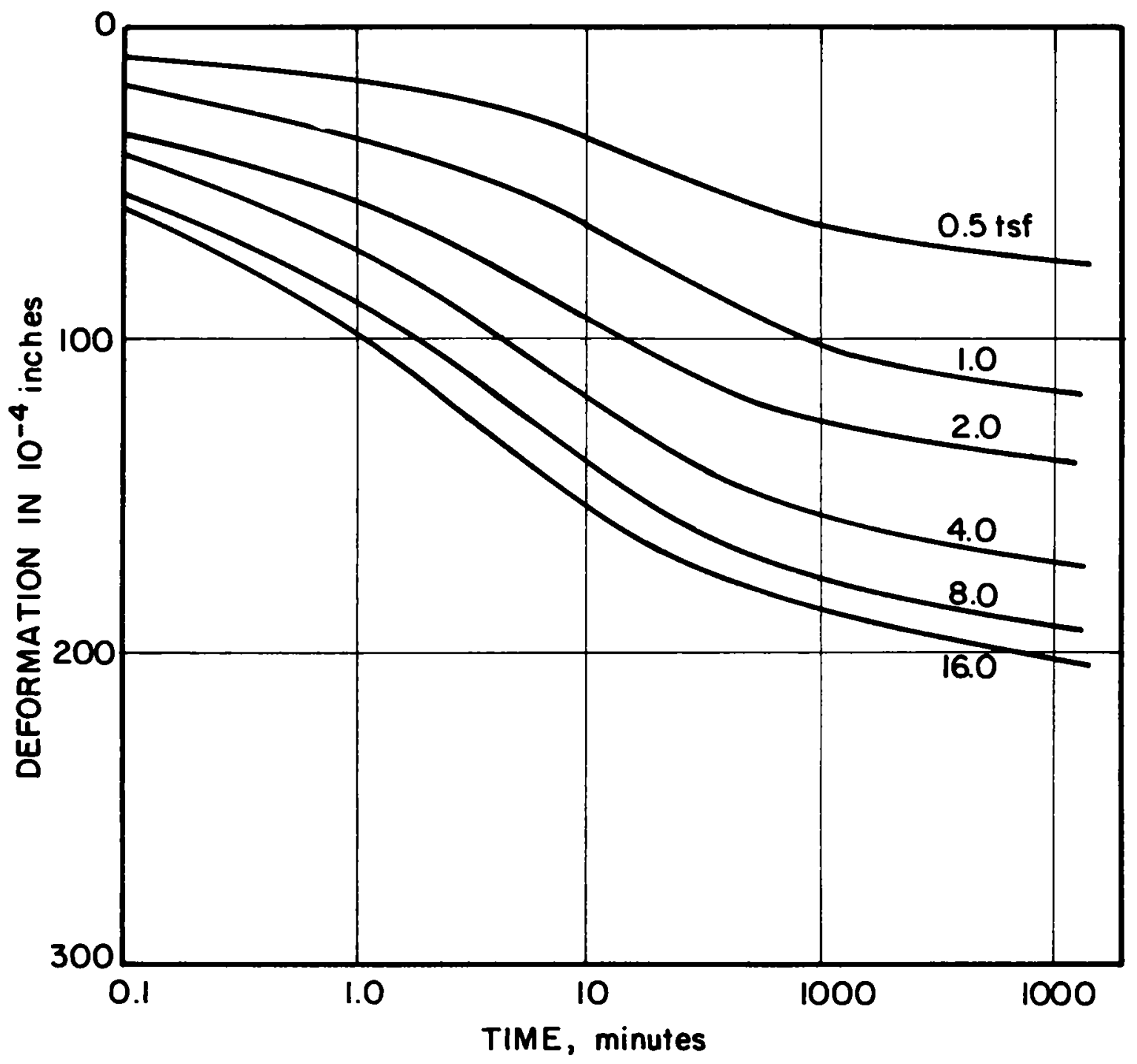

FIG. 16 TYPICAL CONSOLIDATION TIME CURVES OF FOUNDATION SOIL (CL). 


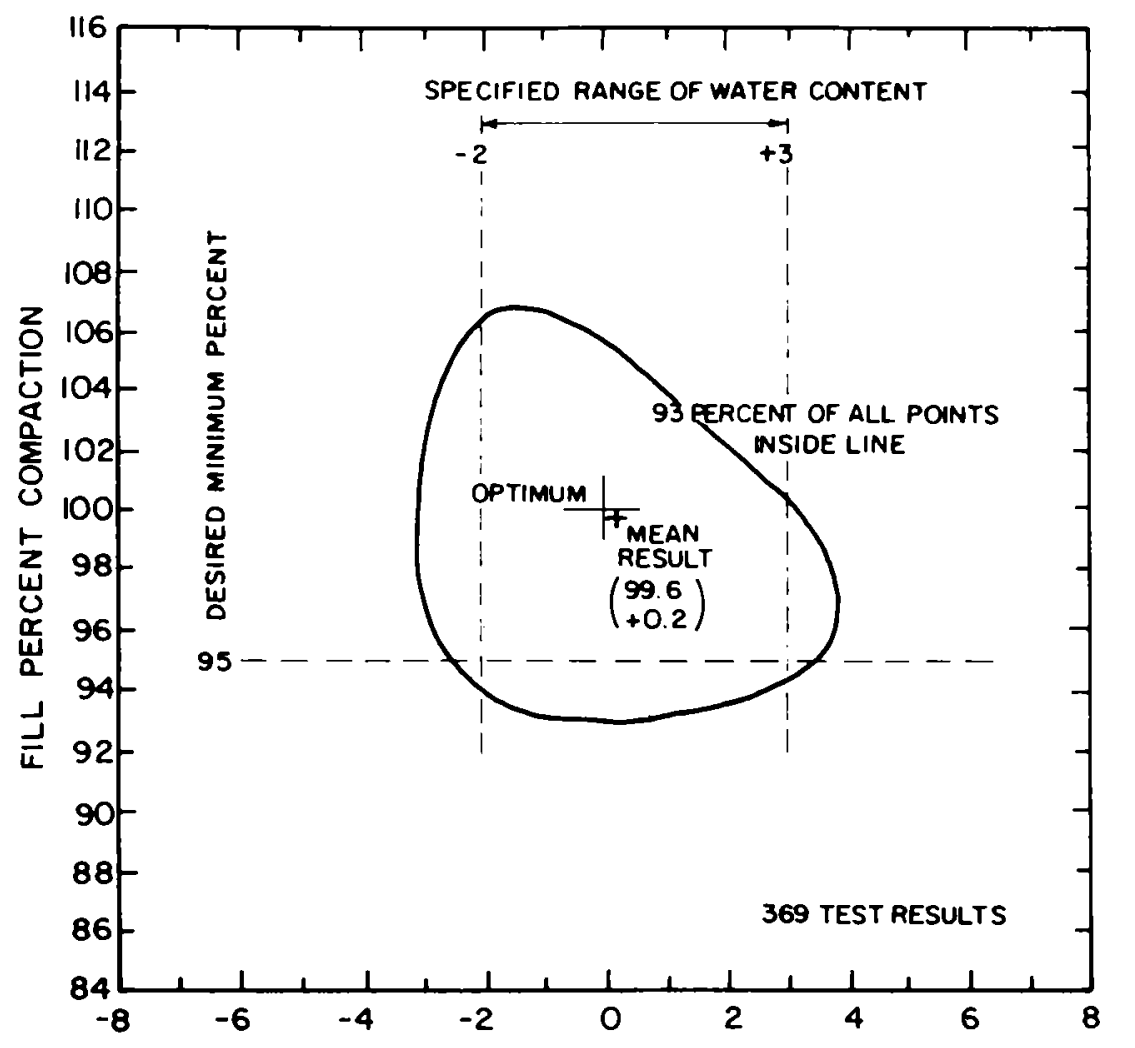

VARIATION OF FILL WATER CONTENT FROM STD AASHO OPTIMUM, \%

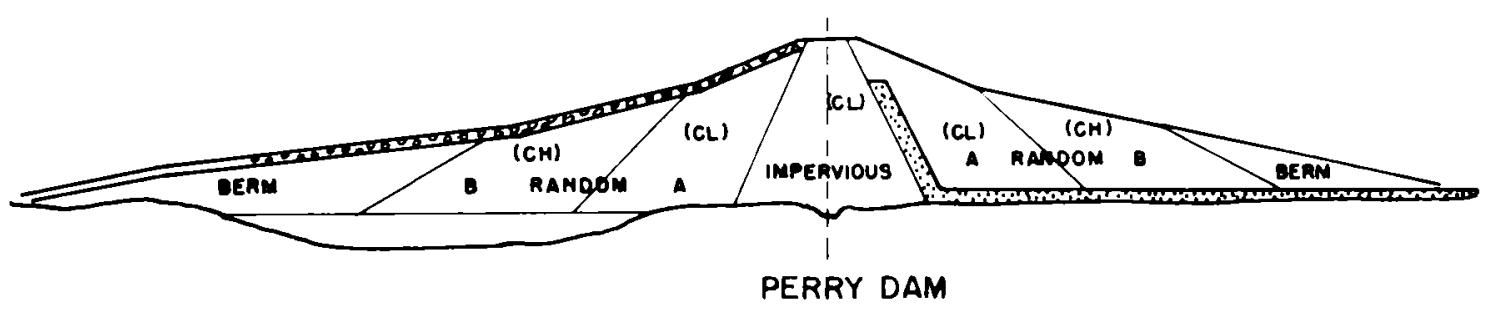

FIG. 17 VARIATION OF TEST VALUES ON FIELD COMPACTED SAMPLES WITH RESPECT TO THE DESIRED LIMITS ON PERRY DAM, ZONE A SHELL MATERIALS. 


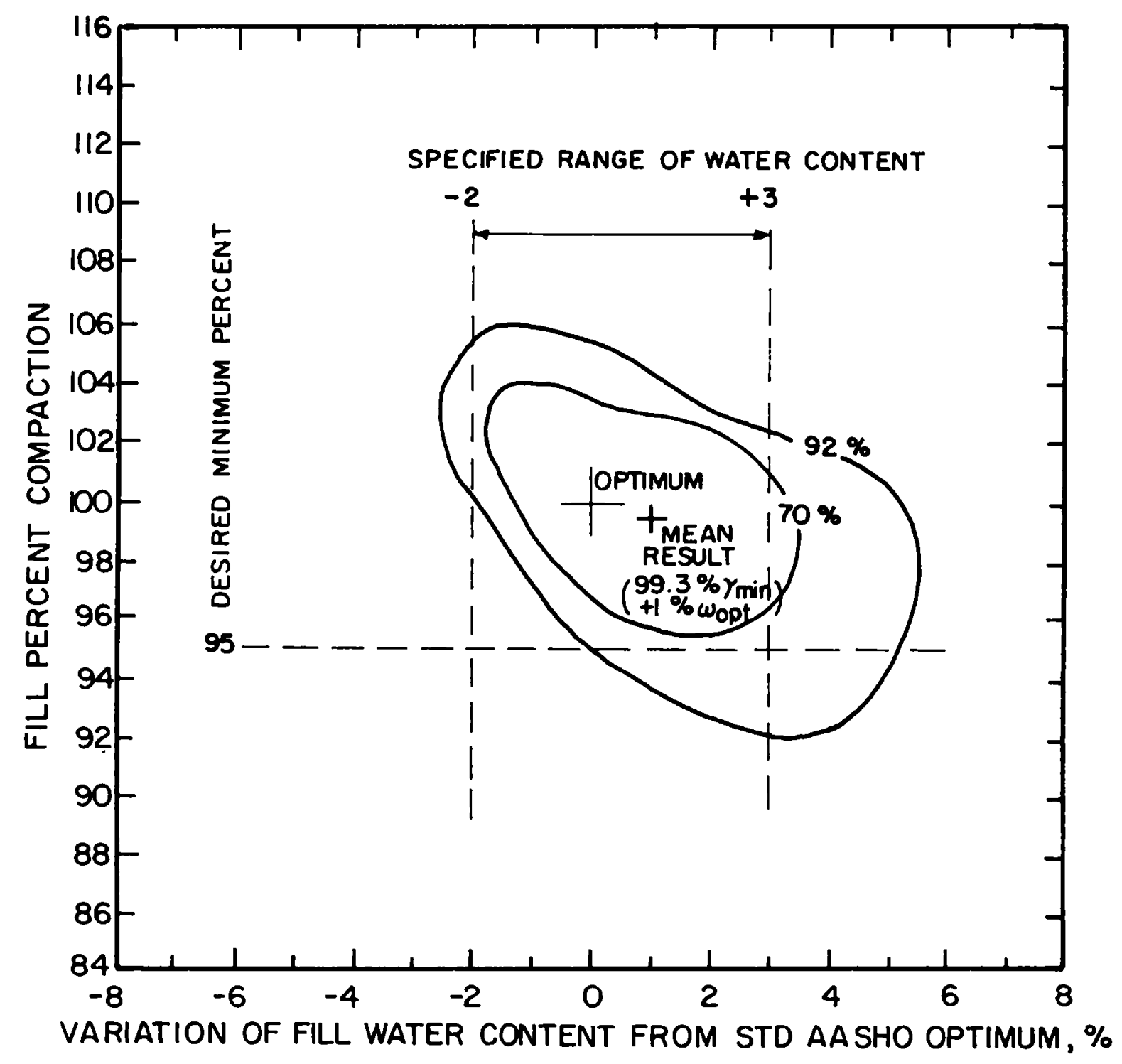

FIG. I8 VARIATION OF TEST VALUES ON FIELD COMPACTED SAMPLES WITH RESPECT TO THE DESIRED LIMITS ON PERRY DAM, ZONE B SHELL MATERIALS. 


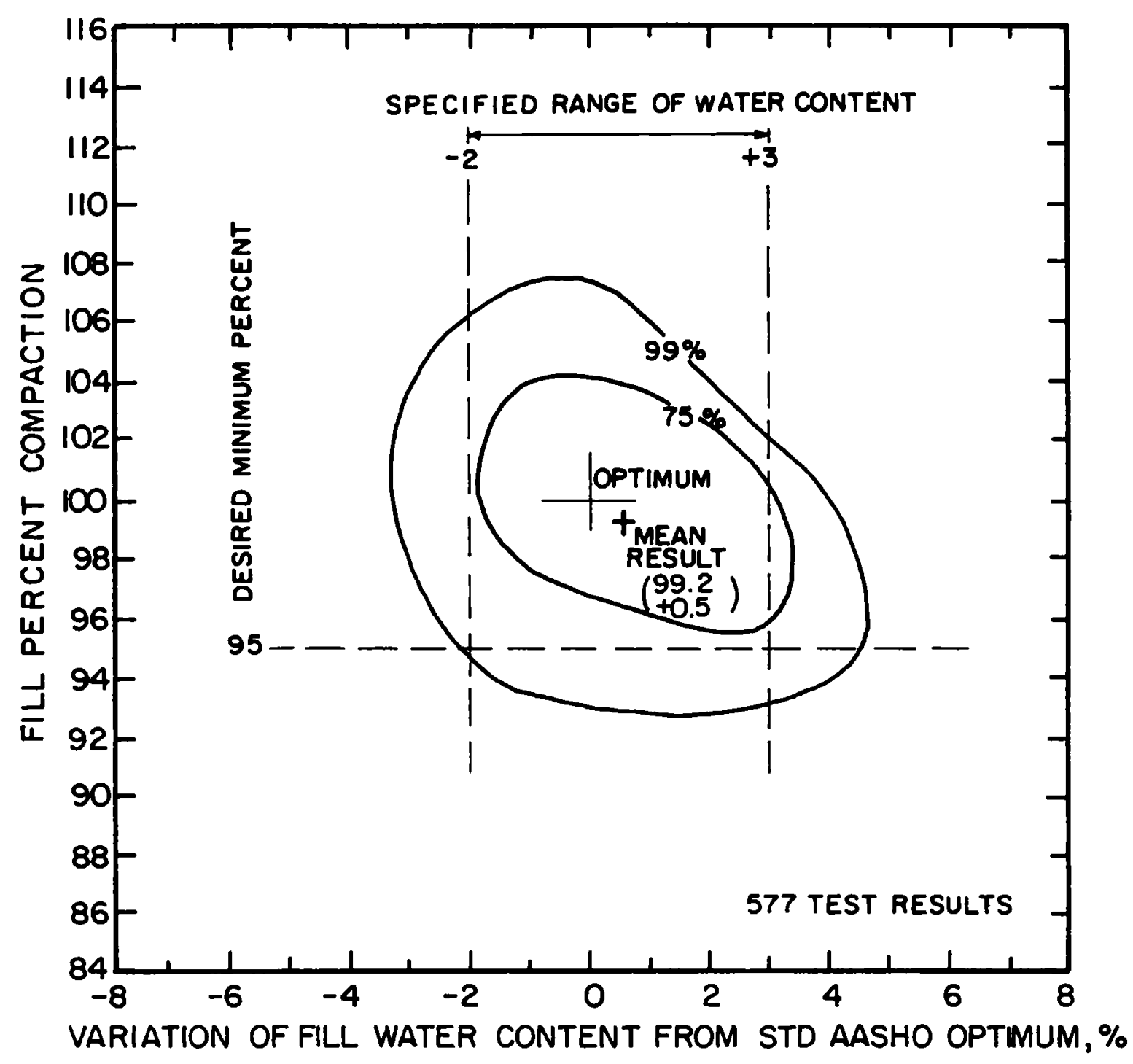

FIG. 19 VARIATION OF TEST VALUES ON FIELD COMPACTED SAMPLES WITH RESPECT TO THE DESIRED LIMITS ON PERRY DAM, IMPERVIOUS ZONE. 

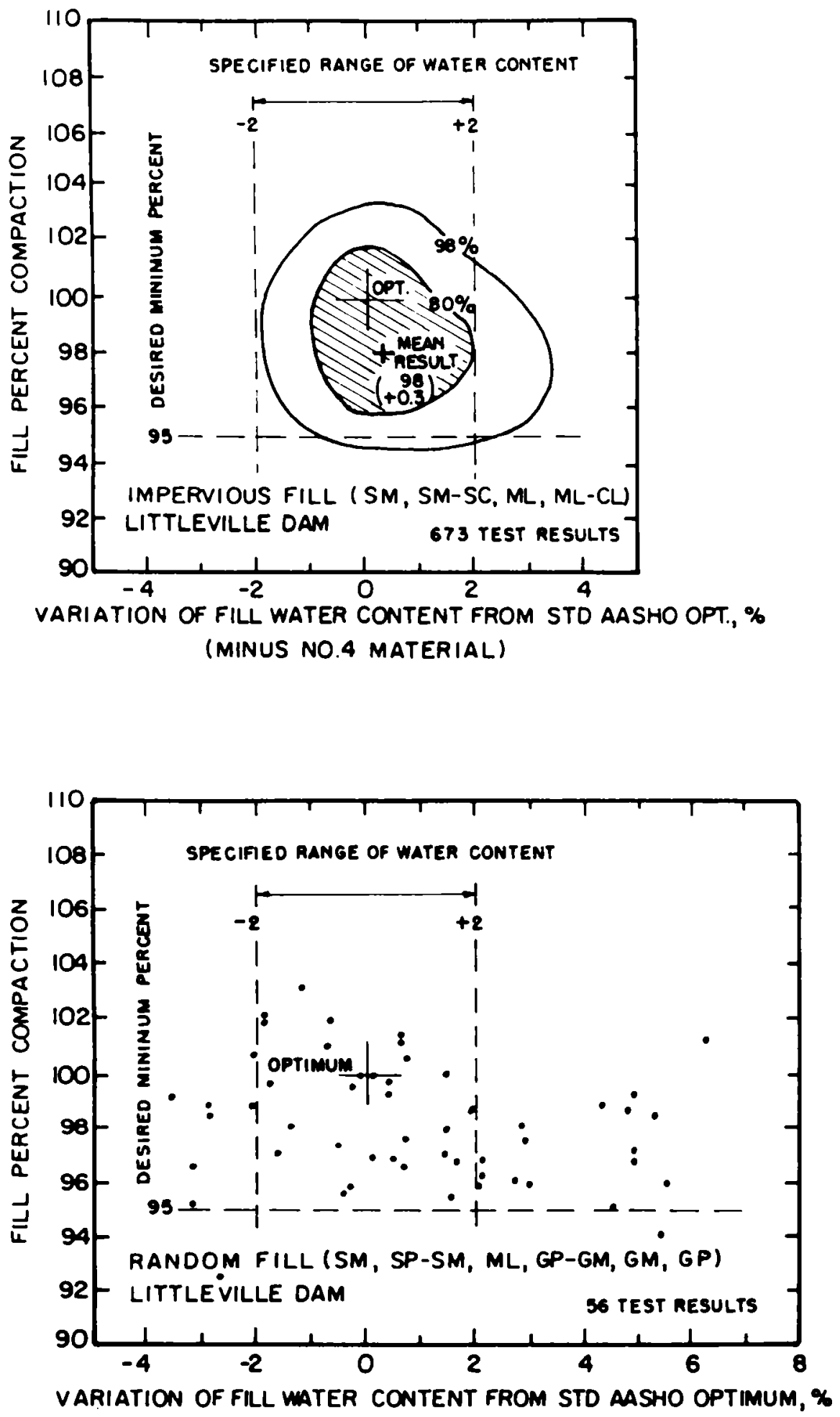

(MINUS NO. 4 MATERIAL)

FIG. 2O VARIATION OF TEST VALUES ON FIELD COMPACTED SAMPLES WITH RESPECT TO THE DESIREO LIMITS ON UTTLEVILE DAM FOR THE IMPERVIOUS FILL AND THE RANDOM FILL. 
Data, by V. H. Torrey, III, U. S. Army WES (1970). As shown in these figures, when the minimum degree of compaction was specified as $95 \%$, the average degree of compaction was about $99 \%$. On this basis it was assumed that the average densities of both the core and shell zones of Birch Dam will correspond to 998 of the Standard AASHO maximum dry density.

The data shown in Figs. 17 through 20 are also useful for estimating the average compaction water contents for the embankment soils. The data for both Perry Dam and Littleville Dam indicate that the average water contents of the fill was close to the center of the allowable range of water contents. Based on the data in these figures, it was estimated that the average water content of the Birch Dam shell would probably be about $0.5 \%$ wet of optimum, and the average water content of the core would probably be about $1.2 \%$ wet of optimum.

Undrained Properties of Embankment Soils. Unconsolidated-undrained triaxial tests were performed on specimens of the shell and core materials which were compacted to three different water contents. The values of the hyperbolic parameters derived from these tests are shown in Figs. 21 and 22. The conditions in these tests differ in two important ways from the conditions expected in the dam:

(1) The specimens were compacted to $95 \%$ relative compaction whereas the average relative compaction in the dam was estimated to be about $99 \%$.

(2) The liquid limits and plasticity indices of the specimens tested do not correspond to the average values expected for the material in the dam.

The sandy silt, for which results are shown in Fig. 21 , had a liquid limit of 19, and a plasticity index of 2 . Judging by the distributions shown in Figs. 6, 7, and 8, it is estimated that the shell material in the dam will have an average liquid limit of 25 and an average plasticity index of 10 . The clay, for which results are shown in Fig. 22, had a liquid limit of 29 and a plasticity index of 15 . On the basis of the 


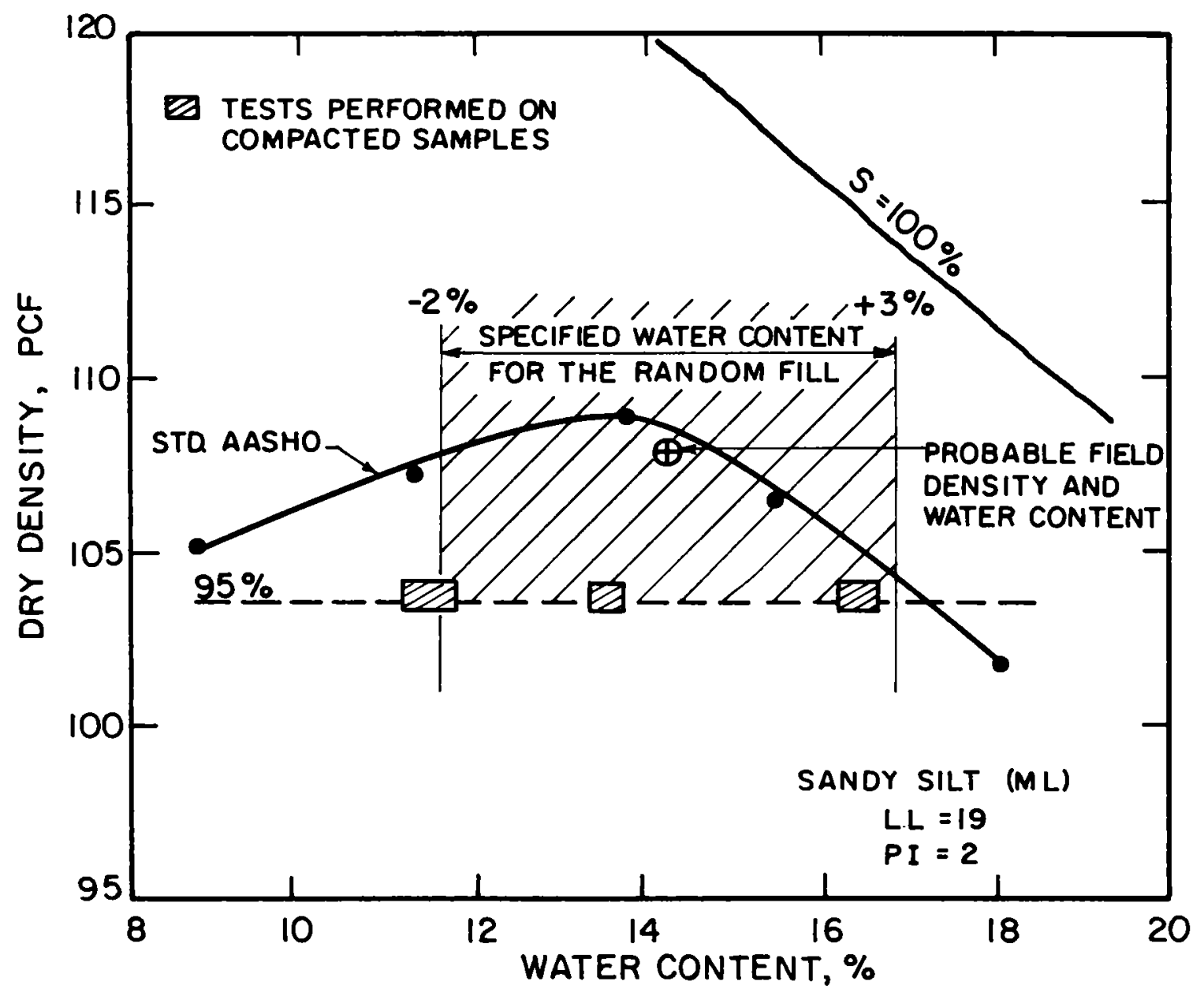

\begin{tabular}{|c|c|c|c|}
\hline $\begin{array}{c}\text { UNCONSOLIDATED } \\
\text { UNDRAINED } \\
\text { PARAMETERS } \\
\end{array}$ & $w_{\text {opt }}-2 \%$ & $w_{\text {opt }}$ & $\left.\right|_{\text {opt }}+3 \%$ \\
\hline$\phi$ & $31.4^{\circ}$ & $30.9^{\circ}$ & $27^{\circ}$ \\
\hline C & 0.42 & 0.19 & 0.54 \\
\hline$K$ & 243 & 274 & 101 \\
\hline$n$ & 0.31 & 0.38 & 0.84 \\
\hline$R_{f}$ & 0.83 & 0.82 & 0.77 \\
\hline
\end{tabular}

FIG. 21 COMPACTION CURVE AND PROPERTIES OF THE SANDY SILT SAMPLE AS SHELL MATERIAL. 


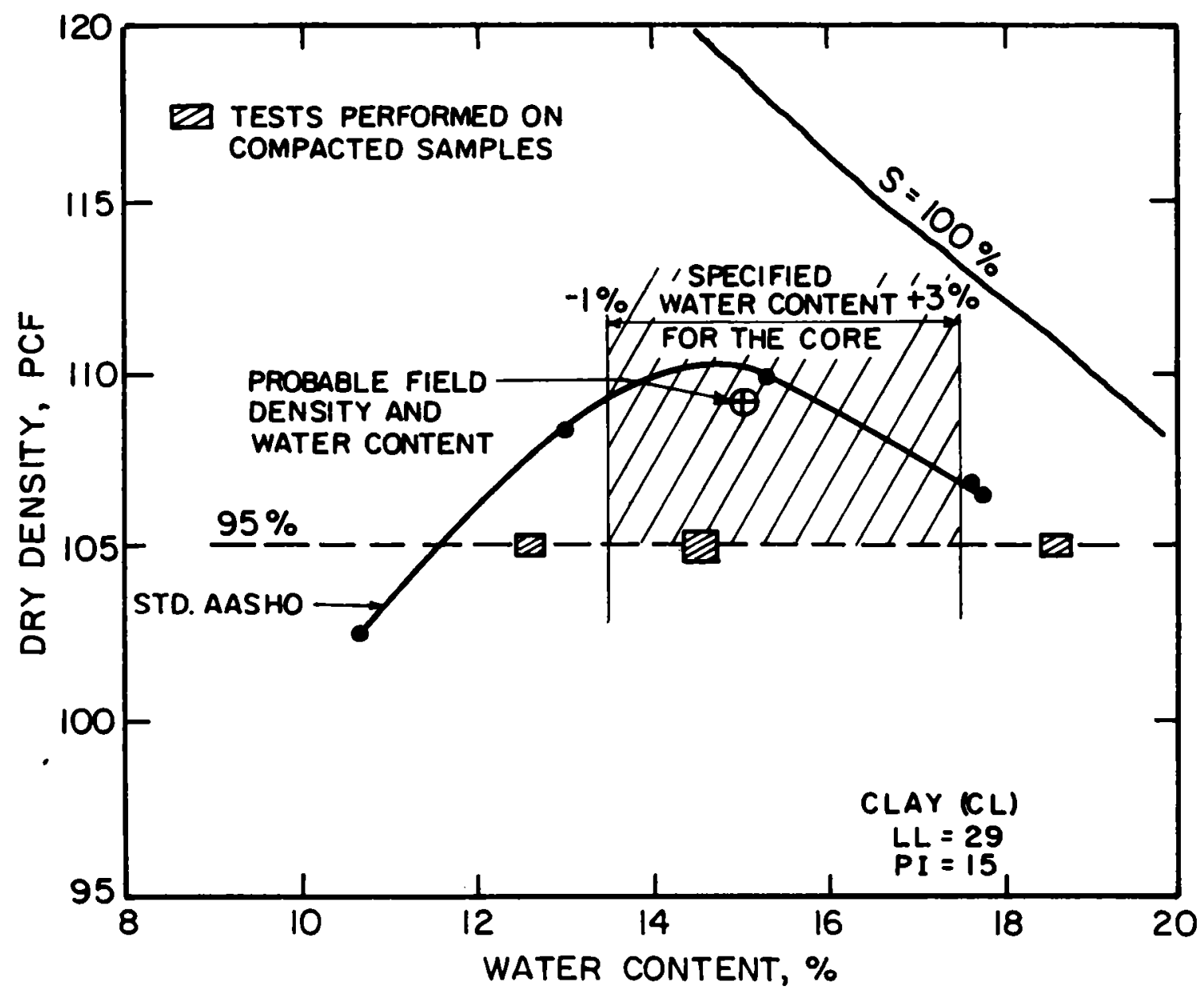

\begin{tabular}{|c|c|c|c|}
\hline $\begin{array}{l}\text { UNCONSOLIDATED } \\
\text { UNDRAINED } \\
\text { PARAMETERS }\end{array}$ & $w_{\text {opt }}-2 \%$ & $w_{\text {opt }}$ & $w_{o p t}+4 \%$ \\
\hline$\phi$ & $29^{\circ}$ & $25^{\circ}$ & $5^{\circ}$ \\
\hline C & 0.64 & 0.5 & 0.6 \\
\hline$K$ & 315 & 185 & 21 \\
\hline$n$ & -0.21 & 0.02 & 0.32 \\
\hline$R_{f}$ & 0.8 & 0.81 & 0.74 \\
\hline
\end{tabular}

FIG. 22 COMPACTION CURVE AND PROPERTIES OF THE CLAY SAMPLE AS CORE MATERIAL. 
data shown in Figs. 6,7 , and 8 , however, it is estimated that the core will have an average Iiquid limit of 35 and an average plasticity index of 20.

Thus, while the test results shown in Figs. 21 and 22 were useful for judging the behavior of the Birch Dam embankment soils, they could not be used directly in the finite element analyses. In selecting values of the hyperbolic parameters for the finite element analyses, the data for similar soils compiled by Wong and Duncan (1974) was used in conjunction with the data in Figs. 21 and 22. The data compiled by Wong and Duncan (1974) were also used to determine values of the Poisson's ratio parameters required for the analyses.

Drained Properties of Embankment Soils. The only test results available for the core and shell materials were for direct shear tests on samples of sandy silt and clay of the same composition as those on which the undrained triaxial tests were performed. The results of these tests are shown in Figs. 23 and 24. While these results were useful for guiding selection of the values of the hyperbolic parameters for use in the finite element analyses, it was necessary to make allowances for the expected differences in density and composition, as discussed previously for the undrained parameters. As for the undrained parameters, use was made of the data compiled by Wong and Duncan (1974) in selecting values of the parameters to represent the drained behavior of the core and shell.

Summary of Parameters for Finite Element Analyses. The values of the hyperbolic parameters used in the undrained (short-term) analyses are shown in Table 6, and those used in the drained (long-term) analyses are summarized in Table 7. The values of $k_{0}$ given in Table 6 are ratios of total horizontal to total vertical stress, whereas those in Table 7 are ratios of effective horizontal to effective vertical stress in the foundation, before the beginning of embankment construction. These two different definitions are required by the fact that the undrained analyses (Table 6) were performed using total stresses, whereas the drained analyses (Table 7) were performed using effective stresses. 


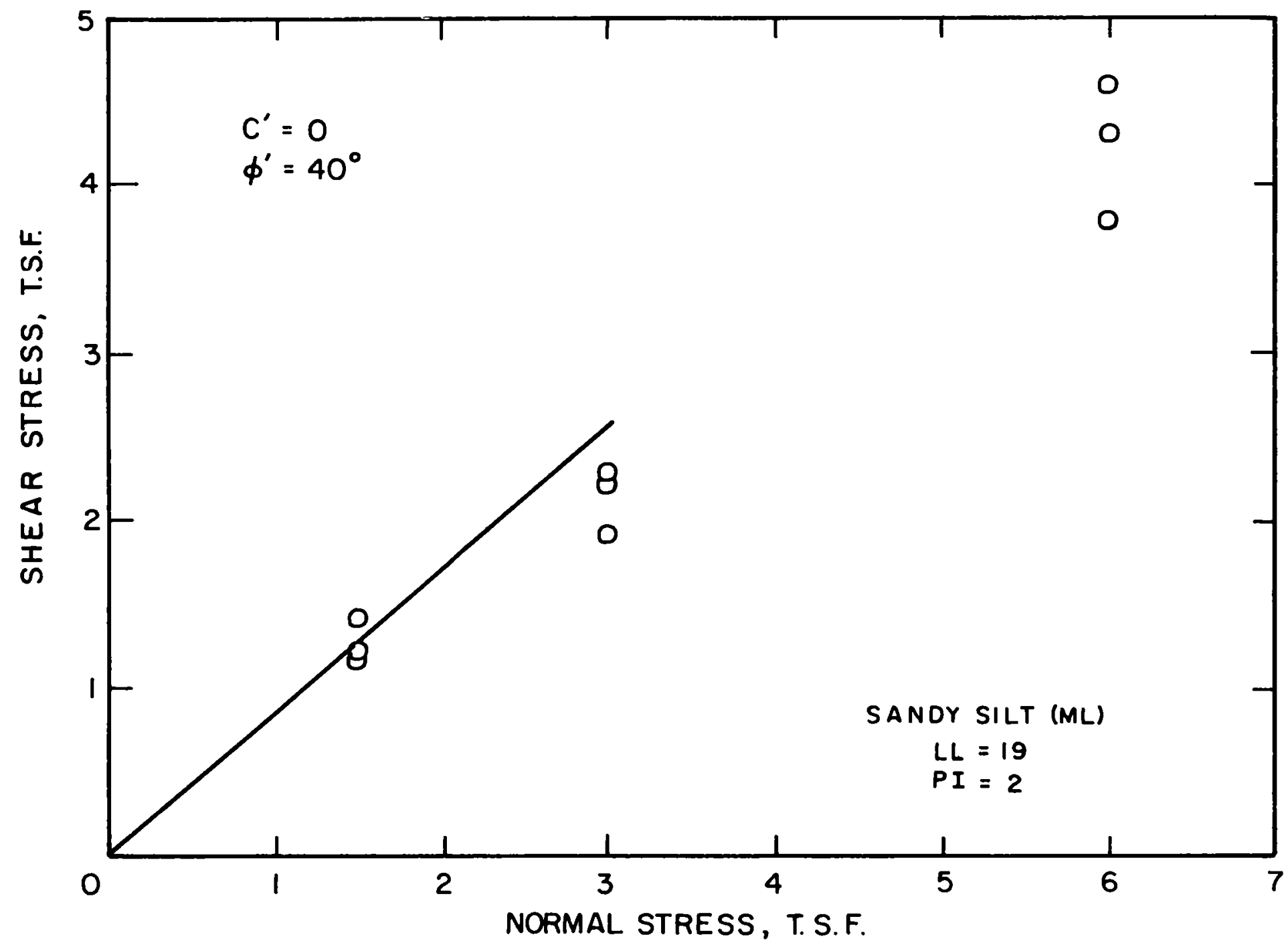

FIG. 23 DRAINED DIRECT SHEAR TEST.S. ON COMPACTED SANDY SILT. 


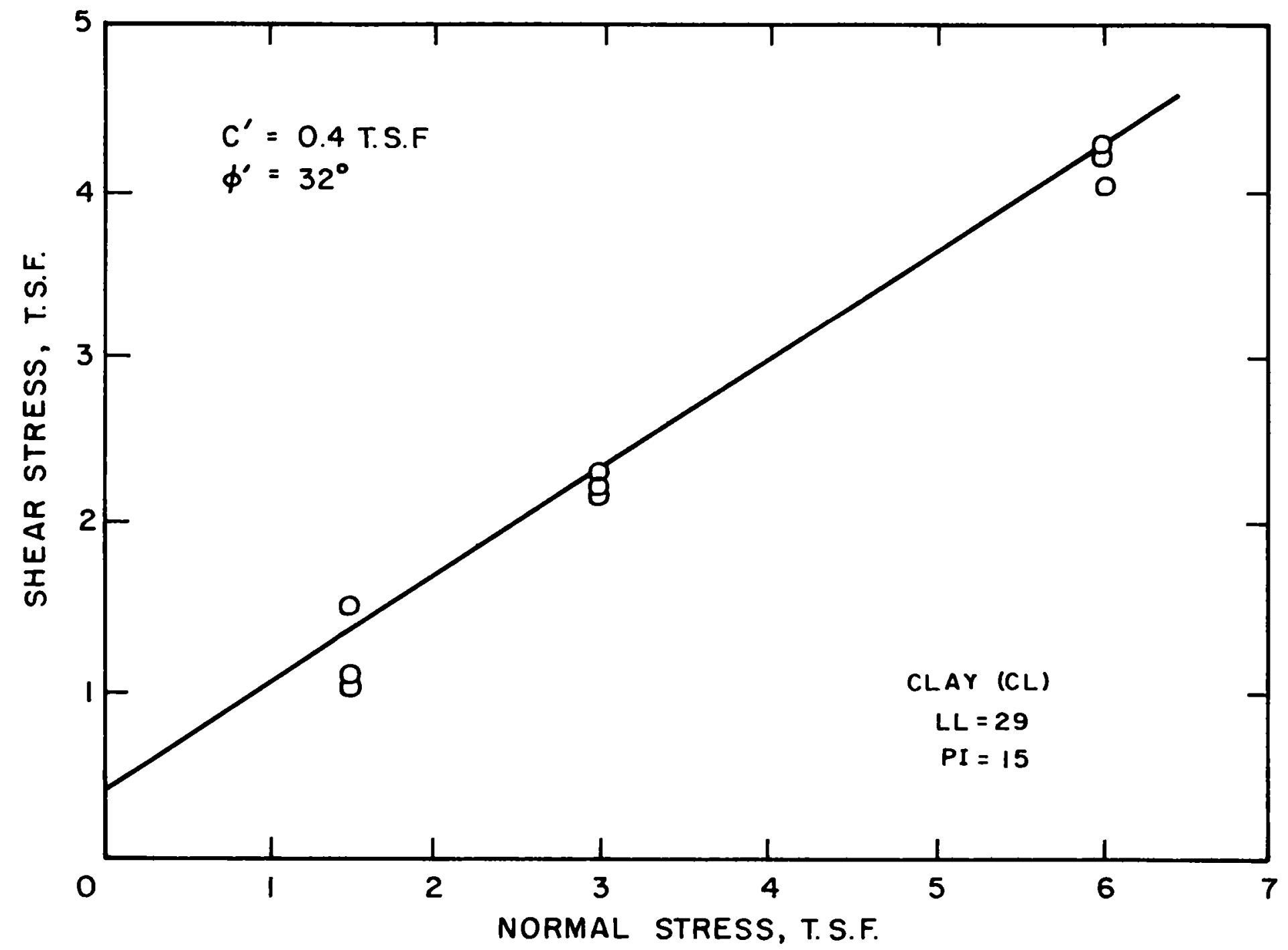

FIG. 24 DRAINED DIRECT SHEAR TESTS ON COMPACTED CLAY. 


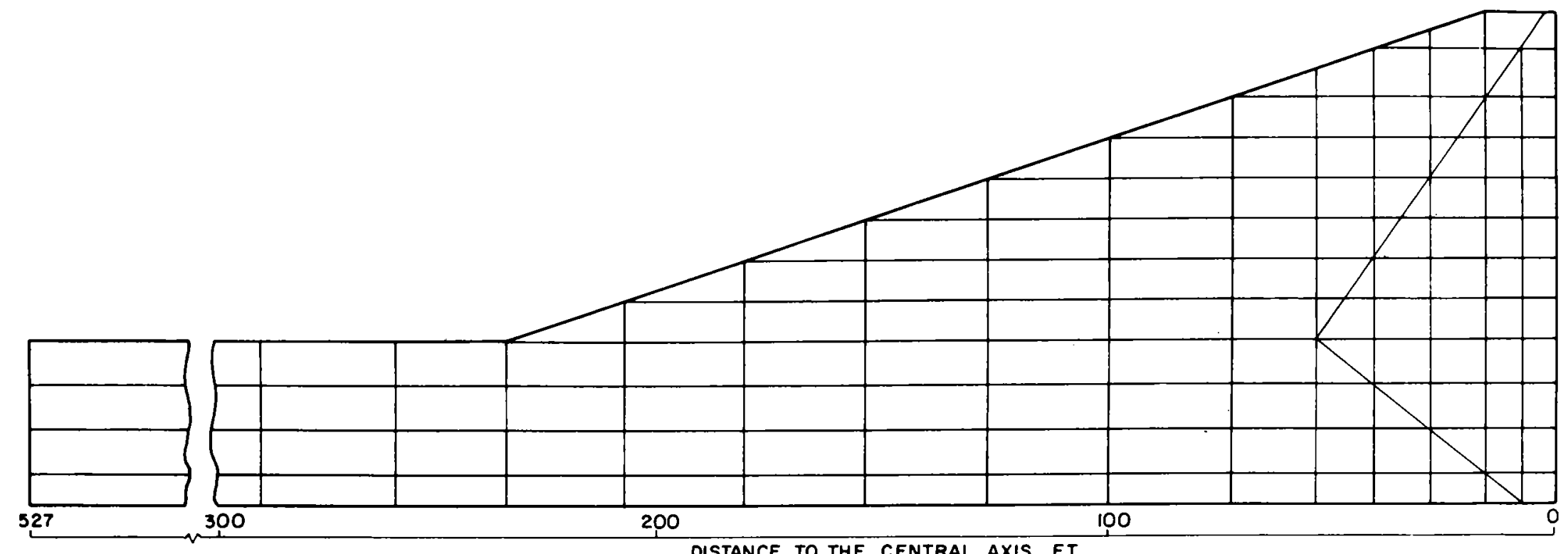

FIG. 25 FINITE ELEMENT MESH FOR BIRCH DAM, UPSTREAM PORTION. 
Table 6. Hyperbolic Parameters Used for Undrained Analyses of Birch Dam

\begin{tabular}{|c|c|c|c|c|c|c|c|c|c|c|c|c|}
\hline & $\begin{array}{l}\text { Mat'l. } \\
\text { No. }\end{array}$ & $\begin{array}{c}\text { Unit } \\
\text { Wt. } \\
\left(t / f t^{3}\right)\end{array}$ & $\mathrm{K}$ & $\mathrm{K}_{\text {ur }}$ & $\mathrm{n}$ & D & G & $\mathbf{F}$ & $\underset{\left(t / f t^{2}\right)}{C}$ & $\begin{array}{c}\phi \\
\text { (degrees) }\end{array}$ & $R_{f}$ & $K_{0}$ \\
\hline Core & 6 & 0.063 & 430 & 650 & 0.1 & 6.0 & 0.28 & 0.06 & 0.8 & 18.0 & 0.93 & 0.0 \\
\hline Shell & 5 & 0.0616 & 250 & 375 & 0.4 & 5.0 & 0.25 & 0.07 & 0.5 & 31.0 & 0.85 & 0.0 \\
\hline \multirow{4}{*}{ 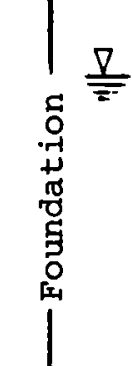 } & 4 & 0.064 & 170 & 250 & 0.85 & 0.0 & 0.49 & 0.0 & 0.95 & 7.5 & 0.9 & 1.0 \\
\hline & 3 & 0.063 & 125 & 150 & 0.3 & 0.0 & 0.49 & 0.0 & 0.5 & 3.0 & 0.9 & 1.0 \\
\hline & 2 & 0.063 & 87 & 100 & 0.0 & 0.0 & 0.49 & 0.0 & 0.35 & 0.0 & 0.9 & 1.0 \\
\hline & 1 & 0.064 & 200 & 250 & 0.0 & 0.0 & 0.49 & 0.0 & 0.8 & 0.0 & 0.9 & 1.0 \\
\hline
\end{tabular}


Table 7. Hyperbolic Parameters Used for Drained Analyses of Birch Dam

\begin{tabular}{|c|c|c|c|c|c|c|c|c|c|c|c|c|}
\hline & $\begin{array}{l}\text { Mat'l. } \\
\text { No. }\end{array}$ & $\begin{array}{c}\text { Unit } \\
\text { wt. } \\
\left(t / f t^{3}\right)\end{array}$ & $\mathrm{K}$ & $\mathrm{K}_{\mathrm{ur}}$ & $\mathrm{n}$ & D & G & $\mathrm{F}$ & $\stackrel{C}{\left(t / f t^{2}\right)}$ & $\begin{array}{c}\phi \\
\text { (degrees) }\end{array}$ & $\mathrm{R}_{\mathrm{f}}$ & $\mathrm{K}_{\mathrm{O}}$ \\
\hline Core & 6 & 0.063 & 200 & 400 & 0.65 & 4 & 0.35 & 0.1 & 0.4 & $32^{\circ}$ & 0.65 & -- \\
\hline Shell & 5 & 0.0616 & 400 & 800 & 0.5 & 5 & 0.4 & 0.13 & 0 & $40^{\circ}$ & 0.75 & -- \\
\hline \multirow{4}{*}{$\frac{\nabla}{\bar{T}}$} & 4 & 0.064 & 50 & 200 & 1.0 & 0 & 0.34 & 0 & 0.3 & $28^{\circ}$ & 0.8 & 1.5 \\
\hline & 3 & 0.031 & 50 & 200 & 1.0 & 0 & 0.34 & 0 & 0.3 & $28^{\circ}$ & 0.8 & 0.58 \\
\hline & 2 & 0.031 & 50 & 200 & 1.0 & 0 & 0.34 & 0 & 0.3 & $28^{\circ}$ & 0.8 & 0.51 \\
\hline & 1 & 0.032 & 500 & 1200 & 0.35 & 5 & 0.4 & 0.15 & 0 & $35^{\circ}$ & 0.7 & 0.4 \\
\hline
\end{tabular}


After the analyses had been completed, it was pointed out by one of the reviewers of the report that the values of total stress $\mathrm{k}_{\mathrm{o}}$ shown in Table 6 are not consistent with the values of effective stress $\mathrm{k}_{\circ}$ shown in Table 7. While these values should not be equal, they are related, and the use of total stress values of $k_{0}$ equal to unity is not consistent with the use of the effective stress values of $k_{0}$ shown in Table 7. However, because this inconsistency was noted after the analyses had been performed and the report had been prepared, it was decided not to redo the analyses. Use of total stress $k_{0}$ values consistent with the effective stress values would have resulted in slightly larger calculated displacements.

\section{ANALYSIS PROCEDURES}

The finite element analyses of stresses and movements in Birch Dam were performed following the procedures for incremental finite element analyses described by Kulhawy, et al. (1969), using the computer program ISBILD (Ozawa and Duncan, 1973). The finite element mesh shown in Fig. 25 was used for these analyses. The mesh, which contains 150 elements and 165 nodal points, represents the conditions in the maximum section of the dam, between stations $16+00$ and $22+00$, where the foundation is about $37 \mathrm{ft}$ deep and the embankment is $73 \mathrm{ft}$ high. The half-section mesh shown in Fig. 25 was used for analysis of stresses and movements during construction, while a mesh representing the full section was used for analysis of movements due to reservoir filling. The full section mesh consisted of the mesh shown in Fig. 25 and its mirror image, and contained twice as many elements.

The analysis procedures described by Kulhawy, et al. (1969) are applicable to conditions where there is either no drainage or complete drainage. For Birch Dam neither of these idealized conditions is fully representative of the actual conditions. Construction of Stage $I$ is expected to proceed rapidly as shown in Fig. 26, and there will be little consolidation of the foundation during this stage. During the interval between Stages I and II, however, a considerable amount of consolidation will take place, which will result in additional movements and increase 


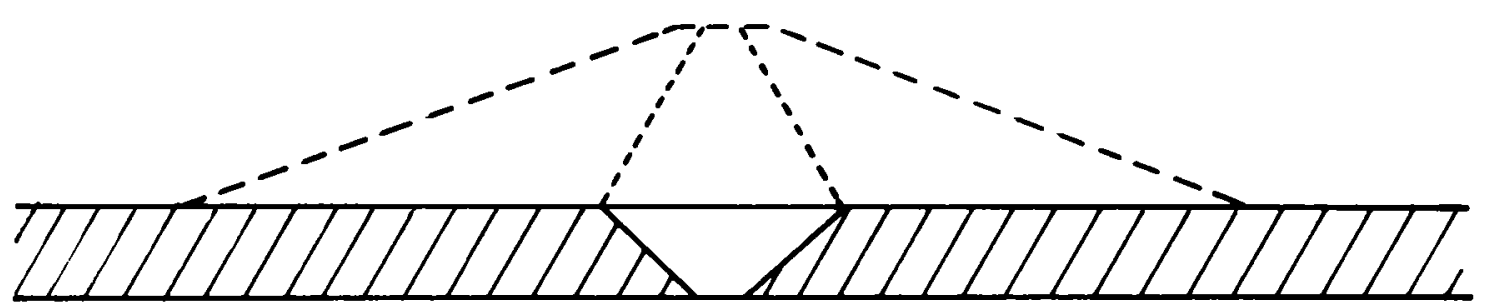

BEGINNING OF FILL PLACEMENT

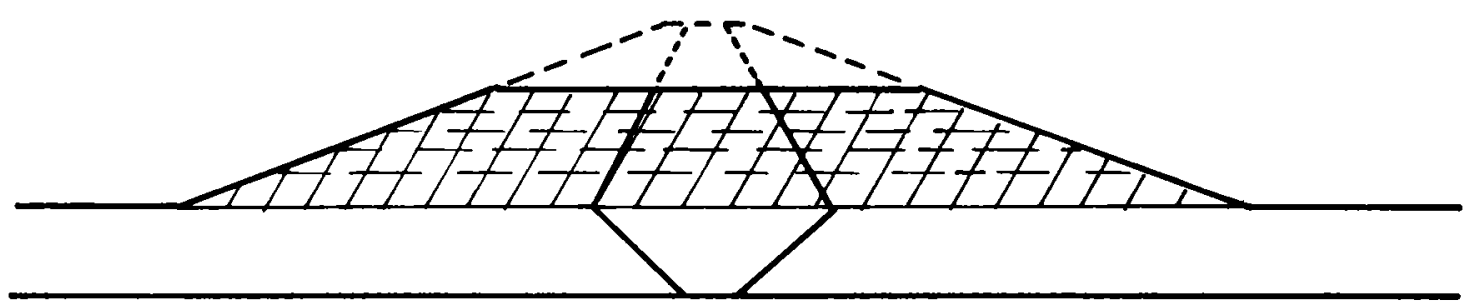

END OF FIRST STAGE

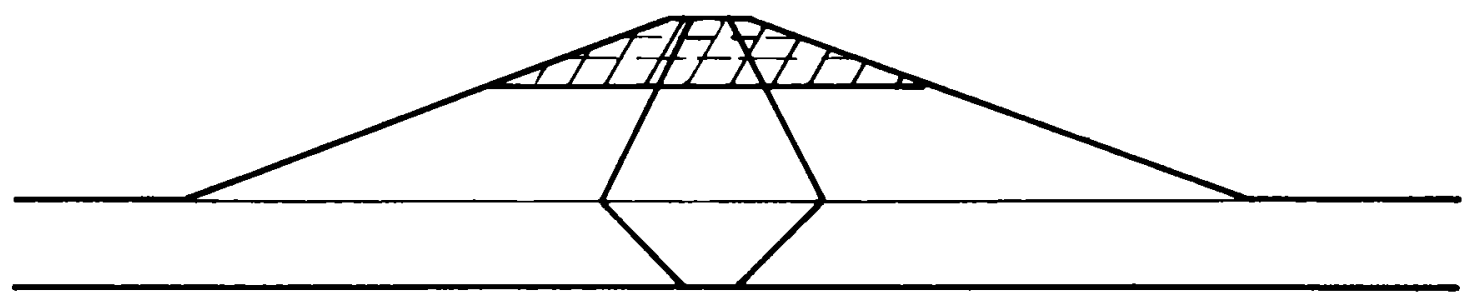

END OF SECOND STAGE

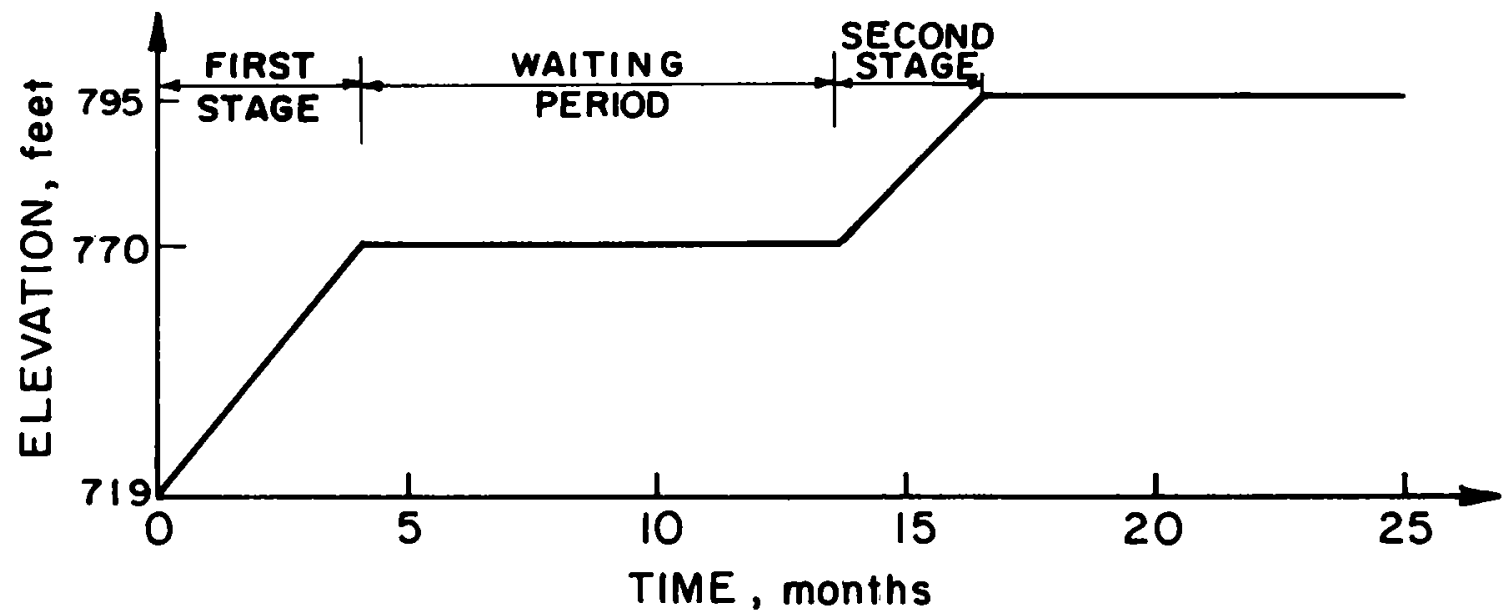

FIG. 26 CONSTRUCTION SEQUENCE FOR BIRCH DAM. 
in the effective stresses in the dam and the foundation as the foundation consolidates. Therefore it was necessary to develop a procedure for accounting for these effects of consolidation.

Detailed analyses of the movements and stress changes due to consolidation of the embankment and its foundation would have required development of new finite element computer programs, a task considerably beyond the scope of the present study. Instead of undertaking the extensive new developments required for a full treatment of the problem, a simplified approximate analysis of the problem was performed, using conventional consolidation theory to supplement finite element analyses performed assuming completely undrained and completely drained conditions. These analyses were performed as follows:

(1) Beginning from the initial stress conditions in the foundation, construction of the entire embankment was analyzed in 8 steps, using undrained soil properties, and assuming completely undrained conditions. Five steps were used up to the end of Stage I, and three more to the end of Stage II. Excavation and backfilling of the core trench was not simulated. The analyses began from the condition where the core trench had been backfilled to the original ground level.

(2) Beginning from the same initial conditions, construction of the entire embankment was again analyzed in 8 steps using the same procedures as for the undrained analysis, using drained soil properties, and assuming completely drained conditions.

(3) The displacements calculated in these two analyses were used to estimate the displacements resulting from construction with partial dissipation of excess pore pressures. The nodal point displacements were calculated using the equation

$$
\delta=\alpha \delta_{\mathrm{d}}+\beta^{2} \delta_{\mathrm{U}}
$$

in which 
$\delta=$ an increment of relative displacement between adjacent nodal points at a given time, due to the placement of a given layer of fill on the embankment;

$\delta_{D}=$ the increment of relative displacement for the same nodal points due to placement of the same layer of fill, calculated using drained soil properties;

$\delta_{U}=$ increment of relative displacement for the same nodal points and layer of fill, calculated using undrained soil properties; and

$\alpha$ and $\beta=$ dimensionless coefficients whose values depend on the position of the nodal points, the value of $\mathrm{c}_{\mathrm{v}}$ of the foundation, and the length of time after placement of the layer of fill. The values of $\alpha$ and $\beta$ were calculated using conventional consolidation theory, as explained in the Appendix.

Although this simplified procedure is not rigorous, and necessarily employs some simplifying assumptions as outlined in the Appendix, it provides reasonable results and is considered to provide sufficient accuracy for the Birch Dam analysis, considering the complexity of the soil conditions and the difficulties involved in determining representative values of all the parameters required for the analyses.

\section{RESULTS CALCULATED ASSUMING NO CONSOLIDATION}

The stresses in the embankment and foundation at the end of Stage $I_{r}$ calculated using undrained soil properties, are shown in Figs. 27 through 30. The values of $\sigma_{1}$ shown in Fig. 27 are very nearly equal to the overburden pressure throughout the embankment and the foundation. The values of $\sigma_{3}$ shown in Fig. 28 are discontinuous between the embankment and the foundation, and the values in the embankment are considerably smaller than those in the foundation, owing to the fact that the values of Poisson's ratio are smaller in the embankment. The values of $\tau_{\max }$ which are shown in Fig. 30 are controlled to a large extent by the shear strength, and are thus quite small within the lower part of the foundation, where the undrained strength is lowest. 


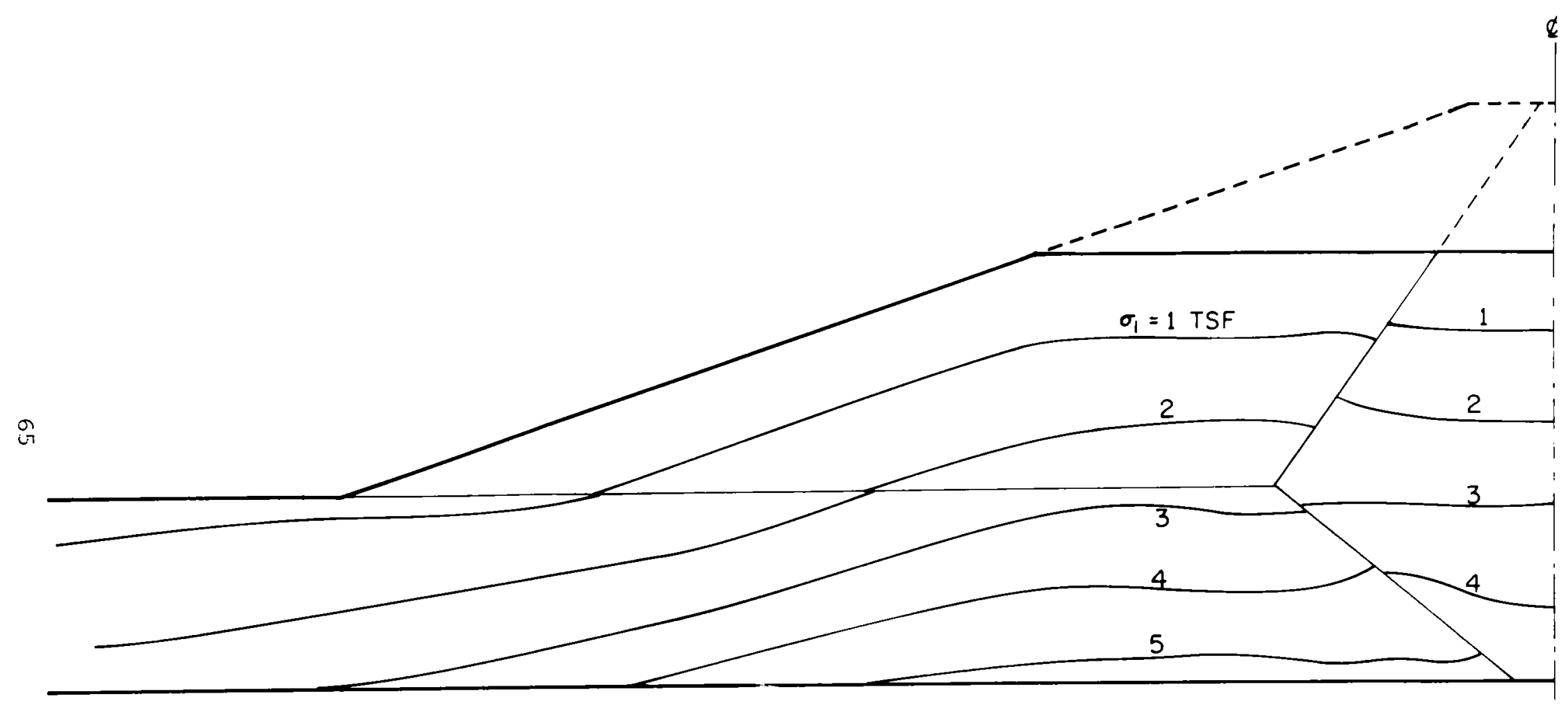

FIG. 27 CONTOURS OF $\sigma_{1}$ FOR UU STAGE 1 


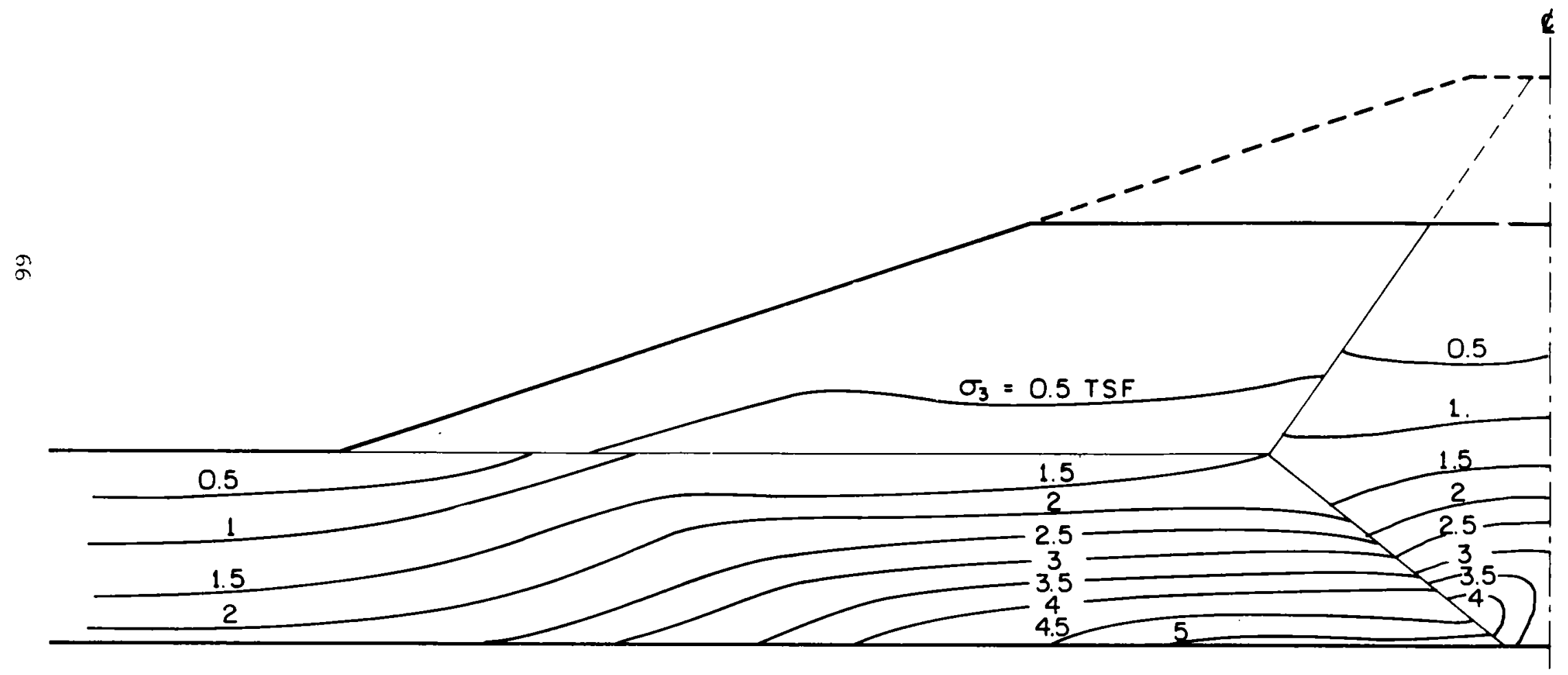

FIG. 28 CONTOURS OF $\sigma_{3}$ FOR UU STAGE 1 . 


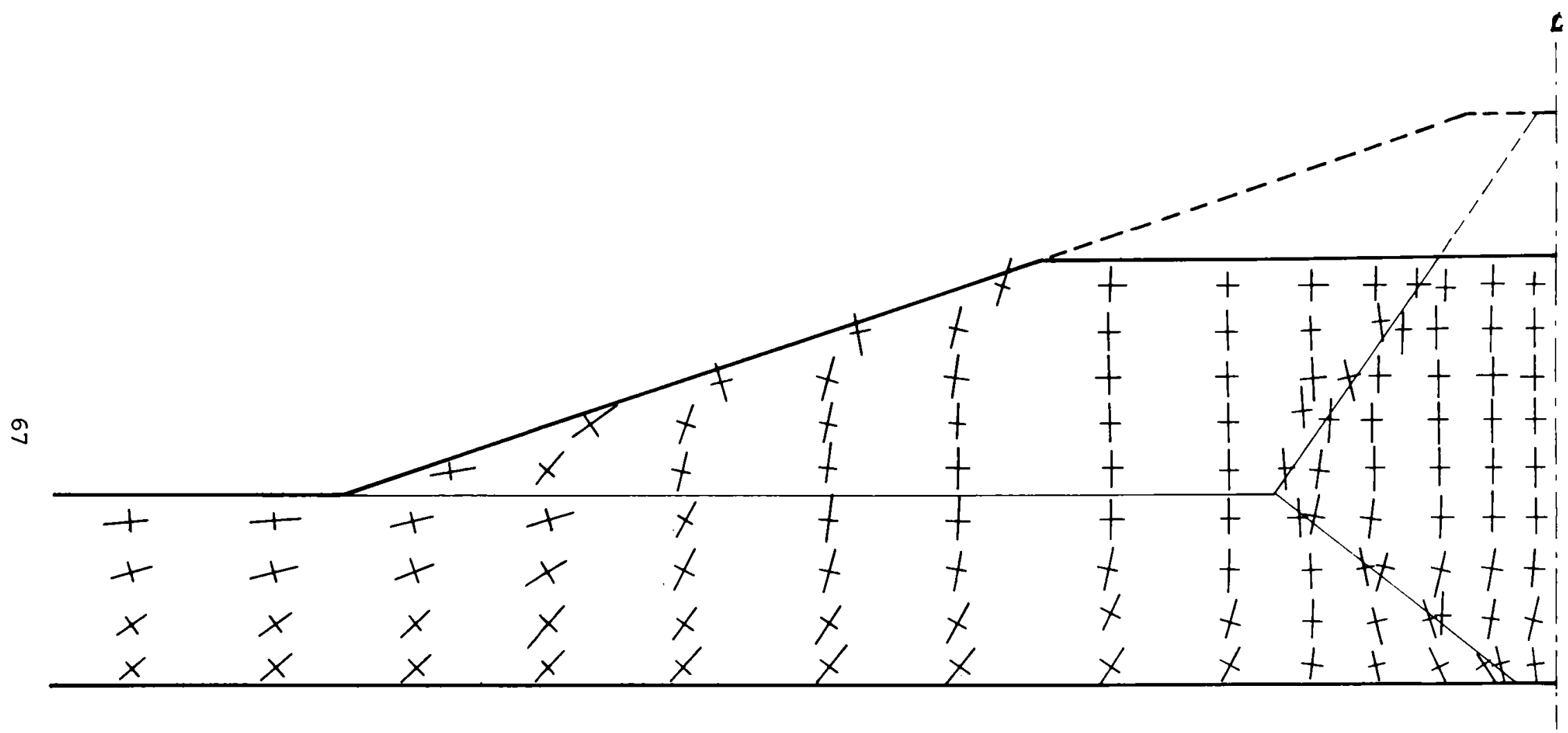

FIG. 29 DIRECTIONS OF PRINCIPAL STRESSES FOR UU STAGE 1. 


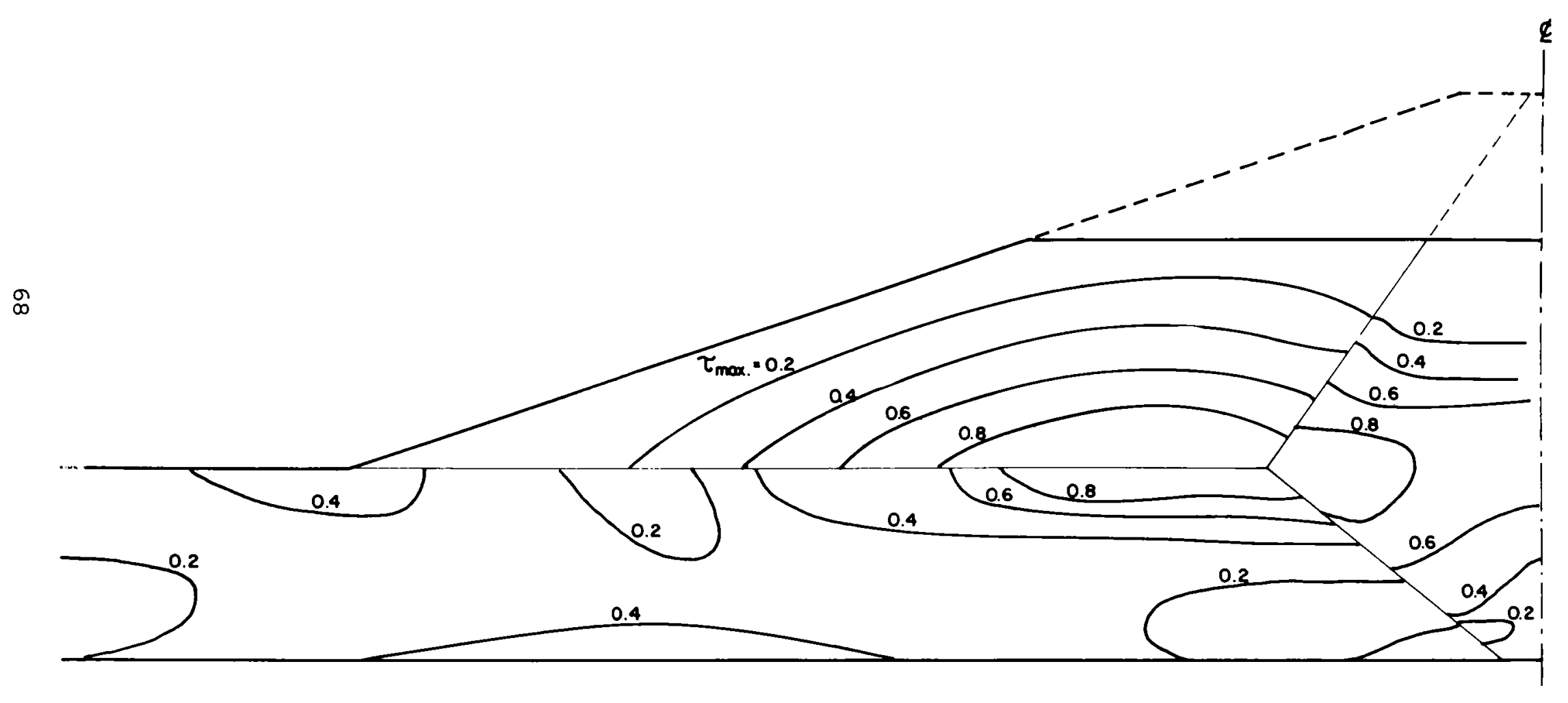

FIG. 30 CONTOURS OF $\tau_{\max .}$ FOR UU STAGE 1. 
One of the most convenient measures of the severity of the stress conditions within the dam is provided by the contours of percentage of strength mobilized, which are shown in Fig. 31. Throughout most of the embankment less than $60 \%$ of the undrained shear strength is mobilized according to the calculations, but within the lower part of the foundation there is a zone within which the percentage of strength mobilized approaches 90\%. As shown in Fig. 32, the location of this zone agrees well with the location of the critical circle determined by the ordinary Method of slices, which has a calculated factor of safety of 1.52 . Bishop's Modified Method gave a minimum factor of safety of 1.60 for this condition.

Contours of percentage of strength mobilized calculated for the end of stage II using undrained strength parameters are shown in Fig. 33. For this condition the percentages of strength mobilized are considerably higher, and within a sizable zone in the lower part of the foundation they have reached 100\%. As shown in Fig. 34, the location of this zone also agrees well with the location of the critical circle, determined by the Ordinary Method of Slices, which for this condition has a calculated factor of safety equal to 1.25. Bishop's Modified Method gave a minimum factor of safety of 1.31 for this condition.

The displacements for Stages I and II calculated using undrained soil properties are shown in Fig. 35. The maximum calculated displacements are about $0.7 \mathrm{ft}$ for Stage $I$, and an additional $0.7 \mathrm{ft}$ for Stage II. Thus, although Stage I involves placing $45 \mathrm{ft}$ of fill and Stage II only $28 \mathrm{ft}$, the displacements are nearly the same because under the stage II loading the foundation is stressed closer to failure and is therefore more easily deformable than under the stage I loading. It may also be noted that the displacements due to the Stage II loading are more nearly horizontal under the central portion of the embankment and are suggestive of slip movements along approximately circular surfaces. 


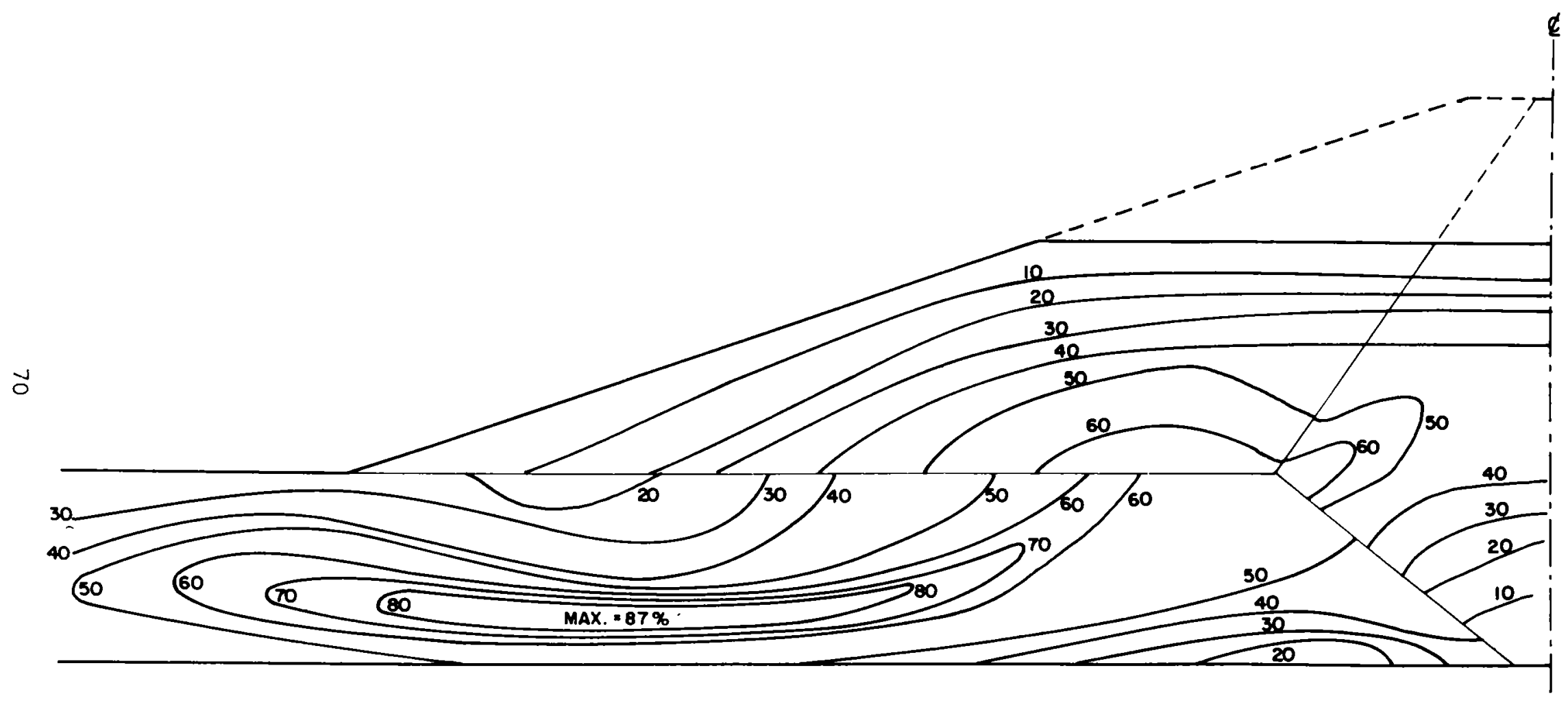

FIG. 31 STRENGTH MOBILIZED FOR UU STAGE 1. 


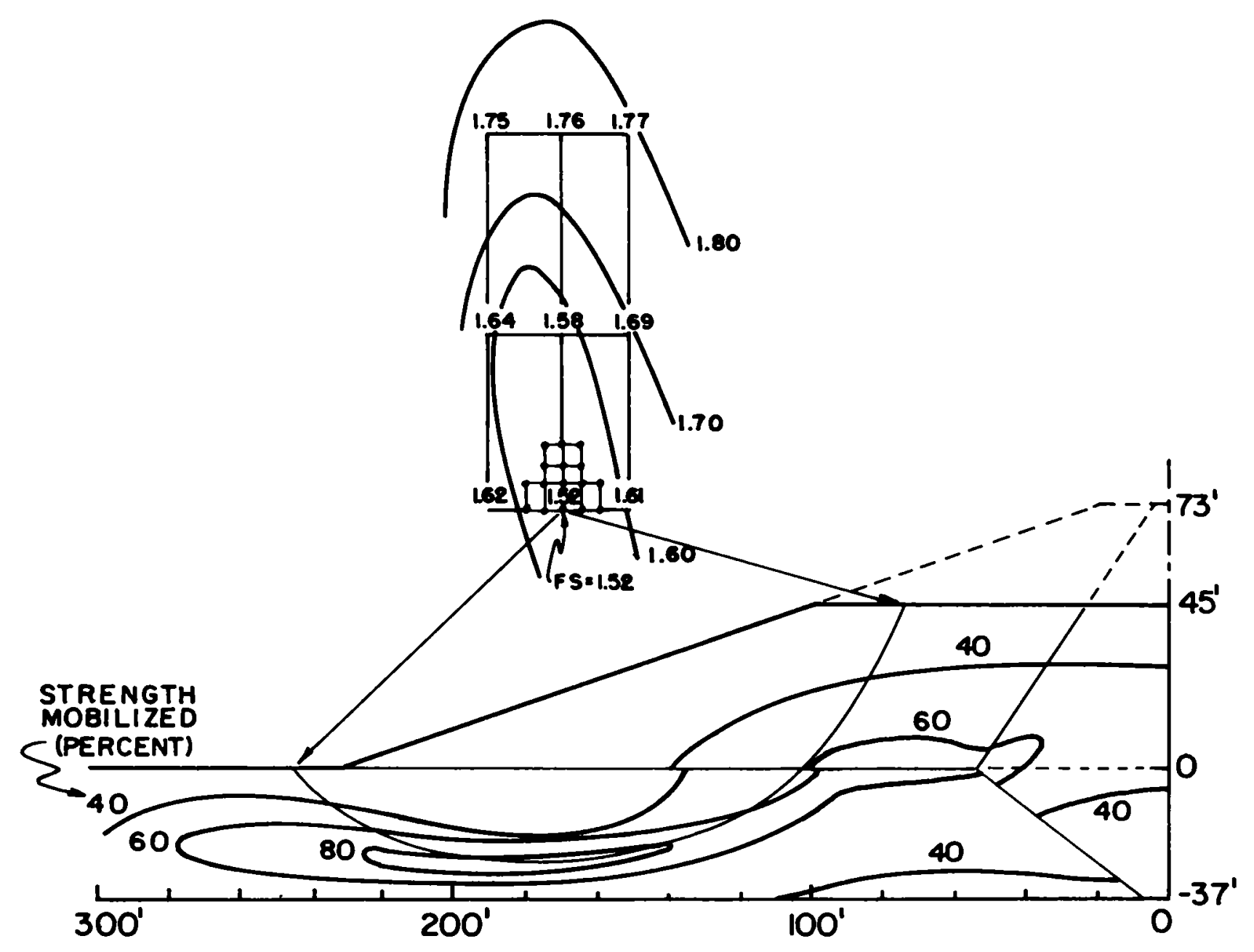

FIG. 32 CRITICAL CIRCLE FOR UU STAGE I. 


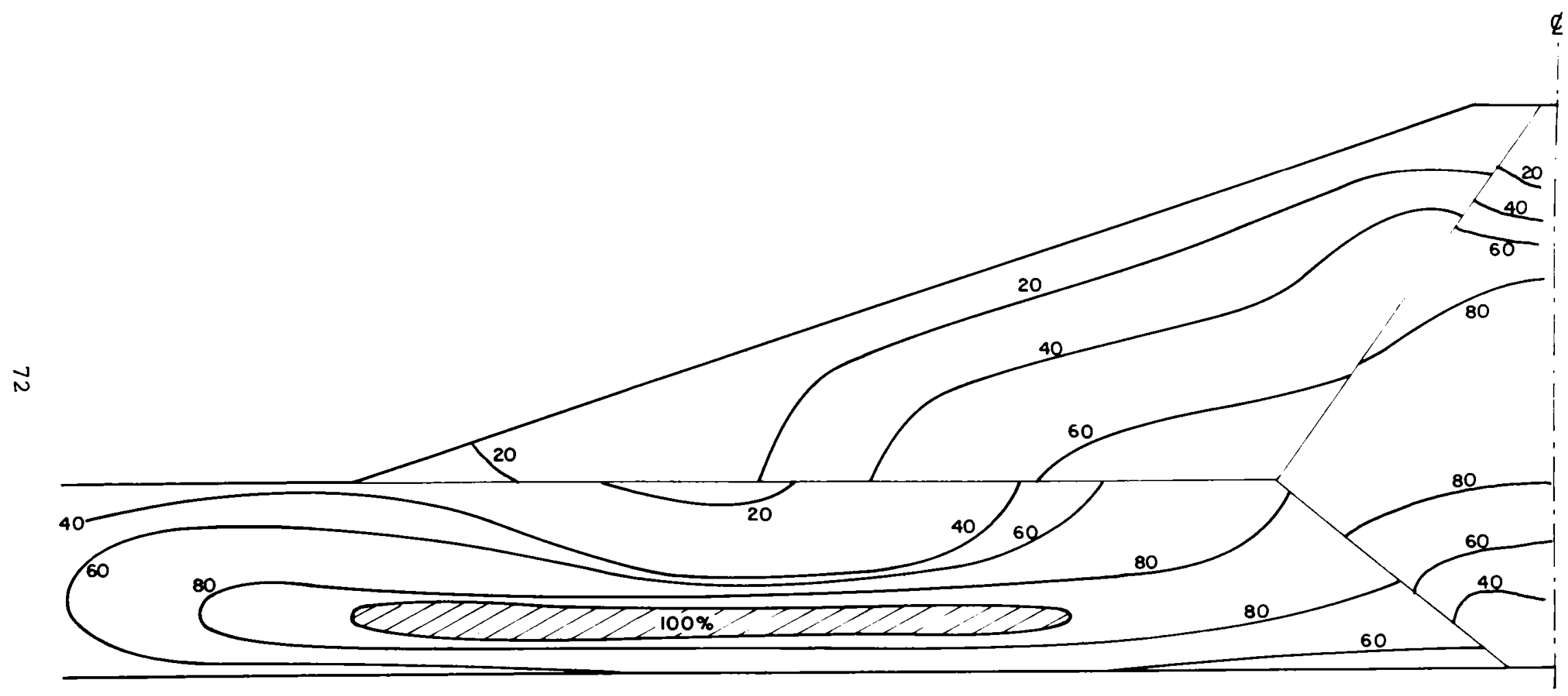

FIG. 33 STRENGTH MOBILIZED FOR UU STAGE 2. 


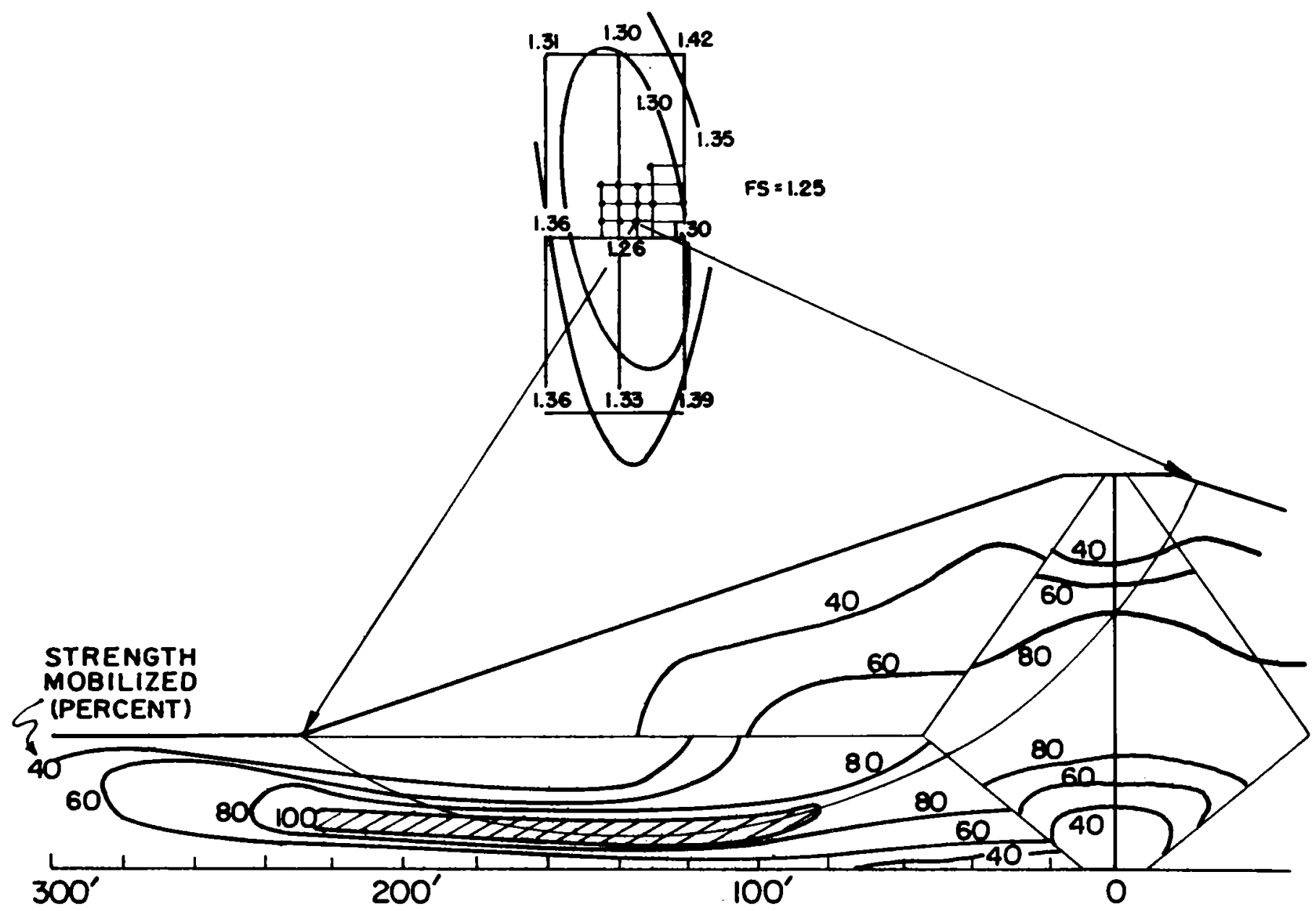

FIG. 34 CRITICAL CIRCLE FOR UU STAGE 2. 


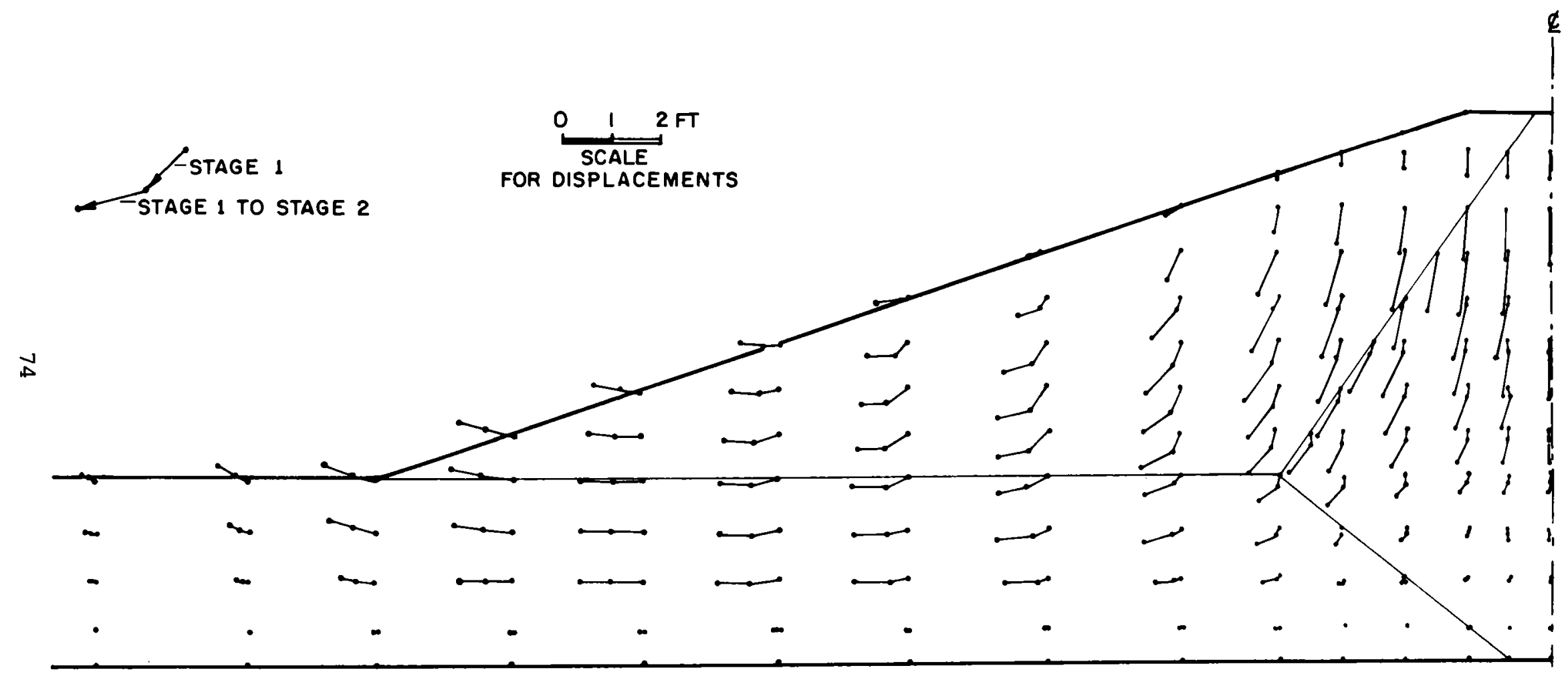

FIG. 35 DISPLACEMENTS FOR UU STAGES 1 AND 2. 
The stresses in the embankment and the foundation at the end of Stage II, calculated using drained properties, are shown in Figs. 36 through 39. It may be noted that the discontinuities of stresses between the embankment and the foundation are considerably smaller than for the undrained conditions at the end of Stage I which were discussed above. This is due to the fact that differences between the drained properties of the embankment and foundation are less than the differences between their undrained properties.

Contours of strength mobilized for drained conditions at the end of Stage II are shown in Fig. 40. The most severely stressed zones are near the toe of the slope and within the lower part of the foundation. The critical circle, shown in Fig. 41, may be seen to pass through the highly stressed zone in the lower part of the foundation. The calculated factor of safety for this circle is 2.33 .

The displacements calculated assuming fully drained conditions throughout construction are shown in Fig. 42. Beneath the central part of the dam the displacements due to the Stage I portion of the embankment are directed primarily downward, and the largest settlements are about $1.2 \mathrm{ft}$. In these drained analyses, the foundation becomes stiffer at higher pressures, and the settlements due to the stage II portion of the embankment are considerably smaller. The horizontal components of the stage II displacements are larger than those due to stage I, however, because the stage II loading is concentrated in the central portion of the embankment and thus causes greater outward displacements.

Horizontal displacements due to reservoir filling, calculated using drained soil properties, are shown in Fig. 43. These movements were calculated by applying the seepage forces corresponding to steady seepage to the nodal points in the core, assuming that no head loss takes place in the shell zones. These displacements, entirely in the downstream direction, were less than $0.3 \mathrm{ft}$ throughout the dam. The calculated vertical movements during reservoir filling were also small, less than $0.15 \mathrm{ft}$ throughout the embankment. 


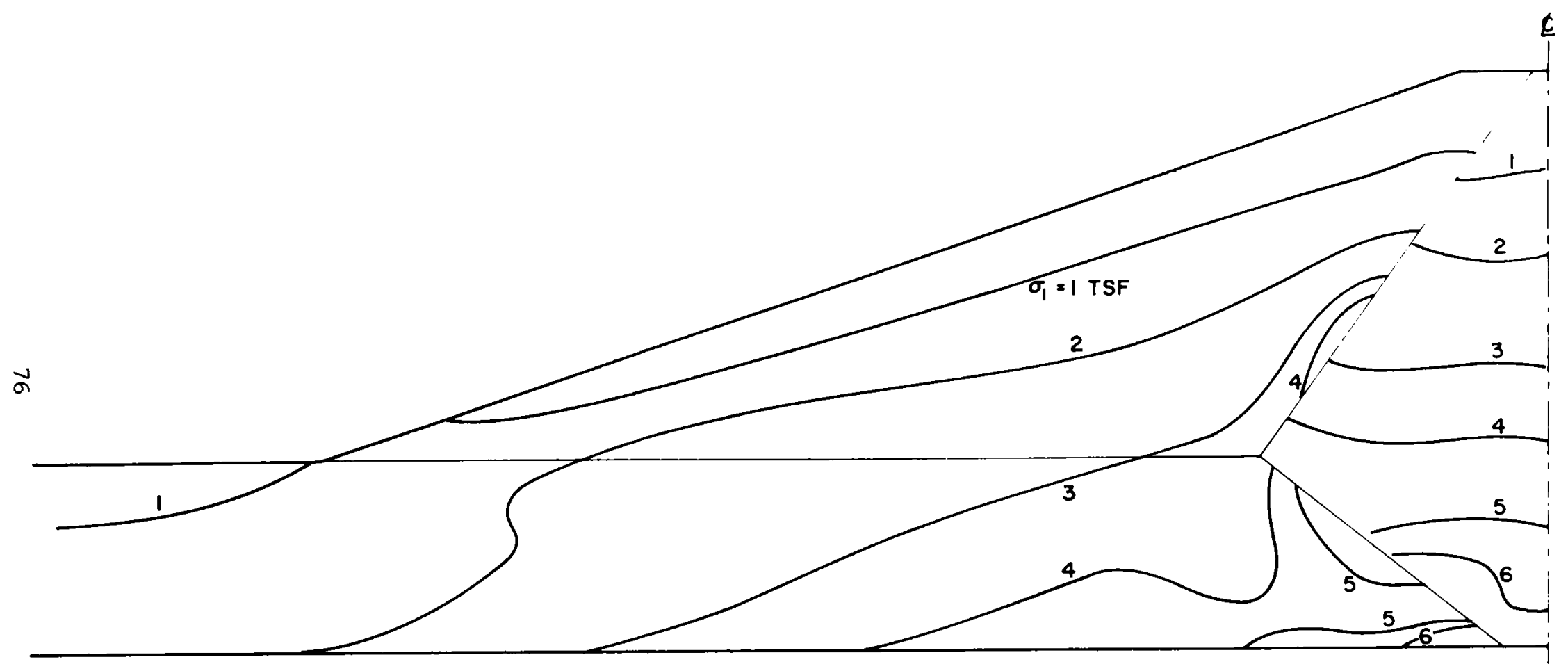

FIG. 36 CONTOURS OF $\sigma_{1}$ FOR CD STAGE 2 


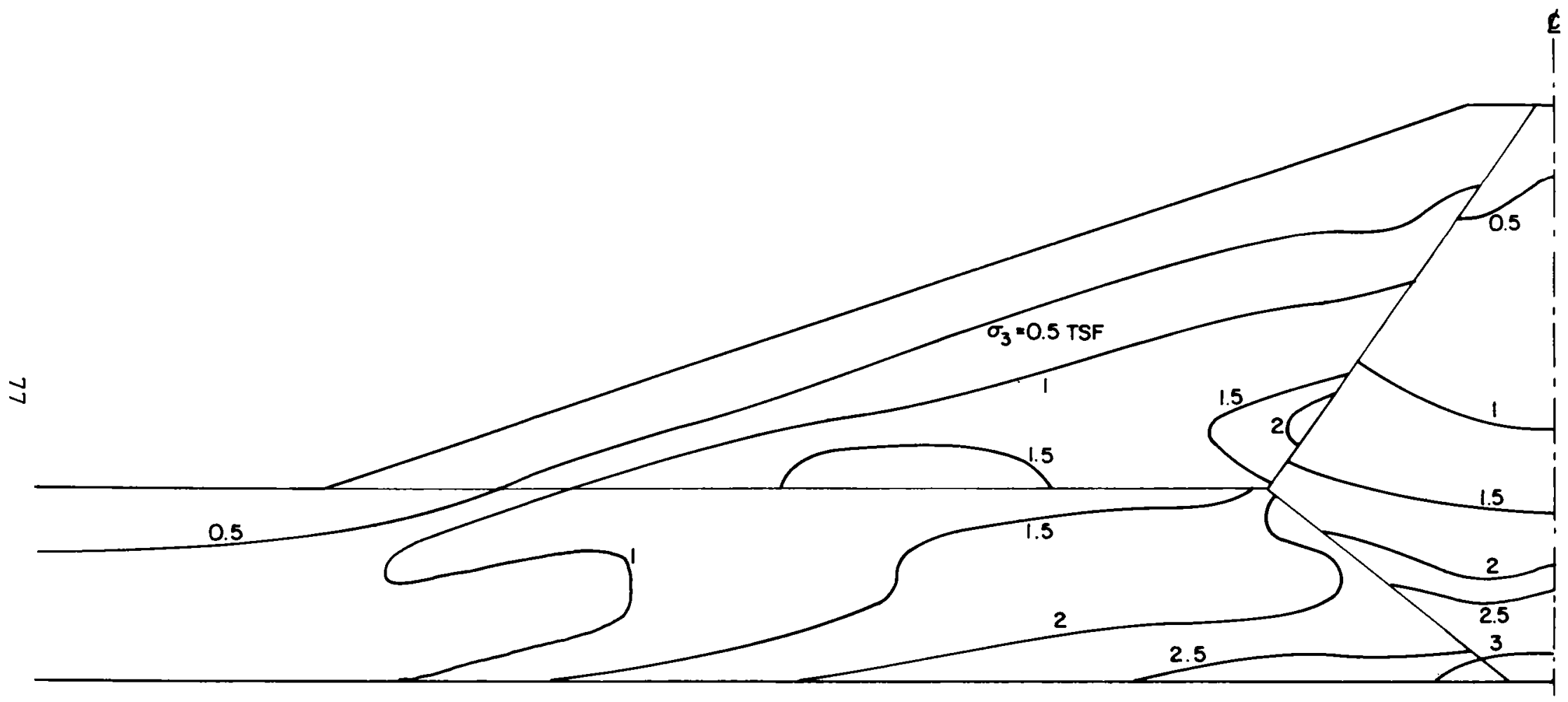

FIG. 37 CONTOURS OF $\sigma_{3}$ FOR CD STAGE 2 


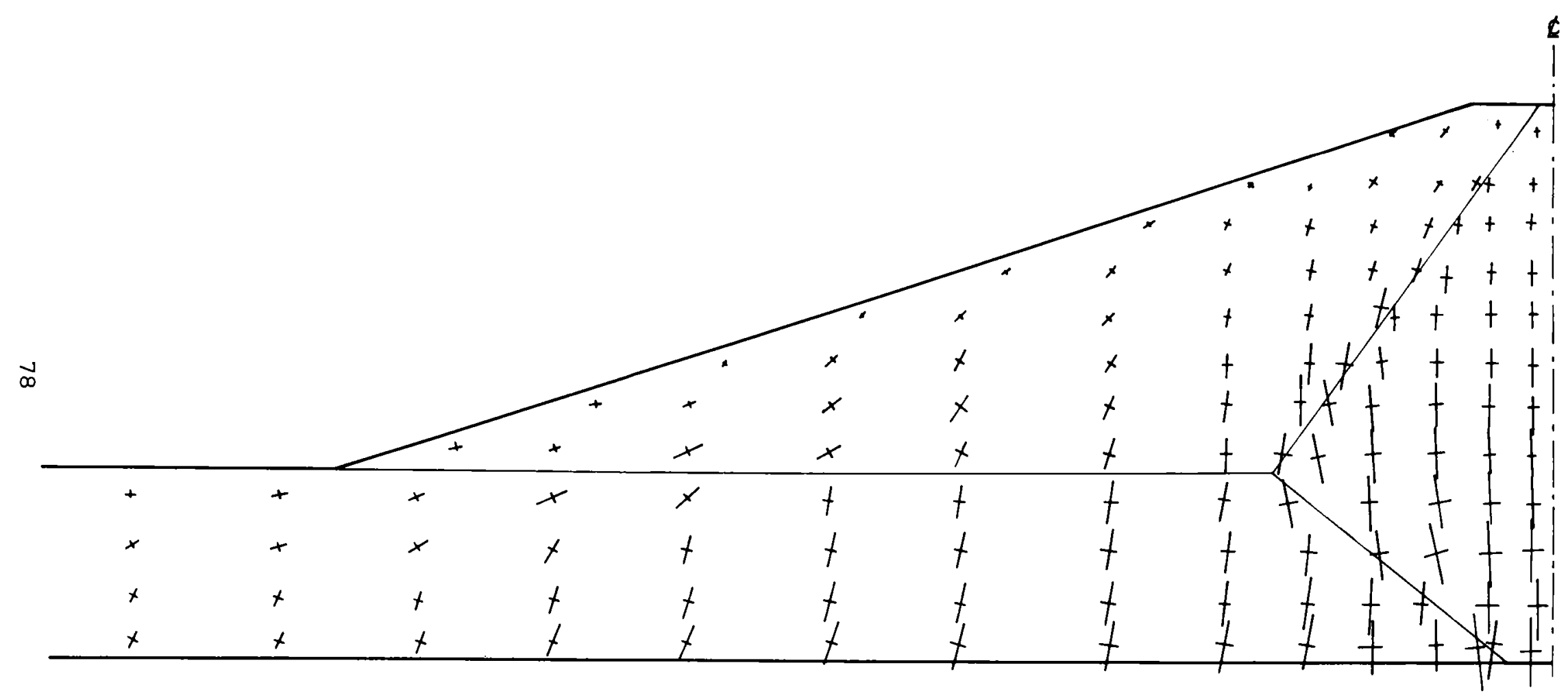

FIG. 38 DIRECTIONS OF PRINCIPAL STRESSES FOR CD STAGE 2. 


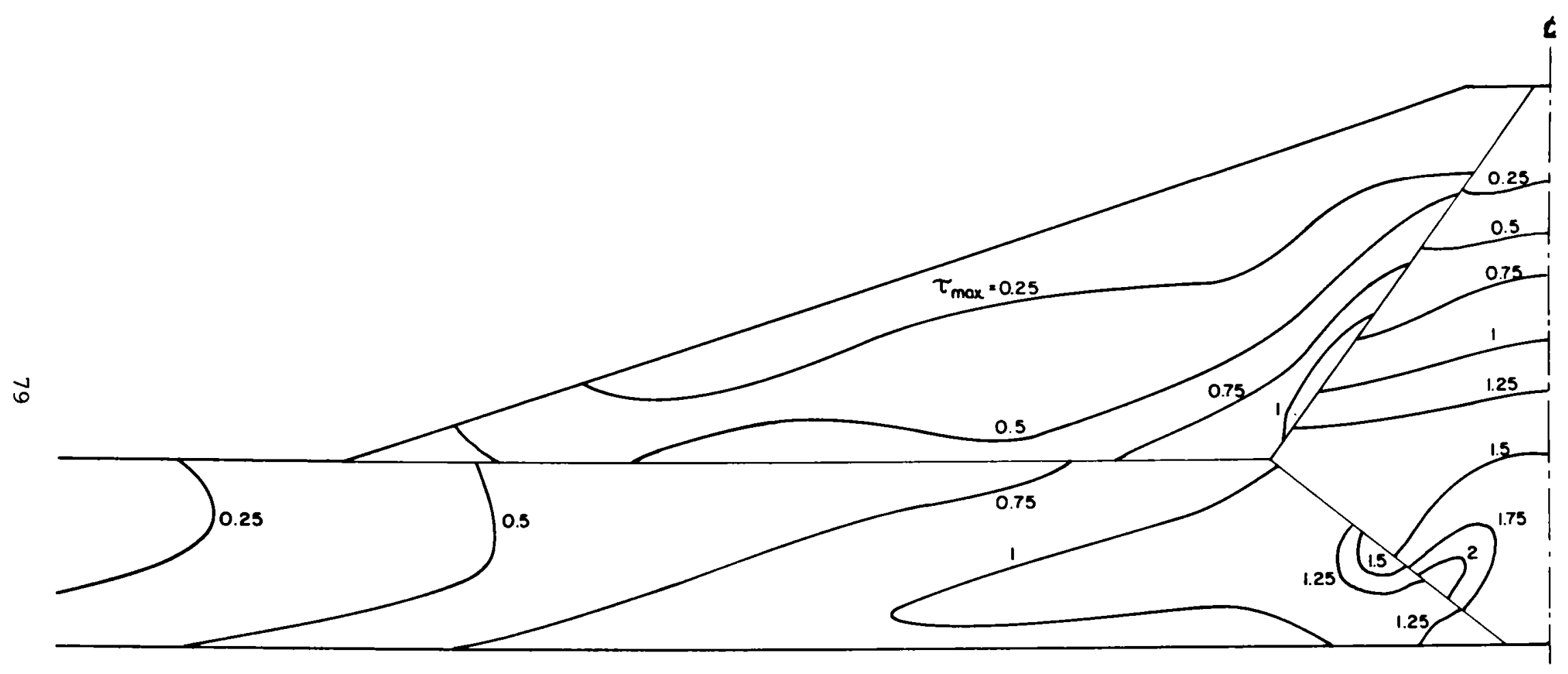

FIG. 39 CONTOURS OF $\tau_{\text {max. }}$ FOR CD STAGE 2. 


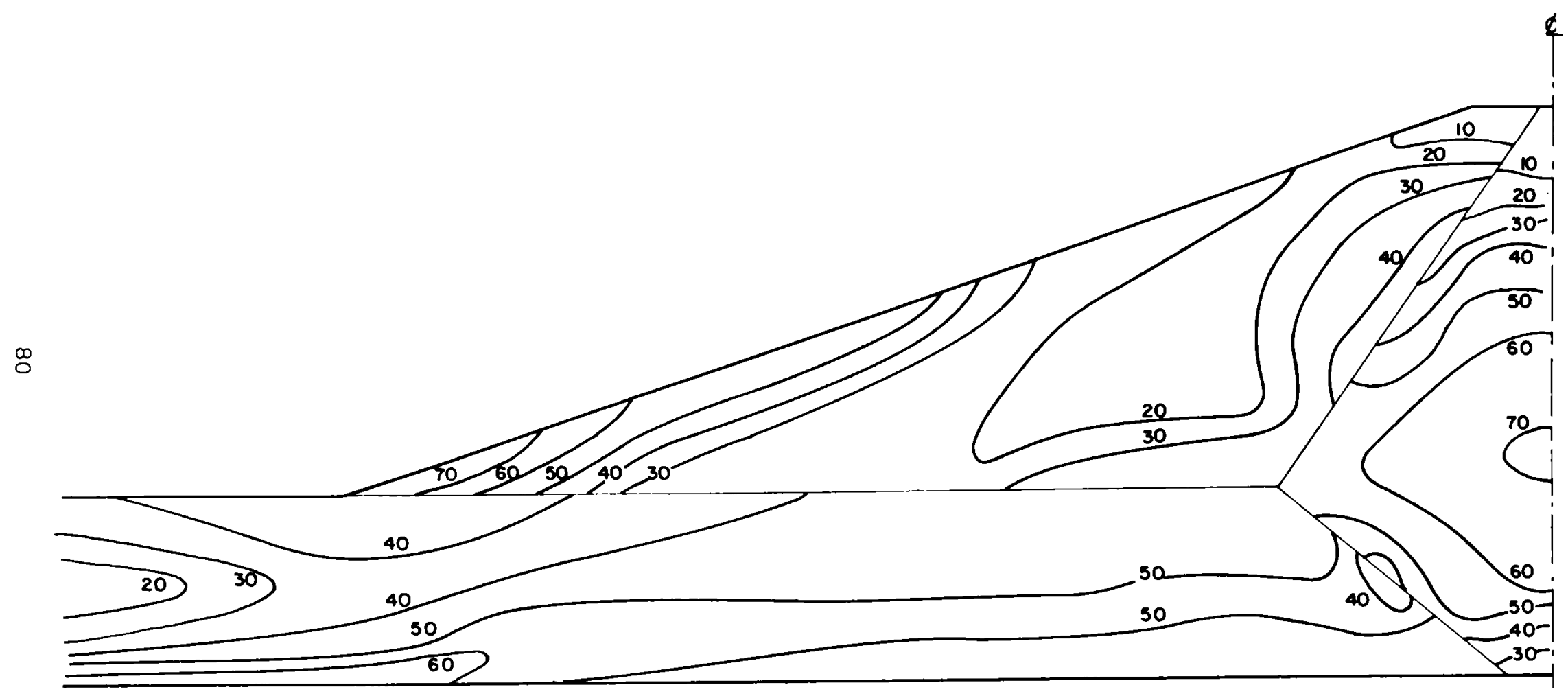

FIG. 40 STRENGTH MOBILIZED FOR CO STAGE 2. 


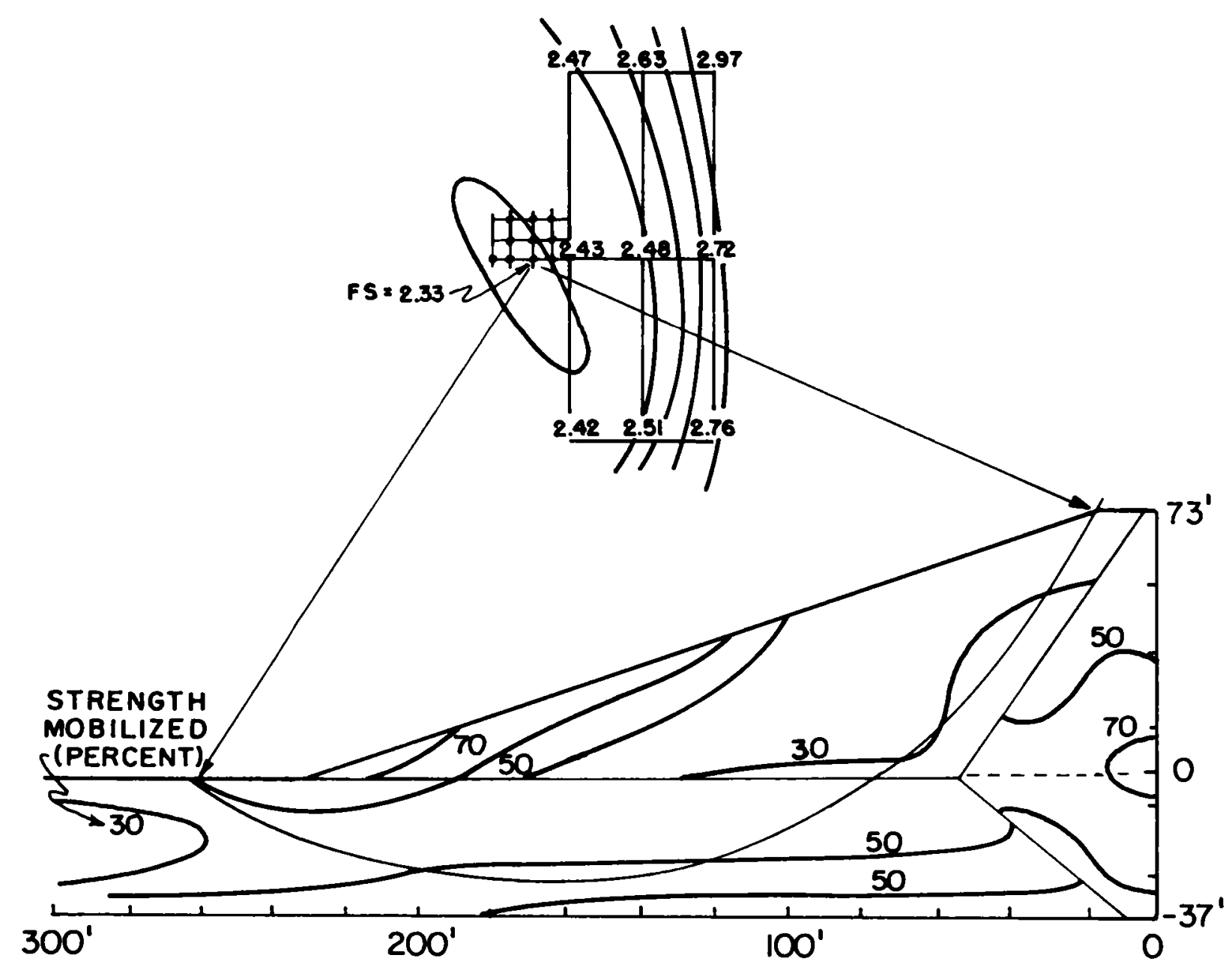

FIG. 41 CRITICAL CIRCLE FOR CD STAGE 2. 


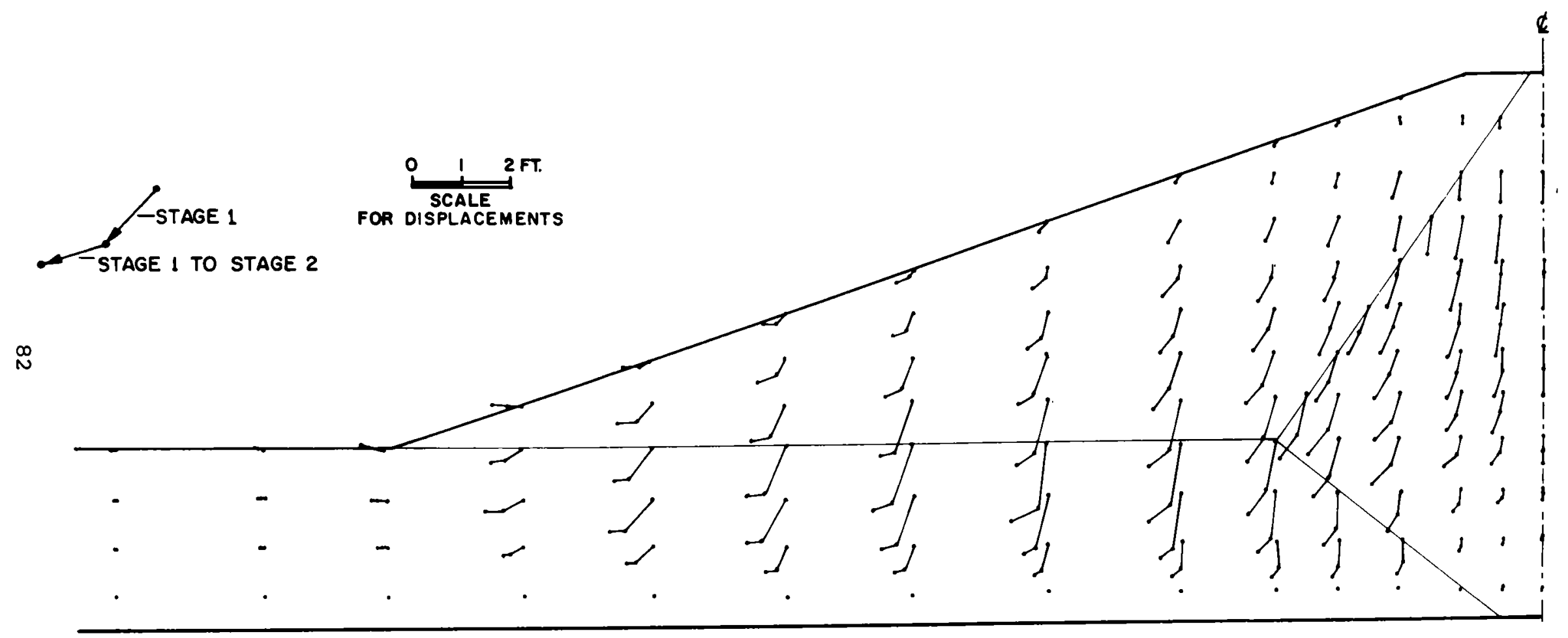

FIG. 42 DISPLACEMENTS FOR CD STAGES 1 AND 2. 


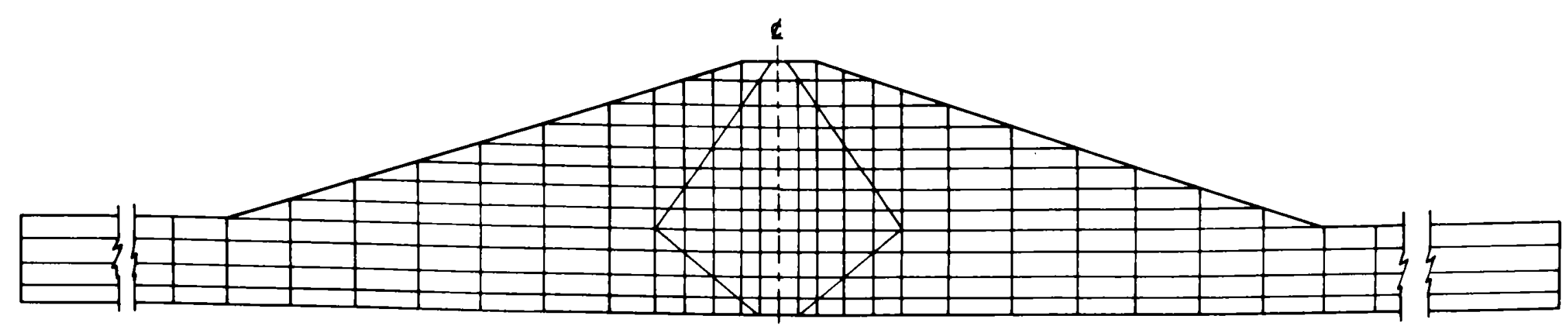

$\stackrel{\infty}{\omega}$

FINITE ELEMENT MESH FOR RESERVOIR FILLING.

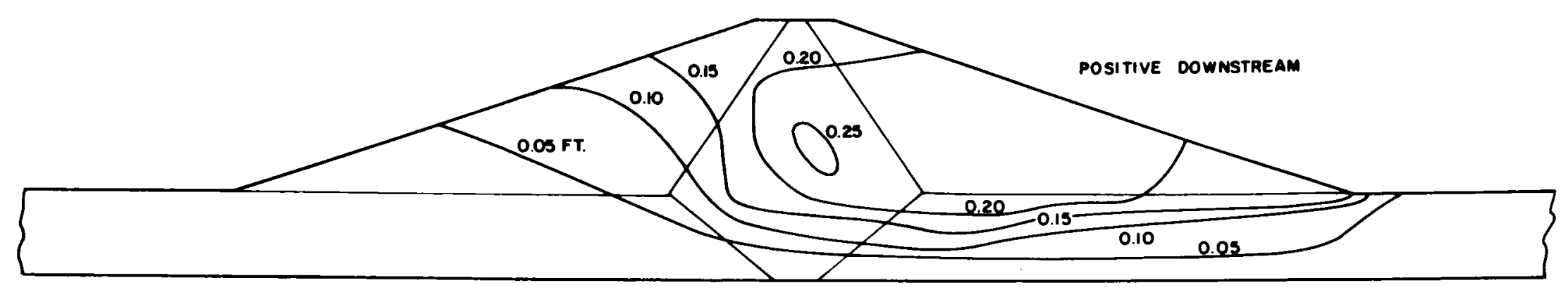

FG. 43 HORIZONTAL DISPLACEMENTS DUE TO RESERVOIR FILLING 
Assuming that the dam will be constructed following the sequence shown in Fig. 26, the displacements have been calculated for the following stages in the life of the embankment:

(1) At the end of stage I ( $t=4$ months).

(2) At the end of the waiting period between Stages I and II $(t=13.5$ months $)$.

(3) At the end of Stage II ( $t=16.5$ months).

(4) At the time when Stage II hás been in place for 13.5 months $(t=30$ months $)$.

(5) At the end of reservoir filling.

Vectors of the calculated displacements are shown in Fig. 44 for the first four stages, and in Fig. 45 for all five stages. It is interesting to note that the displacements during the waiting period from 4 months to 13.5 months, and after construction from 13.5 months to 30 months, are more nearly vertical than are the movements during periods of changing load. The total estimated movements during the 30-month period considered amounts to approximately $1.8 \mathrm{ft}$ in the lower portion of the dam near the center. Compared to the movements due to construction of the embankment, the movements due to reservoir filling may be seen to be quite small.

The calculated movements at the planned locations of the slope indicators are shown in Fig. 46. By comparison with the results shown in Fig. 44, it may be seen that the slope indicators will be placed in the region where the calculated horizontal and vertical movements are large. They will thus provide a good means for monitoring the behavior of the dam and for judging the accuracy of the finite element analyses.

The calculated displacements on the surface of the dam are shown in Fig. 47. It may be noted that the displacements are discontinuous at Elevation $45 \mathrm{ft}$, because of the movements which occur during the pause between Stages I and II. These displacements can be compared with the measured movements of the surface monuments during and after construction of the dam. 


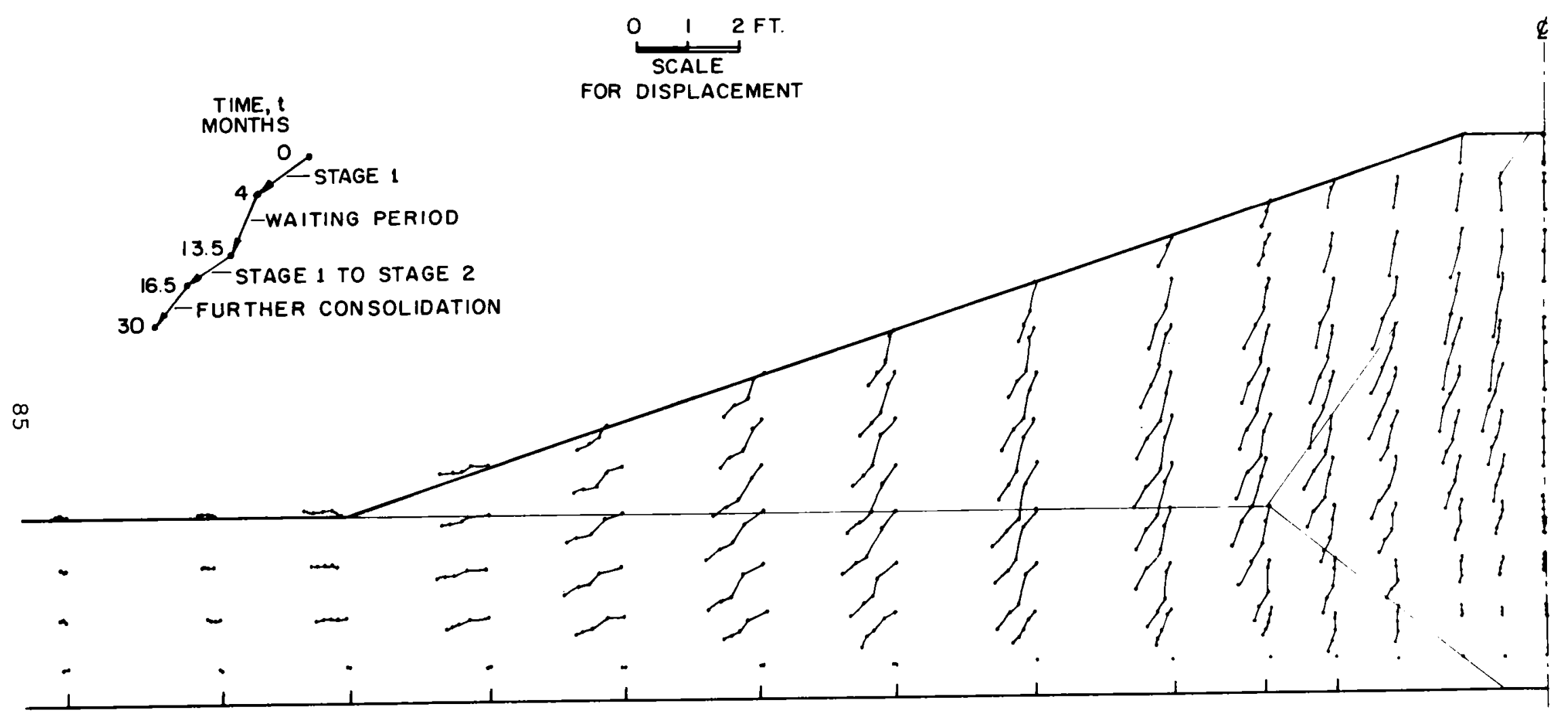

FIG. 44 ESTIMATED DISPLACEMENTS. 



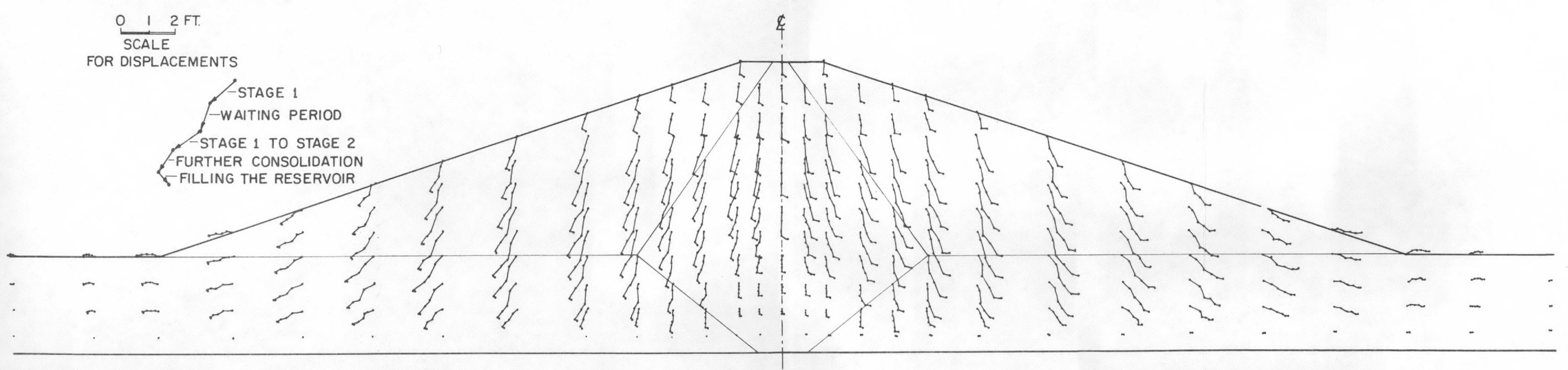

FIG. 45 ESTIMATED DISPLACEMENTS AFTER RESERVOIR FILLING. 



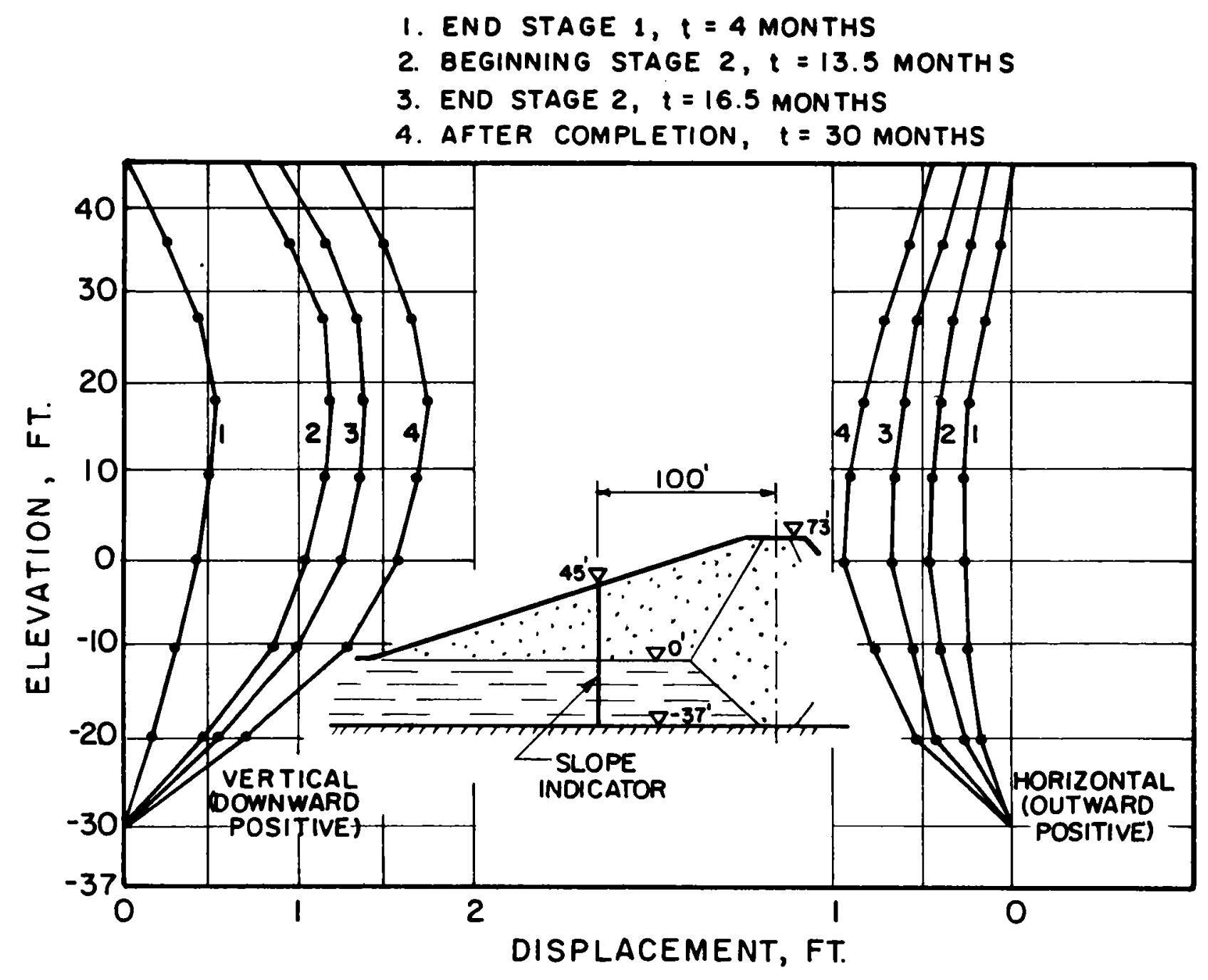

FIG. 46 ESTIMATED MOVEMENTS OF THE SLOPE INDICATORS. 
1. END STAGE $1, t=4$ MONTHS

2. BEGINNING STAGE 2, $t=13.5$ MONTHS

3. END STAGE 2, $t=16.5$ MONTHS

4. AFTER COMPLETION, $t=30$ MONTHS

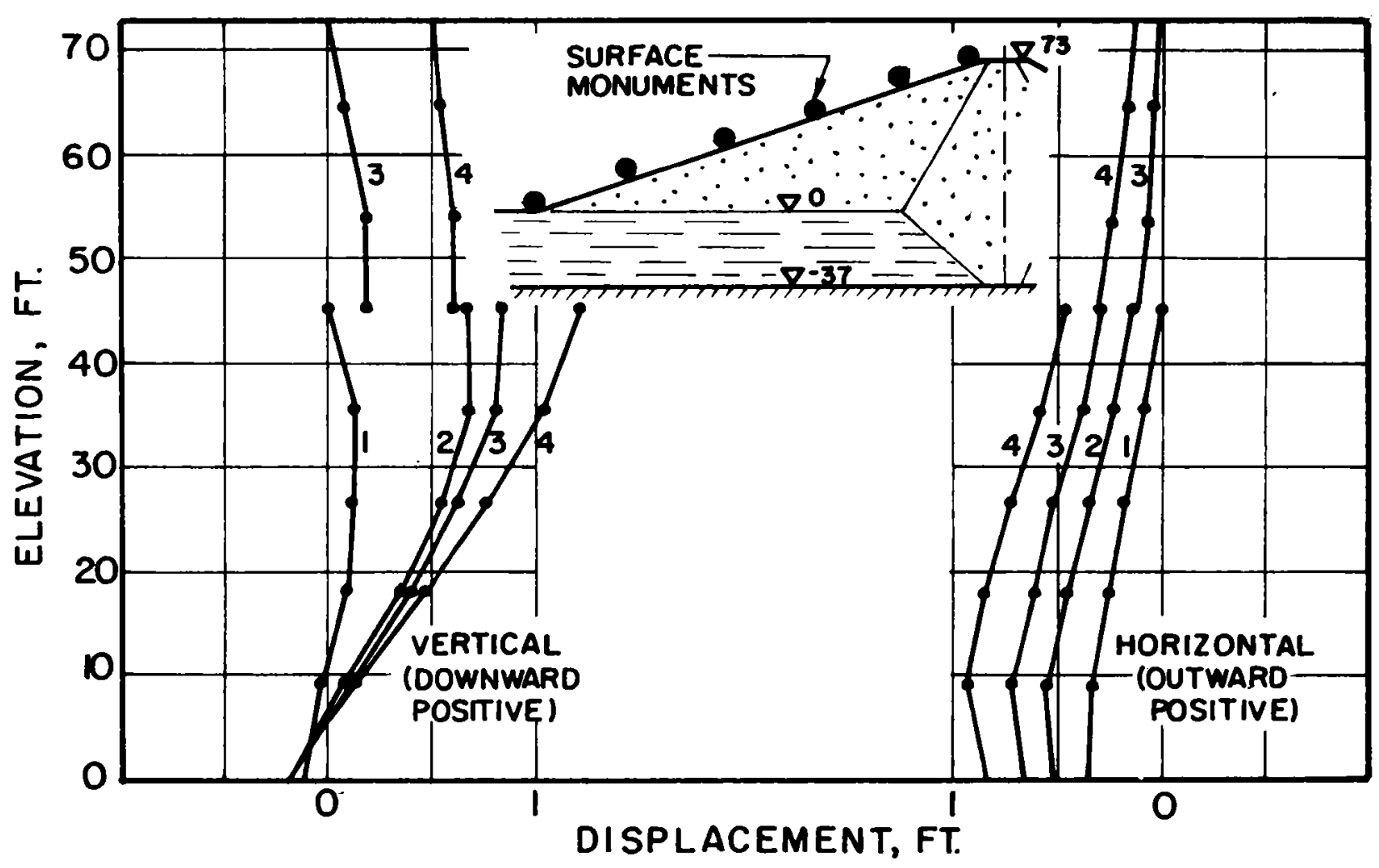

FIG. 47 ESTIMATED MOVEMENTS OF THE SURFACE MONUMENTS. 


\section{ESTIMATED EXCESS PORE PRESSURES}

The calculated stresses within the dam were used to estimate excess pore pressures in the foundation due to the embankment loading, and the rate of dissipation of these pore pressures were calculated using the simple Terzaghi consolidation theory, and assuming vertical drainage. As explained previously, the value of $c_{v}$ was increased from $60 \mathrm{ft}^{2} /$ year (measured in laboratory tests) to $180 \mathrm{ft}^{2} /$ year as an allowance for high horizontal permeability and sand lenses in the foundation clay. The initial pore pressures were estimated from the calculated total stresses using Skempton's pore pressure parameters, with $B=1$ and $\bar{A}=1$. The excess pore pressures calculated for the end of Stage I and for the beginning and the end of stage II are tabulated in Table 8 . It may be seen that the calculations indicate nearly complete dissipation of the excess pore pressures during the pause between Stages I and II. Although not shown in Table 8 , the calculations also indicate rapid dissipation of the excess pore pressures after the end of Stage II.

\section{CONCLUSION}

The difficulties involved in analyzing the movements of a dam on a soft foundation are considerably greater than those involved in a similar analysis for a dam on a hard foundation. These difficulties stem from two sources:

(1) The necessity for characterizing the stress-strain and strength characteristics of a heterogeneous deposit of natural soils, the properties of which vary from one location to another and are subject to alterations due to disturbance.

(2) The necessity for determining consolidation characteristics, both soil properties and drainage conditions, for use in analysis of time-dependent movements.

These greater difficulties in determining parameters for the analyses lead inevitably to greater uncertainties in the accuracy of the results. 
Table 8. Estimated Excess Pore Pressures at Sta. $20+00$

\begin{tabular}{|c|c|c|c|c|c|c|c|}
\hline & \multirow{2}{*}{$\begin{array}{c}\text { Piez. } \\
\text { No. }\end{array}$} & $\begin{array}{c}\text { Distance } \\
\text { to } \\
\text { Dam } \\
\text { Axis }\end{array}$ & Depth & \multicolumn{2}{|c|}{$\begin{array}{c}\text { Excess Pore Pres- } \\
\text { sures for Undrained } \\
\text { Conditions }\left(t / \mathrm{ft}^{2}\right)\end{array}$} & \multicolumn{3}{|c|}{$\begin{array}{c}\text { Estimated Excess } \\
\text { Pore Pressure }\left(t / \mathrm{ft}^{2}\right)\end{array}$} \\
\cline { 4 - 8 } & & Stage I & Stage II & $\begin{array}{c}\text { End } \\
\text { Stage I I }\end{array}$ & $\begin{array}{c}\text { Beginning } \\
\text { Stage II }\end{array}$ & $\begin{array}{c}\text { End } \\
\text { Stage II }\end{array}$ \\
\hline 1 & $130^{\prime}$ & $15^{\prime}$ & 1.02 & 1.21 & 0.8 & 0.1 & 0.3 \\
2 & $130^{\prime}$ & $25^{\prime}$ & 0.93 & 0.95 & 0.7 & 0.1 & 0.2 \\
3,6 & $75^{\prime}$ & $-5^{\prime}$ & 0 & 0 & 0 & 0 & 0 \\
4,7 & $75^{\prime}$ & $15^{\prime}$ & 2.91 & 3.14 & 2.2 & 0.3 & 0.8 \\
5,8 & $75^{\prime}$ & $25^{\prime}$ & 2.84 & 3.69 & 2.0 & 0.2 & 0.7 \\
9 & $160^{\prime}$ & $15^{\prime}$ & 1.51 & 1.61 & 1.2 & 0.2 & 0.4 \\
10 & $160^{\prime}$ & $25^{\prime}$ & 1.74 & 1.73 & 1.2 & 0.1 & 0.3 \\
11 & $235^{\prime}$ & $10^{\prime}$ & 0.90 & 1.22 & 0.4 & 0.1 & 0.2 \\
& & & & & & & \\
\hline
\end{tabular}

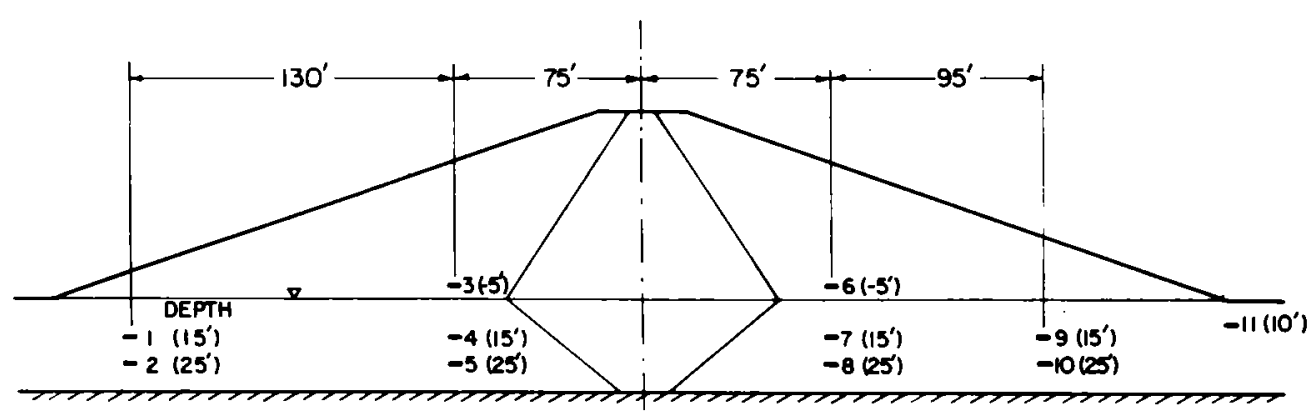

LOCATION OF PIEZOMETERS 
In its present stage this study is incomplete. When Birch Dam has been built, and field measurements are available to compare with the results in this report, it will be possible to judge the effectiveness of the analyses. 
Clough, R. W. and Woodward, R. J. (1967) "Analysis of Embankment Stresses and Deformations," Journal of the Soil Mechanics and Foundations Division, ASCE, Vol. 93, No. SM4, July, 1967, pp. 529-549.

Corps of Engineers (1972) "Design Memorandum No. 6, Birch Lake," Tulsa District.

Corps of Engineers (1972) "Design Memorandum No. 17, Birch Lake," Tulsa District.

Duncan, J. M. and Chang, C-Y. (1970) "Nonlinear Analysis of Stress and Strain in Soils," Journal of the Soil Mechanics and Foundations Division, ASCE, Vol. 96, No. SM5, September, 1970, Proc. Paper 7513, pp. 1629-1653.

Eisenstein, Z. (1974) "Application of Finite Element Method to Analysis of Earth Dams," State of the Art Report, First Brazilian Seminar on Application of Finite Element Method in Soil Mechanics, Universidade Federal do Rio de Janeiro, September, 1974.

Kulhawy, F. H. and Duncan, J. M. (1970) "Nonlinear Finite Element Analysis of Stresses and Movements in Oroville Dam," Report No. TE 70-2, Office of Research Services, University of California, Berkeley, July.

Kulhawy, F. H., Duncan, J. M. and Seed, H. B. (1969) "Finite Element Analysis of Stresses and Movements in Embankments During Construction," Report No. TE 69-4, Office of Research Services, University of California, Berkeley, November.

Ozawa, Y. and Duncan, J. M. (1973) "ISBILD: A Computer Program for Analysis of Static Stresses and Movements in Embankments," Report No. TE 73-4, Office of Research Services, University of California, Berkeley, December.

Torrey III, V. H. (1970) "Analysis of Field Compaction Data'," Reports 1 and 2, Miscellaneous Paper S-70-13, U. S. Army Engineer Waterways Experiment Station, Vicksburg, Mississippi.

Wong, K. S. and Duncan, J. M. (1974) "Hyperbolic Stress-Strain Parameters for Nonlinear Finite Element Analyses of Stresses and Movements in Soil Masses," Report No. TE 74-3, Office of Research Services, University of California, Berkeley, July. 


\section{APPENDIX -- PROCEDURE FOR ESTIMATING \\ TIME-DEPENDENT DISPLACEMENTS}

The finite element analyses of stresses and movements in Birch Dam were performed using two extreme assumptions regarding the dissipation of pore pressures during construction:

(1) That there was no dissipation of excess pore pressures, and

(2) That there was complete dissipation of excess pore pressures at all stages.

Analyses of the rate of consolidation, made using the simple Terzaghi Theory, showed that during the construction period there would be appreciable but incomplete dissipation of excess pore pressures in the foundation. As a result it was considered that neither the undrained nor the drained analyses would provide an accurate estimate of the actual movements, and that a better estimate of the actual movements might be developed using the simple Terzaghi consolidation theory.

Examination of the movements calculated by the undrained and drained finite element analyses showed that the undrained displacements increased approximately in proportion to the square of the height of the embankment, whereas the drained displacements increased more nearly in direct proportion to the embankment height. Based on this observation, it seemed reasonable to assume that:

(1) The undrained displacements are proportional to the square of the excess pore pressures, and

(2) The drained displacements are directly proportional to the increase in effective stress.

These assumptions served as the guiding principles for estimating the actual movements for conditions of partial pore pressure dissipation. In order to apply these principles to the calculation of the movements, it was necessary to determine the increments of movement of each 
nodal point which was caused by each layer of fill, because the placement of each layer of fill corresponds to a different time, and therefore to a different degree of dissipation of the excess pore pressures. Further, these increments of movements had to be decomposed to determine the components due to the deformations within each layer of the foundation below the point considered. These components of the undrained and drained movements are denoted by $\delta_{U i j k}$ and $\delta_{D i j k}$ in which

$\delta_{U}=a$ component of the undrained displacement

$\delta_{D}=$ a component of the drained displacement

$i=$ the nodal point at which the displacement occurs

$j=$ the fill layer whose weight causes the incremental displacement

$k$ = the foundation layer whose deformation is responsible for the displacement component.

Using the Terzaghi consolidation theory, the degree of dissipation of the pore pressures caused by each layer of the fill were calculated for each layer of the foundation. These values are denoted by $\alpha_{j k}$ in which:

$\alpha_{j k}=$ the degree of dissipation of excess pore pressure in layer $\mathrm{k}$. The value of $\alpha$ increases with time after the layer which induces the pore pressure increment (layer $j$ ) is placed.

The calculated values of $\alpha$ are shown in Fig. Al. It may be seen that the values of $\alpha$, which are different for each of the four foundation layers, vary from zero toward unity as the value of dimensionless time factor increases. A value of $c_{v}=180 \mathrm{ft}^{2} / \mathrm{yr}$ was used in the calculations. Double drainage was assumed, and the length of the drainage path was $18.5 \mathrm{ft}$, one=half of the foundation thickness. The actual time is related to the dimensionless time factor shown in Fig. Al by the equation

$$
t_{j}=1.90 \mathrm{~T}_{j}
$$

in which: 

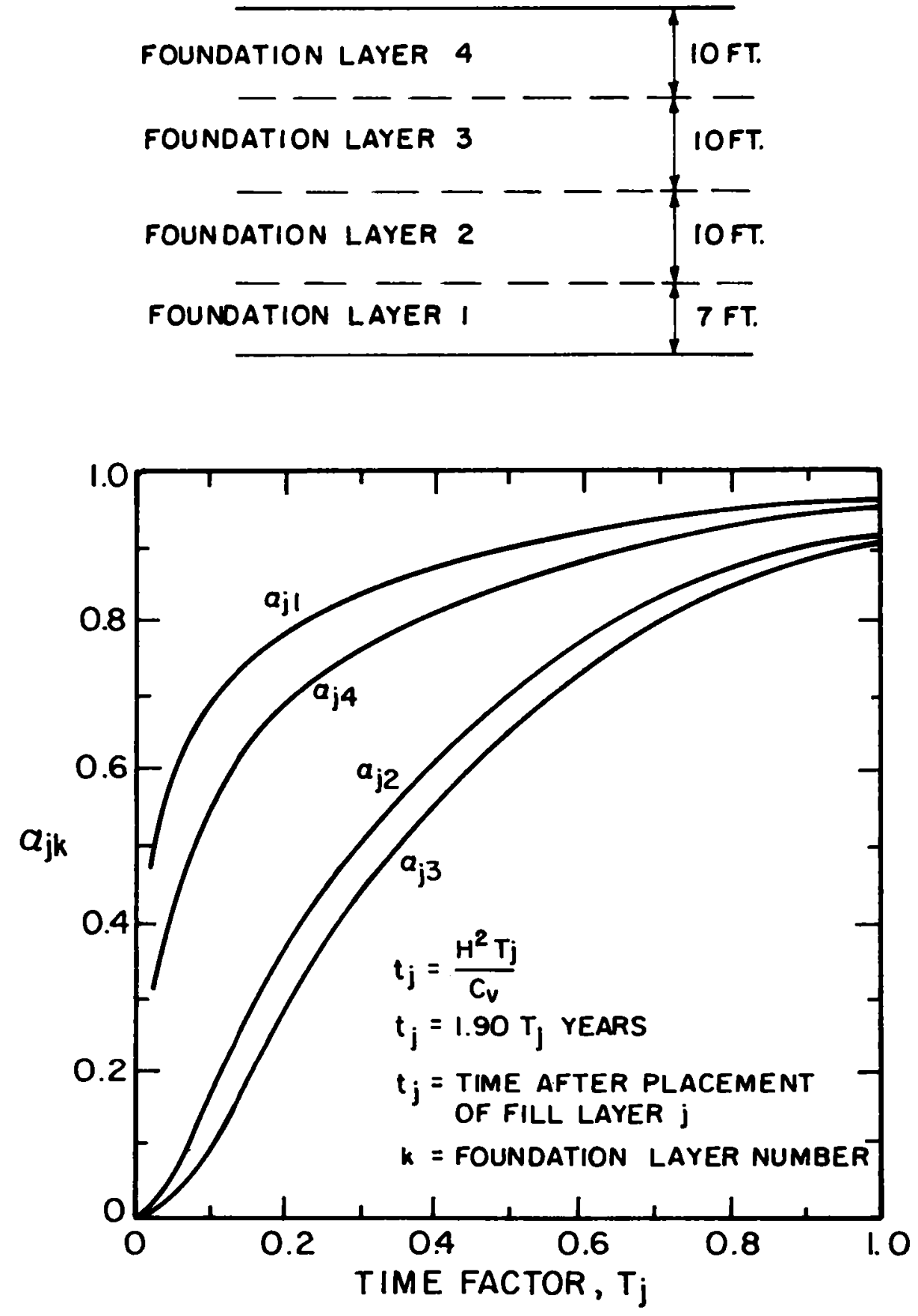

FIG. Al VARIATIONS OF $a_{j k}$ WITH TIME FACTOR $T_{j}$. 


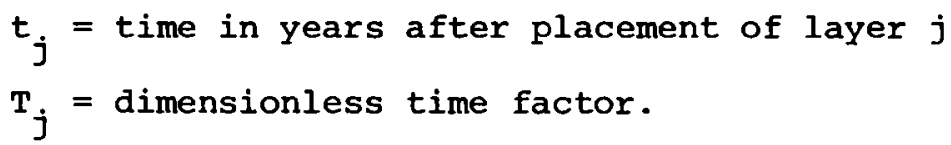

The coefficient $\alpha$ represents the fraction of excess pore pressure due to a given layer of fill which has been dissipated at any time. By considering all of the layers placed up to a given time, the average degree of dissipation at that time can be calculated. In the Birch Dam analysis, the thicknesses of all of the fill layers was the same, and it was assumed that they each induced equal initial excess pore pressures in the foundation. Therefore the average degree of dissipation at any time was simply an average of the degrees of dissipation for each of the fill layers placed prior to that time:

$$
c_{k}=\frac{1}{n} \sum_{j=1}^{n} a_{j k}
$$

in which

$$
\begin{aligned}
c_{k}= & \text { average degree of dissipation of excess pore pressure in } \\
& \text { foundation layer } k \\
j= & \text { fill layer number } \\
n= & \text { total number of fill layers placed prior to the time for } \\
& \text { which } c_{k} \text { is computed. }
\end{aligned}
$$

Because the coefficient $c_{k}$ represents the average degree of pore pressure dissipation in a layer, it also represents the average degree of effective stress increase. Its complement, given by the equation below, represents the average degree of undissipated excess pore pressure:

$$
\beta_{\mathbf{k}}=\left(1-C_{\mathbf{k}}\right)
$$

in which

$$
\begin{aligned}
\beta_{k}= & \text { average degree of undissipated excess pore pressure in } \\
& \text { layer } k \text {. }
\end{aligned}
$$

The values of the coefficients $C_{k}$ and $B_{k}$ vary with time after the various fill layers are added, and they therefore depend on the rate at which the embankment is built. The estimated rate of fill placement 
shown in Fig. 9 was used in calculating the variations $\beta_{k}$ with time which were used in estimating the time-dependent displacements. Construction Stage 1, up to elevation 770.0, was represented by placement of five layers of fill at equal intervals of time, and stage 2 , up to elevation 795.0, was represented by placement of three more layers, also at equal intervals. The calculated values of $\beta_{k}$ are shown in Fig. A2.

Finally, the time-dependent displacements were calculated using the assumption that the undrained displacements are proportional to the square of the remaining excess pore pressures and that the drained displacements are proportional to the effective stresses, as outlined in the beginning of the appendix. Using the coefficients $\alpha_{j k}$ and $\beta_{k}$ ' the increments of the time-dependent displacements may be expressed as

$$
\delta_{i j k}=\alpha_{j k} \delta_{D i j k}+\left(\beta_{k}\right)^{2} \delta_{u i j k}
$$

The value of $\alpha_{j k}$ depends on the time at which the layer $j$ is added, and varies with times as shown in Fig. Al. The value of $\beta_{k}$ depends on the time from the beginning of construction, and varies with time as shown in Fig. A2.

When the displacement components had been calculated as shown by equation $\mathrm{A} 4$, they were summed to calculate the displacements, using the following equation:

$$
\Delta_{i}=\sum_{j=1}^{n} \sum_{k=1}^{m} \delta_{i j k}
$$

in which

$$
\begin{aligned}
\Delta_{i}= & \text { displacement of nodal point } i, \\
n= & \text { total number of layers of fill added up to the time the } \\
& \text { displacements are calculated, and } \\
m= & \text { number of layers below the point at which the displace- } \\
& \text { ment is calculated. }
\end{aligned}
$$




$$
\begin{aligned}
& t=\frac{H^{2} T}{C_{V}}=1.90 T \text { YEARS } \\
& t=\text { TIME AFTER BEGINNING OF CONSTRUCTION }
\end{aligned}
$$

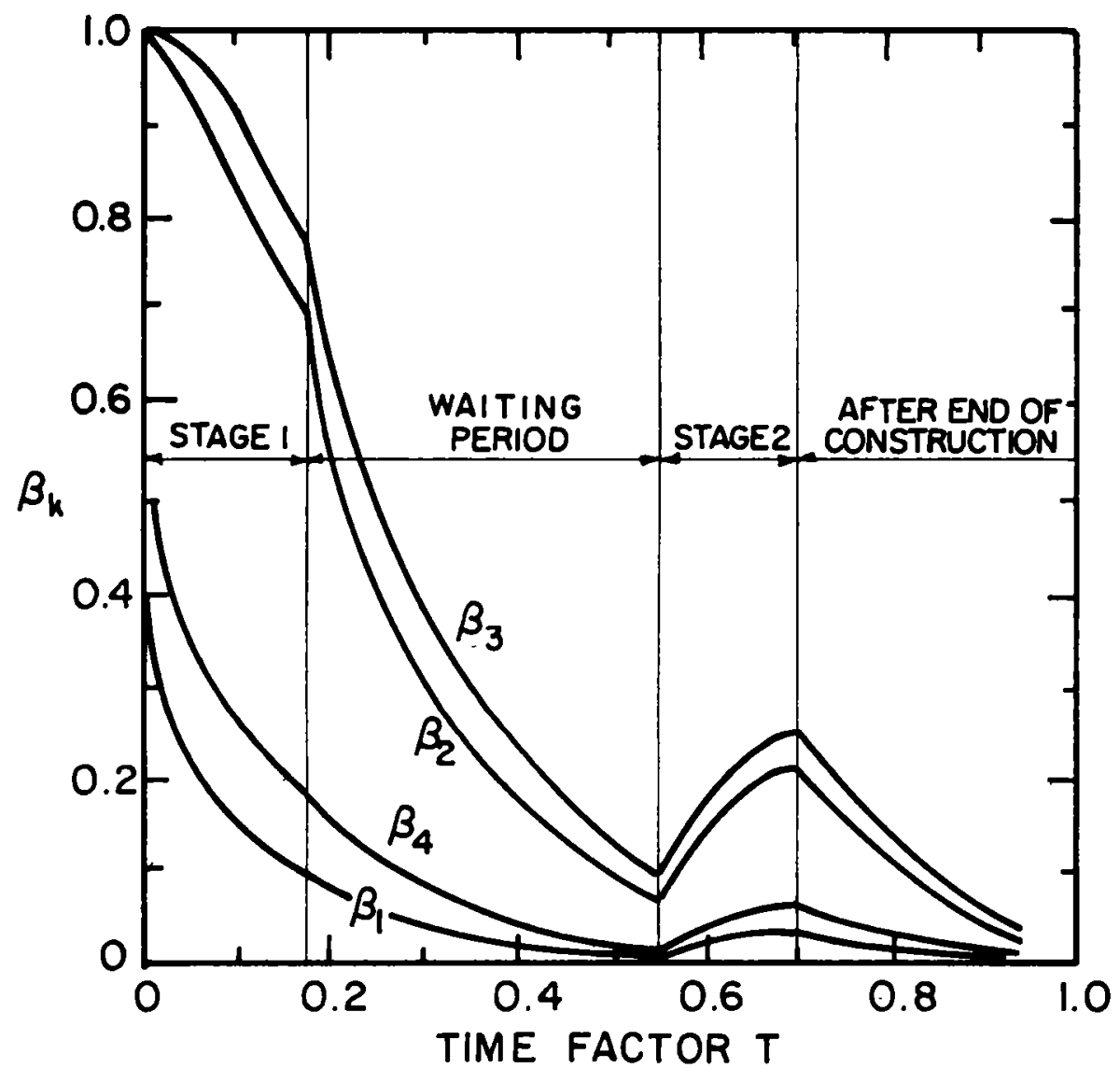

FIG. A2 VARIATIONS OF $\beta_{k}$ WITH TIME FACTOR T. 
The resulting displacements, $\Delta_{i}$, for a vertical line through the embankment and foundation are shown in Fig. A3. It is interesting to note that although the magnitudes of the displacements $\Delta_{i}$ are intermediate between the undrained and the drained values over most of the height, in some locations they are smaller or larger than either one. Thus the undrained and drained displacements do not constitute bounds on the actual displacements. 


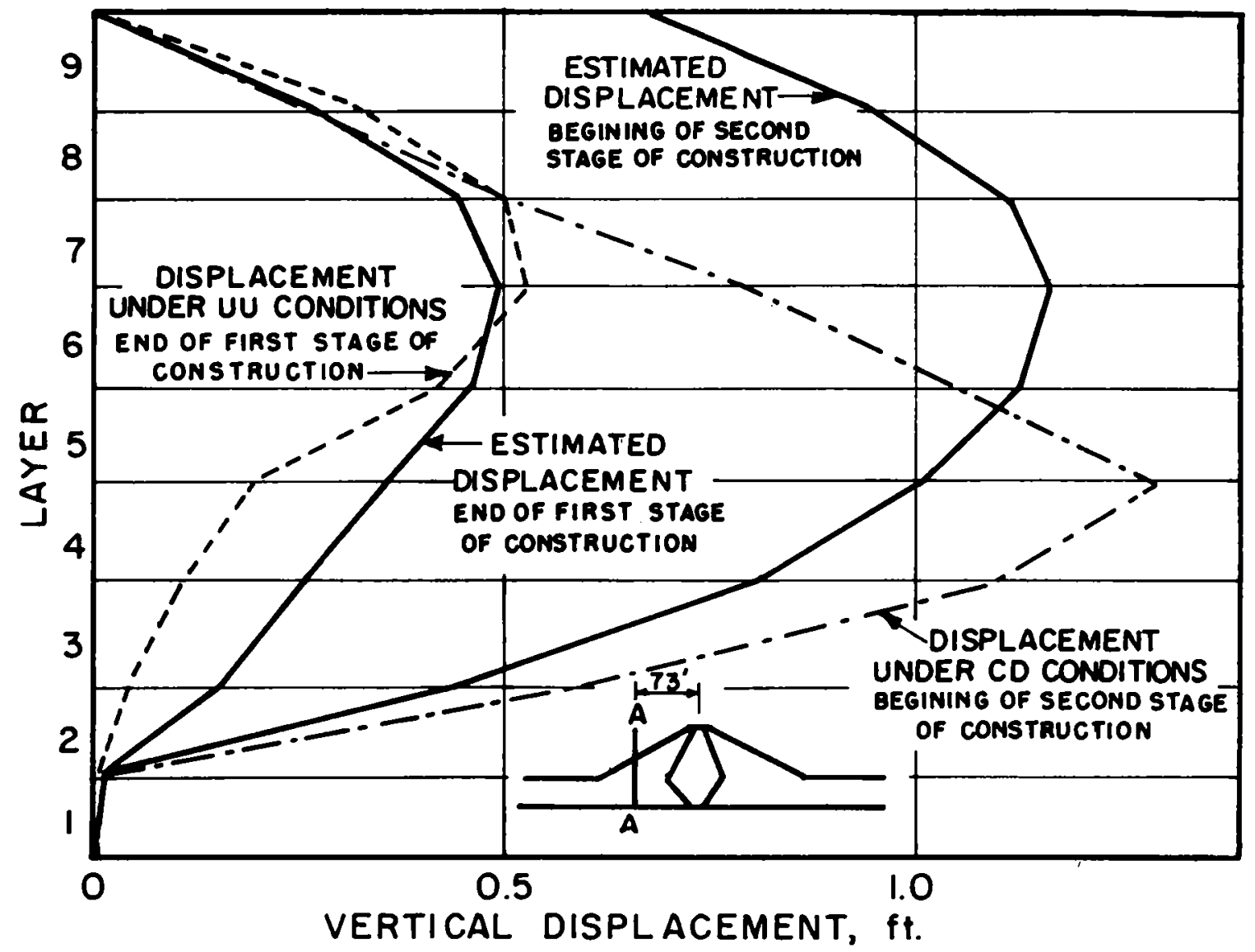

FIG. A3 COMPARISON OF UU, CD AND ESTIMATED VERTICAL DISPLACEMENTS ALONG A TYPICAL VERTICAL LINE A-A. 


In accordance with FR 70-2-3, paragraph $6 c(1)(b)$, dated 15 Pebruary 1973, a racoinile catalog card in Library of Congress format is reproduced below.

California. University. Office of Research Services.

Finite element analyses of stresses and movements in Birch Dam, by Antonio Sortano, J. M. Duncan, Ka1 Wong, [and Jean-Michel Simon. Vicksburg, U. S. Army

Engineer Waterways Experiment Station, 1976.

100 p. illus. $27 \mathrm{~cm}$. (U. S. Waterways Experiment Station. Contract report S-76-2)

Prepared for office, Chief of Engineers, U. S. Army, Washington, D. C., under Contract No. DACW39-68-C0078 .

References: p. 92.

1. Birch Dam. 2. Consolidation (Soils). 3. Embankments. 4. Finite element method. 5. Soil stresses. I. Soriano, Antonio. II. Duncan, James Michael, joint author. III. Wong, Kai, joint author. IV. Simon, Jean-Michel, joint author. V. U. S. Army. Corps of Engineers. (Series: U. S. Waterways Experiment Station, Vicksburg, Miss. Contract report S-76-2) TA7.W34c no.s-76-2 


